\title{
Preparations of Anthraquinone and Naphthoquinone Derivatives and Their Cytotoxic Effects
}

\author{
Xing-Ri Cui ${ }^{a}$ Ryota Saito, ${ }^{b}$ Takatsugu Kubo, ${ }^{a}$ Daijiro Kon,${ }^{a}$ Yuich Hirano, ${ }^{a}$ and Setsuo Saito*, $a$ \\ ${ }^{a}$ Faculty of Pharmaceutical Sciences, Josai University; 1-1 Keyakidai, Sakado, Saitama 350-0295, Japan: and \\ ${ }^{b}$ Department of Chemistry, Faculty of Sciences, Toho University; 2-2-21 Miyama, Funabashi, Chiba 274-8510, Japan. \\ Received July 20, 2010; accepted December 14, 2010
}

Chrysophanol and 1,8-di- $O$-hexylchrysophanol derivatives having nucleic acid bases at position 5 were synthesized. Furthermore, derivatives of menadione substituted at position 11 (type A naphthoquinone derivatives) or methylmenadione substituted at position 7 (type B naphthoquinone derivatives) modified with nucleic acid bases, amines and thiocyano, selenocyano or thioacetyl groups were synthesized. The cytotoxic effects of these derivatives on HCT 116 cells, which poorly express P-glycoprotein (P-gp), and Hep G2 cells, which stably express P-gp, were evaluated by performing 3-(4,5-dimethylthiazol-2-yl)-2,5-diphenyltetrazolium bromide (MTT) assay. Results were compared with those obtained using 5-fluorouracil (5-FU), which has been used clinically. Several of these derivatives exhibited markedly higher potent cytotoxic effects not only on HCT cancer cells but also Hep G2 cancer cells as compared with 5-FU.

Key words anthraquinone derivative; naphthoquinone derivative; cytotoxic effect; HCT 116 cell; Hep G2 cell

Previously, we reported ${ }^{1)}$ a comparison of the cytotoxic effects of naturally occurring hydroxyanthraquinone derivatives, isolated from the root of Rhubarb (Rheum palmatum (Polygonaceae)) and hydroxynaphthoquinone derivatives, isolated from the roots of Lithosperumum erythrorhizon SieB. et Zucc. and Macrotomia euchroma (Royle) Pauls. (Boraginaceae), using human colorectal (HCT 116) $)^{2}$ and human hepatoma (Hep G2) ${ }^{3)}$ cell lines. In addition, we prepared 1,8-di$O$-alkylaloe-emodins and 15-amino-, 15-thiocyano- and 15selenochrysophanol derivatives from aloe-emodin, which is one of hydroxyanthraquinone compounds isolated from the root of Rhubarb. A comparison of cytotoxic acivities of the derivatives using the same cancer cell lines were also reported. ${ }^{4}$

The present study deals with preparations of chrysophanol and 18-di-O-hexylchrysophanol derivatives having various nucleic acid bases at position of 15 from aloe-emodin and 18-di- $O$-hexylaloe-emodin, respectively. We also synthesize napthoquinone derivatives having various nucleic acid bases, amines, and thiocyanato (-SCN), selenocyanato $(-\mathrm{SeCN})$ and thioacetyl (-SAc) groups on the side chains of the naphthoquinone skeletons derived from menadione (Vitamin $\mathrm{K}_{3}$, 2methylnaphthoquinone). Furthermore, we evaluate the cytotoxic effects of the synthetic derivatives using HCT 116 and Hep G2 cancer cell lines, and compare the effects with those of 5-fluorouracil (5-FU).

\section{Chemical Results and Dicscussion}

Several cytotoxic compounds having purine or pyrimidine bases in the molecule, such as azathiopurine $1,5,6) 5$-fluorouracil $2(5-\mathrm{FU})^{7-10)}$ and tegafur $3{ }^{11,12)}$ have been synthesized and used in clinical chemotherapy. In this study, syntheses of anthraquinone derivatives having nucleic acid bases (adenine, thymine, uracil or 5-FU) on the side chain of the anthraquinone skeleton were performed (Fig. 1).

Firstly, anthraquinone derivatives having the nucleic acid bases at position 15 were synthesized. 1,8-Di- $O$-hexylaloeemodin 4 , which displayed the highest cytotoxic activity of the synthesized $1,8-O$-alkylaloe-emodins, ${ }^{4)}$ was selected as the starting material. The synthesis of tosylate $\mathbf{5}$ from $\mathbf{4}$ was<smiles>Cn1cnc([N+](=O)[O-])c1Sc1ncnc2nc[nH]c12</smiles>

1 Azatiopurine<smiles>O=c1[nH]cc(F)c(=O)[nH]1</smiles>

2 5-Fluorouracil (5-FU)<smiles>O=c1[nH]c(=O)n(C2CCCO2)cc1F</smiles>

3 Tegafur
Fig. 1. Purine and Pyrymidine Base Derivatives Used in Clinical Chemotherapy<smiles>[R]OCc1cc(O[R10])c2c(c1)C(=O)c1cccc(O[Y10])c1C2=O</smiles><smiles>Nc1ncnc2[nH]cnc12</smiles><smiles>Cc1c[nH]c(=O)[nH]c1=O</smiles><smiles>O=c1cc[nH]c(=O)[nH]1</smiles>

8 uracil<smiles>O=c1[nH]cc(F)c(=O)[nH]1</smiles>

$25-\mathrm{FU}$

Fig. 2. Structures of Compounds 4 and 5 and Nucleic Acid Bases 6, 7, 8 and 2 Used in This Study

previously reported. ${ }^{13)}$ Compound $\mathbf{5}$ was reacted with adenine 6, thymine 7, uracil 8 or 5-FU 2 in the presence of $\mathrm{NaH}$ in $N, N$-dimethylformamide (DMF) to give $\mathbf{9}, \mathbf{1 0}, \mathbf{1 1}$ and $\mathbf{1 2}$ in $19.5 \%, 27.9 \%, 39.7 \%$ and $55.9 \%$ yield, respectively (Fig. 2). The substituted positions of the nucleic acid bases of compounds 9-12 were confirmed from the heteronuclear multiple bond connectivity (HMBC) spectra shown in Fig. 3. In the spectrum of compound $\mathbf{9}$, correlations between the proton signals due to the methylene group $\left(\mathrm{CH}_{2}\right)$ on the anthraquinone residue at $\delta 5.43$ and the carbon signal at $\delta 117.2$ due to $\mathrm{C}-4$ on the quinone residue and those at $\delta 153.4$ and 140.2 


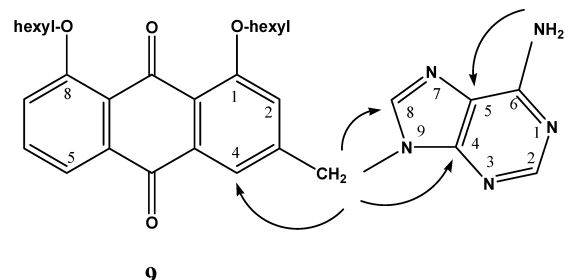
9

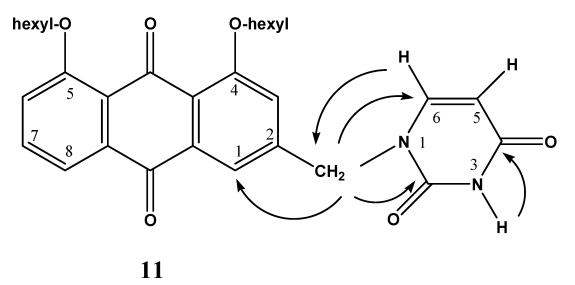

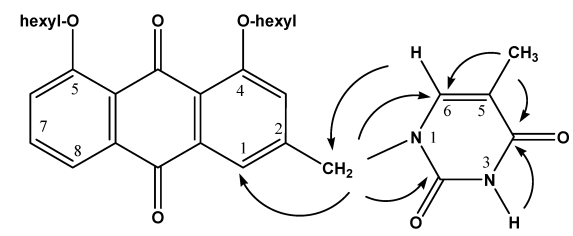

10

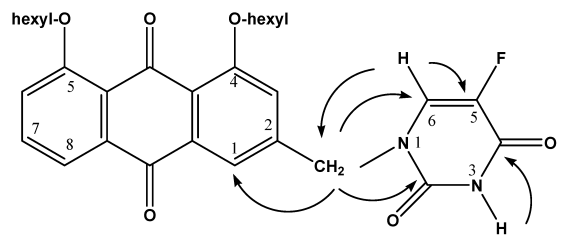

12

Fig. 3. Structures of Compounds $\mathbf{9 - 1 2}$ and ${ }^{1} \mathrm{H}-{ }^{13} \mathrm{C}$ Long-Range Correlations Observed for Compounds $\mathbf{9}-\mathbf{1 2}$<smiles>CCc1cc(O)c2c(c1)C(=O)c1cccc(O)c1C2=O</smiles>

13

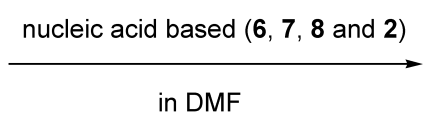

in DMF<smiles>O=Cc1cc(O)c2c(c1)C(=O)c1cccc(O)c1C2=O</smiles>

products $(14,15,16$ and 17)
14<smiles>[R]#Cn1cnc2c(N)ncnc21</smiles>

16

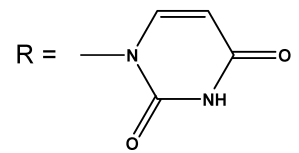

15<smiles>[R]#Cn1cc(C)c(=O)[nH]c1=O</smiles>

17<smiles>[R]#Cn1cc(F)c(=O)[nH]c1=O</smiles>

Fig. 4. Structures of Compounds $\mathbf{1 4 - 1 7}$ Obtained by the Reactions of $\mathbf{1 3}$ with $\mathbf{6 , 7 , 8}$ and $\mathbf{2}$, Respectively

due to $\mathrm{C}-4$ and $\mathrm{C}-8$ on the adenine residue, respectively, were observed. Thus, compound 9 was confirmed as 3-[(6amino-9H-purin-9-yl)-methyl]-1,8-bis(hexyloxy)anthracene9,10-dione. Correlations between proton signals at $\delta 4.94$, 4.98 and 4.93 due to the methylene groups on the anthraquinone residues of $\mathbf{1 0}, \mathbf{1 1}$ and $\mathbf{1 2}$, respectively, and carbon signals due to C-2 and C-6 at $\delta 150.9$ and 136.4, $\delta 150.7$ and 143.6, and $\delta 149.3$ and 127.9 on the thymine, uracil and 5fluorouracil residues, respectively, were observed. As a result, compounds $\mathbf{1 0}, \mathbf{1 1}$ and $\mathbf{1 2}$ are confirmed as 1-([4,5-bis (hexyloxy)-9,10-dinoe-9,10-dihydroanthracene-2yl]methyl)5-methylpyrimidine-2,4(1H,3H)-dione, 1-([4,5-bis(hexyloxy)9,10-dinoe-9,10-dihydroanthracene-2yl]methyl)pyrimidine2,4(1H,3H)-dione and, 1-([4,5-bis(hexyloxy)-9,10-dinoe-9, 10-dihydroanthracene-2yl]methyl)-5-fluoropyrimidine-2, $4(1 H, 3 H)$-dione, respectively.
1,8-Dihydroxyl anthraquinone derivatives having nucleic acid bases were synthesized as follows. 15-Bromochrysophanol $13^{4)}$ was reacted with adenine 6 , thymine 7 , uracil 8 or 5-FU 2 in the presence of $\mathrm{NaH}$ in DMF to give compounds 14, 15, 16 and 17 in $18.1 \%, 57.0 \%, 68.2 \%$ and $45.9 \%$ yield, respectively (Fig. 4 ).

Next, naphthoquinone derivatives having various nucleic acid bases or amines, and thiocyanato (-SCN), selenocyanato $(-\mathrm{SeCN})$ and thioacetyl (-SAc) groups on the side chains of the naphthoquinone skeletons were synthesized. In this study, we aimed to obtain two types of naphthoquinone derivatives (type A and B shown in Fig. 5) from menadione 18 (Vitamin $\mathrm{K}_{3}$, an easily obtainable compound from commercial suppliers) in order to investigate the structure-cytotoxic activity relationships of the products.

A key 2-bromomethoxy-1,4-dimethoxynaphthalene 19 for 


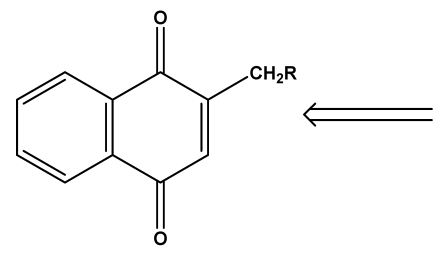

type A derivatives<smiles>C=C=Cc1ccc2c(c1)C(=O)C(C)=CC2=O</smiles>

type $B$ derivatives

$\mathrm{R}=$ nucleic acid bases, amines, $-\mathrm{SCN},-\mathrm{SeCN}$ or $-\mathrm{SAc}$ groups

Fig. 5. Structures of Compound $\mathbf{1 8}$ and Type A and B Derivatives

the preparation of type A (Fig. 5) derivatives was synthesized as follows. Compound $\mathbf{1 8}$ was reacted with $\mathrm{SnCl}_{2}$ in acidic $\mathrm{MeOH}$, followed by treatment with dimethyl-sulfate and $\mathrm{K}_{2} \mathrm{CO}_{3}$ in acetone ${ }^{14)}$ to give $\mathbf{2 0}$ in $71.5 \%$ yield. Compound $\mathbf{2 0}$ was oxidized with $\mathrm{KMnO}_{4}$ in aqueous pyridine to give compound 21 in $32.3 \%$ yield, and then reduced with $\mathrm{LiAlH}_{4}$ to obtain alcohol 22 (57.1\% yield). The alcohol was then reacted with $\mathrm{CBr}_{4}$ and $\mathrm{PPh}_{3}$ in ether to give compound 19 (50.3\% yield) (Fig. 6).

A key 7-bromomethoxy-1,4-dimethoxynaphthalene $\mathbf{2 3}$ for the preparation of type B derivatives (Fig. 5) was synthesized as follows. Friedel-Crafts reaction ${ }^{15)}$ of compound $\mathbf{2 0}$ with $\mathrm{CH}_{3} \mathrm{COCl}$ gave 24 in $65.2 \%$ yield. The position of the substituted acetyl group $\left(\mathrm{COCH}_{3}\right)$ of $\mathbf{2 4}$ was confirmed from the HMBC spectrum (Fig. 7). Correlation between proton signals at $\delta 8.06$ and 8.83 due to $\mathrm{H}-6$ and $\mathrm{H}-8$, respectively, and carbon signal at $\delta 198.1$, due to the newly introduced acetyl group, and that between the methyl proton signal at $\delta 2.73$ of the acetyl group and carbon signals at 133.2 and 124.5 due to C-7 and C-8, respectively, were observed. The NMR data shows compound $\mathbf{2 4}$ is 7-acetyl-1,4-dimethoxy-2-methylnaphthalene.

Compound 24 was successively treated with $\mathrm{KOH},{ }^{16)}$ reduced with $\mathrm{LiAlH}_{4}$ and brominated with $\mathrm{CBr}_{4}$ and $\mathrm{PPh}_{3}$ to give $\mathbf{2 5}, \mathbf{2 6}$ and $\mathbf{2 3}$, in $43.5 \%, 64.7 \%$ and $65.8 \%$ yield, respectively. Bromide 19 was reacted with adenine, thymine, uracil and 5-fluorouracil in the presence of $\mathrm{NaH}$ in DMF to give compounds 27, 28, 29 and $\mathbf{3 0}$ in $28.3 \%, 53.7 \%, 41.9 \%$ and $54.7 \%$ yield, respectively (Fig. 8 ). The same reactions with bromide 23 afforded compounds $\mathbf{3 1}, \mathbf{3 2}, \mathbf{3 3}$ and $\mathbf{3 4}$ in $57.0,54.7,56.6$ and $47.8 \%$ yield, respectively. Cleavage of the protecting group of $\mathbf{2 7}$ was carried out by three different methods; i) hydrolysis with $\mathrm{HNO}_{3}$ in $\mathrm{AcOH}$, ii) treatment with $\left(\mathrm{NH}_{4}\right)_{2} \mathrm{Ce}\left(\mathrm{NO}_{3}\right)_{6}(\mathrm{CAN})$ in aqueous $\mathrm{CH}_{3} \mathrm{CN}^{14)}$ and iii) treatment with $\mathrm{N}$-bromosuccinimide (NBS) in acidified aqueous tetrahydrofuran (THF). ${ }^{17)}$ Most of the procedures gave mixtures, although treatment of compounds $28-\mathbf{3 4}$ by the method i) afforded the desired products $35,36,37,38,39,40$ and 41 in $53.2 \%, 47.8 \%, 51.7 \%, 21.9 \%, 64.1 \%, 63.5 \%$ and $56.1 \%$ yield, respectively.

Naphthoquinone derivatives having various amines at the side chain in the molecules were synthesized next (Fig. 9). Bromide 19 was reacted with pyrrolidine, 1-methylpiperazine, morpholine, imidazole, theophylline and theobromine in THF to give compounds $\mathbf{4 2 , 4 3 , 4 4 , 4 5 , 4 6}$ and $\mathbf{4 7}$ in 64.2, $51.4,62.6,46.7,32.6$ and $55.5 \%$ yield, respectively. Bromide 23 was reacted with morpholine in THF to give compound $\mathbf{4 8}$ in $\mathbf{4 9 . 8 \%}$ yield. Bromide $\mathbf{2 3}$ was reacted with theophylline

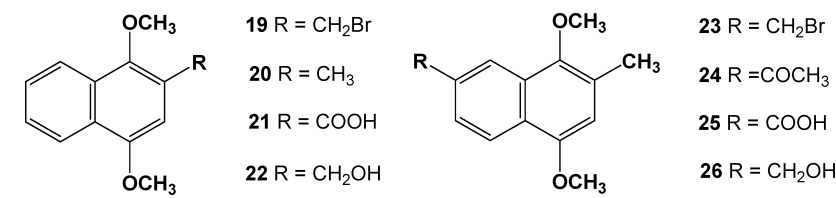

Fig. 6. Structures of Compounds 19-26

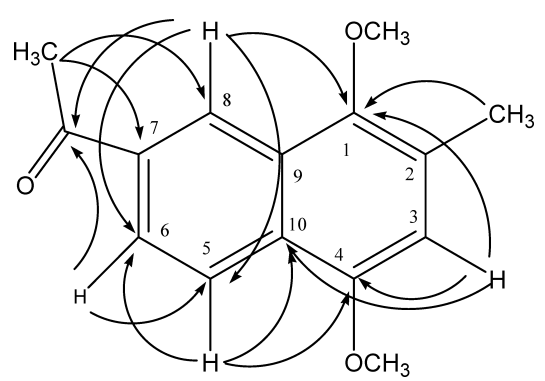

Fig. 7. $\quad{ }^{1} \mathrm{H}-{ }^{13} \mathrm{C}$ Long-Range Correlations Observed for Compound 24

and theobromine in the presence of $\mathrm{NaH}$ in DMF to afford compounds 49 and $\mathbf{5 0}$ in $38.4 \%$ and $69.8 \%$ yield, respectively. Cleavage of the protecting group of $\mathbf{4 2}$ and $\mathbf{4 3}$ by the method iii) (described earlier) gave compounds $\mathbf{5 1}$ and $\mathbf{5 2}$ in $59.0 \%$ and $54.8 \%$ yield, respectively. Compounds $\mathbf{4 4}$ and $\mathbf{4 6}$ were deprotected by the method ii) to afford compounds $\mathbf{5 3}$ and $\mathbf{5 4}$ in $63.5 \%$ and $53.7 \%$ yield, respectively. The protecting group of $\mathbf{4 7}$ was cleaved by the method i) to give compound $\mathbf{5 5}$ in $58.6 \%$ yield. Unfortunately, cleavage of the protecting group of $\mathbf{4 5}$ gave a mixture of products using each of the three methods. The cleavages of the protecting group of compounds $\mathbf{4 8}-\mathbf{5 0}$ by the method iii) gave compounds $\mathbf{5 6}$ $\mathbf{5 8}$ in $49.5 \%, 41.2 \%$ and $38.5 \%$ yield, respectively.

Finally, type A and B naphthoqinone derivatives (Fig. 5) having thiocyanato (-SCN), selenocyanato $(-\mathrm{SeCN})$ and thioacetyl (-SAc) groups at the side chains of the molecules were prepared. In these preparations, bromide 19 and bromide 23 were also utilized as starting materials. Bromide $\mathbf{1 9}$ was reacted with $\mathrm{KSCN}, \mathrm{KSeCN}$ and $\mathrm{KOAc}$ to give naphthalene derivatives 59-61 in 73.6\%, 76.4\% and 55.3\% yield, respectively. Reactions of bromide 23 with $\mathrm{KSCN}, \mathrm{KSeCN}$ and KOAc gave naphthalene derivatives $\mathbf{6 2}-\mathbf{6 4}$ in the yields of $65.3 \%, 52.2 \%$ and $48.3 \%$ yield, respectively. Cleavage of the protecting groups of compounds 59-64 was carried out by the three methods described earlier. Method i) was used to obtain compounds $\mathbf{6 5 - 7 0}$ in $46.6 \%, 38.9 \%, 45.3 \%, 42.3 \%$, $41.8 \%$ and $71.5 \%$ yield, respectively. 
<smiles>[R]Cc1cc(OC)c2ccccc2c1OC</smiles>

$27 \mathrm{R}=\mathrm{a}$

$28 \mathrm{R}=\mathrm{b}$

$29 \mathrm{R}=\mathrm{C}$

$30 \mathrm{R}=\mathrm{d}$

$35 \mathrm{R}=\mathrm{b}$<smiles>[R]CC1=CC(=O)c2ccccc2C1=O</smiles>

$36 \mathrm{R}=\mathrm{c}$

$37 \mathrm{R}=\mathrm{d}$<smiles>Cn1cnc2c(N)ncnc21</smiles><smiles>C#Cn1ccc(=O)[nH]c1=O</smiles>

Fig. 8. Structures of Compounds $27-\mathbf{4 1}$

\section{Pharmacological Results and Discussion}

Cytotoxic effects of all anthraquinone and naphthoquinone derivatives prepared in this study were tested against HCT 116 and Hep G2 cancer cell lines using the 3-(4,5-dimethylthiazol-2-yl)-2,5-diphenyltetrazolium bromide (MTT) assay ${ }^{18)}$ and compared with those of 5-FU, which has been used clinically. In this study, the effects are represented by $\mathrm{IC}_{50}$ values i.e., concentration of compound required to give $50 \%$ inhibition of cell growth. Although multidrug resistance 1 (MDR 1) (P-glycoprotein; P-gp) ${ }^{2)}$ is overexpressed in Hep G2 cells, it is barely expressed in HCT 116 cells. ${ }^{3)}$ P-gp acts as an efflux pump to remove several antitumor agents such as $\mathrm{Ca}^{2+}$ antagonists, cyclosporine and digoxin from cells. ${ }^{19}$

Table 1 shows the comparison of cytotoxic effects of 1,8di- $O$-hexylchrysophanol derivatives 9-12 and chrysophanol derivatives 14-17 having nucleic acid bases at position 15 with those of clinically used 5-fluorouracil (5-FU) 2 against HCT 116 and Hep G2 cancer cells. In the case of compounds 9-12, 9 and $\mathbf{1 0}$ substituted with adenine and thymine, respectively, showed more potent effects on the both cell lines $\left(\mathrm{IC}_{50}: 8.1 \pm 1.1\right.$ and $3.8 \pm 0.11 \mu \mathrm{M}$, respectively, on HCT 116 cells, and 10.4 \pm 3.6 and $4.2 \pm 0.4 \mu \mathrm{M}$, respectively, on Hep $\mathrm{G} 2$ cells) than those of $2\left(\mathrm{IC}_{50}: 45.0 \pm 6.8\right.$ and $50.8 \pm 3.7 \mu \mathrm{M}$ on HCT 116 and Hep G2 cells, respectively). Compounds 11 and 12 substituted with uracil and 5-fluorouracil, respec-<smiles>COc1cc(C)c(OC)c2cc(C=O)ccc12</smiles>

$31 \mathrm{R}=\mathrm{a}$

$32 \mathrm{R}=\mathrm{b}$

$33 \mathrm{R}=\mathrm{c}$

$34 R=d$

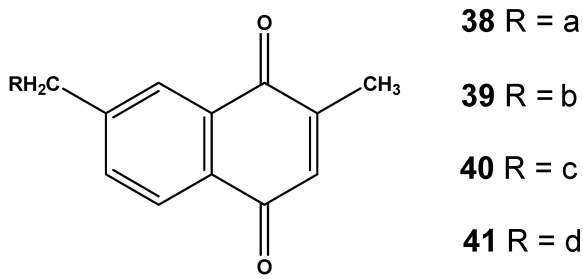

$b=$<smiles>Cc1cn(C)c(=O)[nH]c1=O</smiles>

$\mathbf{d}=$<smiles>Cn1cc(F)c(=O)[nH]c1=O</smiles>

tively, have, however, slightly greater effects $\left(\mathrm{IC}_{50}: 29.3 \pm 6.9\right.$ and $39.6 \pm 4.4 \mu \mathrm{M}$, respectively) on HCT 116 cells than that of 2. Using Hep G2 cells, compound $\mathbf{1 2}$ displayed only a marginally greater effect $\left(\mathrm{IC}_{50}: 45.3 \pm 10.5 \mu \mathrm{M}\right)$ than that of $\mathbf{2}$, while the effect of compound $\mathbf{1 1}\left(\mathrm{IC}_{50}\right.$ : more than $\left.100 \mu \mathrm{M}\right)$ was weaker than that of $\mathbf{2}$ on the same cells. We also tested the biological effect of chrysophanol derivatives 14-17 substituted with adenine, thymine, uracil or 5-fluorouracil, respectively. All these derivatives showed greater effects than those of 2 both on TCT 116 cells and Hep G2 cells. Among these compounds, 14, 16 and 17 had potent effects both on HCT 116 cells $\left(\mathrm{IC}_{50}: 2.8 \pm 0.4-7.8 \pm 0.4 \mu \mathrm{M}\right)$ and Hep $\mathrm{G} 2$ cells $\left(\mathrm{IC}_{50}: 3.1 \pm 0.4-9.8 \pm 0.6 \mu \mathrm{M}\right)$, although the exact $\mathrm{IC}_{50}$ values for 15 were not obtained because of problems with turbidity.

Next, cytotoxic effects of type A and B naphthoquinone derivatives having nucleic acid bases (Fig. 8) were evaluated and compared with those of 2 (5-FU). Table 2 shows the cytotoxic effects of compounds 35-37 (type A) and compounds $38-41$ (type B). Both types of compounds had potent effects on HCT 116 cells $\left(\mathrm{IC}_{50}: 1.8 \pm 0.1-3.0 \pm 0.1 \mu \mathrm{M}\right.$ for 35-37 and $1.8 \pm 0.1-8.6 \pm 0.6 \mu \mathrm{M}$ for 38-41) and Hep $\mathrm{G} 2$ cells $\left(\mathrm{IC}_{50}: 2.3 \pm 0.1-4.1 \pm 0.2 \mu \mathrm{M}\right.$ for $35-37$ and $2.5 \pm 0.2-7.8 \pm 0.3 \mu \mathrm{M}$ for 38-41). The effects of type A and type B derivatives against HCT 116 and Hep G2 cells 
<smiles>[R]Cc1cc(OC)c2ccccc2c1OC</smiles>

$42 R=e \quad 43 R=f$

$44 R=g \quad 45 R=h$

$46 R=i \quad 47 R=j$<smiles>[R]CC1=CC(=O)c2ccccc2C1=O</smiles>

$51 R=e \quad 52 R=f$

$53 \mathrm{R}=\mathrm{g} \quad 54 \mathrm{R}=\mathrm{i}$

$55 R=j$
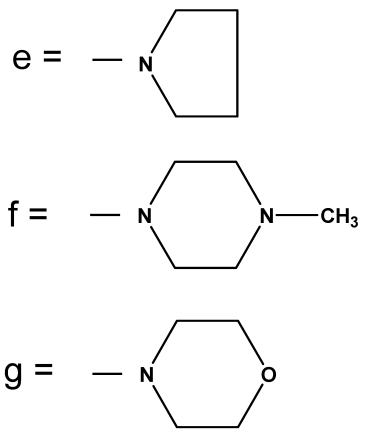

$\mathrm{h}=-{ }^{\mathrm{N}}$

Fig. 9. Structures of Compounds $\mathbf{4 2}-\mathbf{5 8}$

were $5.2-25.0$ and $6.5-22.1$ times higher than those of 2 $\left(\mathrm{IC}_{50}: 45.0 \pm 6.8\right.$ and $50.8 \pm 3.7 \mu \mathrm{M}$, respectively). However, there was no significant difference between the effects of type A derivatives and those of type B derivatives.

Amino derivatives 51-54 (type A) and 56-58 (type B) also showed more potent effects on HCT 116 cells $\left(\mathrm{IC}_{50}\right.$ : $1.6 \pm 0.1-6.7 \pm 0.1 \mu \mathrm{M})$ and Hep $\mathrm{G} 2$ cells $\left(\mathrm{IC}_{50}: 2.1 \pm 0.3-\right.$ $8.5 \pm 0.4 \mu \mathrm{M}$ ) (Table 3 ) than the corresponding effect of compound 2 . In this case, no significant difference between type $\mathrm{A}$ and type B amines was also observed.<smiles>COc1cc(C)c(OC)c2cc(C=O)ccc12</smiles>

$48 \mathrm{R}=\mathrm{g} \quad 49 \mathrm{R}=\mathrm{i}$

$50 R=j$<smiles>CC1=CC(=O)c2ccc(CP)cc2C1=O</smiles>

$56 \mathrm{R}=\mathrm{g} \quad 57 \mathrm{R}=\mathrm{i}$

$58 R=j$<smiles>Cn1c(=O)c2c(ncn2C)n(C)c1=O</smiles><smiles>Cn1c(=O)c2c(ncn2C)n(C)c1=O</smiles>

Finally, cytotoxic effects of type A and B naphthoquinone derivatives 65-67 and 68-70, respectively, having - $\mathrm{SCN}$, -SeCN and -SAc groups (Fig. 10) were evaluated and compared with those of $\mathbf{2}$ (5-FU) (Table 4). All these type A and $\mathrm{B}$ compounds displayed a greater biological effects $\left(\mathrm{IC}_{50}\right.$ : $2.7 \pm 0.1-16.0 \pm 0.5 \mu \mathrm{M}$ on HCT 116 cells, $4.4 \pm 0.1-$ $20.9 \pm 1.4 \mu \mathrm{M}$ on Hep G2 cells) than compound 2 using both cell lines. A comparison of the effects shown in Table 4 between type A and type B compounds illustrates that there is no difference in the structure-activity relationships. Interes- 
Table 1. Comparison of the Cytotoxic Effects of Anthraquinone Derivatives 9-12 and 14-17 with Those of 5-FU (2)

\begin{tabular}{ccc}
\hline \hline & \multicolumn{2}{c}{$\mathrm{IC}_{50} \pm$ S.D. $(\mu \mathrm{M})^{b)}$} \\
\cline { 2 - 3 } Compound & HCT 116 cells & Hep G2 cells \\
\hline $\mathbf{2}(5-\mathrm{FU})$ & $45.0 \pm 6.8$ & $50.8 \pm 3.7$ \\
$\mathbf{9}$ & $8.1 \pm 1.1$ & $10.4 \pm 3.6$ \\
$\mathbf{1 0}$ & $3.8 \pm 0.1$ & $4.2 \pm 0.4$ \\
$\mathbf{1 1}$ & $29.3 \pm 6.9$ & $>100^{c}$ \\
$\mathbf{1 2}$ & $39.6 \pm 4.4$ & $45.3 \pm 10.5$ \\
$\mathbf{1 4}$ & $7.8 \pm 0.4$ & $3.1 \pm 0.4$ \\
$\mathbf{1 5}$ & $29.4 \pm 1.9^{d)}$ & $21.5 \pm 0.6^{d)}$ \\
$\mathbf{1 6}$ & $5.1 \pm 0.2$ & $3.9 \pm 0.5$ \\
$\mathbf{1 7}$ & $2.8 \pm 0.4$ & $9.8 \pm 0.6$ \\
\hline
\end{tabular}

a) Each experiment was performed in duplicate wells, and drug treatments were performed separately three times. $b$ ) $\mathrm{IC}_{50}$ values (mean \pm S.D.) are the concentrations at which $50 \%$ of the cells are inhibited from growing. c) $\mathrm{IC}_{50}$ values more than $100 \mu \mathrm{m}$ are indicated as $>100 . \quad d$ ) Precise values for compound 15 were not obtained because the turbidity of the solution was too great at the concentrations of compound giving $50 \%$ growth inhibition.

Table 2. Comparison of the Cytotoxic Effects of Compounds 35-41 with Those of 5-FU (2)

\begin{tabular}{ccc}
\hline \hline & \multicolumn{2}{c}{$\mathrm{IC}_{50} \pm \mathrm{S} . \mathrm{D} .(\mu \mathrm{M})^{b)}$} \\
\cline { 2 - 3 } Compound & HCT 116 cells & Hep G2 cells \\
\hline $\mathbf{2}(5-\mathrm{FU})$ & $45.0 \pm 6.8$ & $50.8 \pm 3.7$ \\
$\mathbf{3 5}$ & $1.8 \pm 0.1$ & $2.8 \pm 0.1$ \\
$\mathbf{3 6}$ & $3.0 \pm 0.1$ & $3.5 \pm 0.1$ \\
$\mathbf{3 7}$ & $2.5 \pm 0.2$ & $4.1 \pm 0.2$ \\
$\mathbf{3 8}$ & $1.8 \pm 0.1$ & $2.5 \pm 0.2$ \\
$\mathbf{3 9}$ & $2.7 \pm 0.1$ & $2.3 \pm 0.1$ \\
$\mathbf{4 0}$ & $5.8 \pm 0.3$ & $7.8 \pm 0.3$ \\
$\mathbf{4 1}$ & $8.6 \pm 0.6$ & $6.4 \pm 0.1$ \\
\end{tabular}

a) Each experiment was carried out in duplicate wells, and drug treatments were performed separately three times. b) $\mathrm{IC}_{50}$ values (mean \pm S.D.) are the concentrations at which $50 \%$ of the cells are inhibited from growing.

Table 3. Comparison of the Cytotoxic Effects of Compounds $\mathbf{5 1 - 5 8}$ with Those of 5-FU $(2)^{a)}$

\begin{tabular}{lcc}
\hline \hline & \multicolumn{2}{c}{$\mathrm{IC}_{50} \pm$ S.D. $(\mu \mathrm{M})^{b)}$} \\
\cline { 2 - 3 } Compound & HCT 116 cells & Hep G2 cells \\
\hline $\mathbf{2}(5-\mathrm{FU})$ & $45.0 \pm 6.8$ & $50.8 \pm 3.7$ \\
$\mathbf{5 1}$ & $5.3 \pm 0.1$ & $4.1 \pm 0.1$ \\
$\mathbf{5 2}$ & $1.6 \pm 0.1$ & $4.5 \pm 0.2$ \\
$\mathbf{5 3}$ & $5.4 \pm 0.2$ & $4.7 \pm 0.3$ \\
$\mathbf{5 4}$ & $1.9 \pm 0.1$ & $2.1 \pm 0.3$ \\
$\mathbf{5 5}$ & $2.9 \pm 0.1$ & $3.8 \pm 0.1$ \\
$\mathbf{5 6}$ & $6.7 \pm 0.1$ & $8.5 \pm 0.4$ \\
$\mathbf{5 7}$ & $4.2 \pm 0.1$ & $6.8 \pm 0.1$ \\
$\mathbf{5 8}$ & $3.1 \pm 0.1$ & $3.8 \pm 0.1$ \\
\hline
\end{tabular}

a) Each experiment was carried out in duplicate wells, and drug treatments were performed separately three times. b) $\mathrm{IC}_{50}$ values (mean \pm S.D.) are the concentrations at which $50 \%$ of the cells are inhibited from growing.

tigly, the effect of compounds $\mathbf{6 5}$ and $\mathbf{6 7 - 7 0}$ on HCT 116 cells was greater than the corresponding effect on Hep G2 cells. However, in the case of compound $\mathbf{6 6}$, both cell lines were affected to a similar extent. Among these compounds 65-70, compound 68 (type B derivative having -SCN group) in particular displayed a remarkably potent effects against both the HCT 116 cells $\left(\mathrm{IC}_{50}: 2.7 \pm 0.1 \mu \mathrm{M}\right)$ and Hep<smiles>[R]Cc1cc(OC)c2ccccc2c1OC</smiles><smiles>[R]Cc1ccc2c(OC)cc(C)c(OC)c2c1</smiles>

$59 \mathrm{R}=-\mathrm{SCN}$

$62 \mathrm{R}=-\mathrm{SCN}$

$60 \mathrm{R}=-\mathrm{SeCN}$

$63 \mathrm{R}=-\mathrm{SeCN}$

$61 \mathrm{R}=-\mathrm{SAC}$

$64 R=-S A C$<smiles>[R]CC1=CC(=O)c2ccccc2C1=O</smiles><smiles>[R]Cc1ccc2c(c1)C(=O)C(C)=CC2=O</smiles>

$65 \mathrm{R}=-\mathrm{SCN}$

$66 \mathrm{R}=-\mathrm{SeCN}$

$68 \mathrm{R}=-\mathrm{SCN}$

$67 R=-S A C$

$69 \mathrm{R}=-\mathrm{SeCN}$

$70 R=-S A C$

Fig. 10. Structures of Compounds 59-70

Table 4. Comparison of the Cytotoxic Effects of Compounds $\mathbf{6 5}-\mathbf{7 0}$ with Those of 5-FU (2) ${ }^{a)}$

\begin{tabular}{lcc}
\hline \hline \multirow{2}{*}{ Compound } & \multicolumn{2}{c}{$\mathrm{IC}_{50} \pm \mathrm{S} . \mathrm{D} .(\mu \mathrm{M})^{b)}$} \\
\cline { 2 - 3 } & $\mathrm{HCT} 116$ cells & Hep G2 cells \\
\hline $\mathbf{2}(5-\mathrm{FU})$ & $45.0 \pm 6.8$ & $50.8 \pm 3.7$ \\
$\mathbf{6 5}$ & $16.0 \pm 0.5$ & $20.9 \pm 1.4$ \\
$\mathbf{6 6}$ & $8.5 \pm 0.2$ & $7.9 \pm 0.8$ \\
$\mathbf{6 7}$ & $3.8 \pm 0.6$ & $6.6 \pm 0.2$ \\
$\mathbf{6 8}$ & $2.7 \pm 0.1$ & $4.4 \pm 0.1$ \\
$\mathbf{6 9}$ & $4.1 \pm 0.1$ & $10.1 \pm 0.1$ \\
$\mathbf{7 0}$ & $6.5 \pm 0.1$ & $13.4 \pm 0.3$ \\
\hline
\end{tabular}

a) Each experiment was carried out in duplicate wells, and drug treatments were performed separately three times. b) $\mathrm{IC}_{50}$ values (mean \pm S.D.) are the concentrations at which $50 \%$ of the cells are inhibited from growing.

$\mathrm{G} 2$ cells $\left(\mathrm{IC}_{50}: 4.4 \pm 0.1 \mu \mathrm{M}\right)$ lines.

\section{Conclusion}

In this study, anthraquinone and naphthoquinone derivatized with various nucleic acid bases, amines and thiocyanato, selenocyanato or thioacetyl groups were synthesized. From 1,8-di- $O$-hexyl-15-O-tosylchrysophanol 5, 1,8di-O-hexylchrysophanol derivatives $\mathbf{9 - 1 2}$ substituted with adenine, thymine, uracil and 5-fluorouracil, respectively, were prepared. Starting from 15-bromochrysophanol 13, chrysophanol derivatives 14-17 substituted with adenine, thymine, uracil and 5-fluorouracil, respectively, were prepared. For the preparations of naphthoquinone derivatives, 1,4-dimethoxynaphthalene $\mathbf{2 0}$ derived from menadione $\mathbf{1 8}$ (Vitamin $\mathrm{K}_{3}$ ) was used as a key intermediate. From compound 20, both type A and type B bromides (11-bromo-1,4dimethoxynaphthalene 19 and 7-bromomethyl-1,4-dimethoxynaphthalene 23, respectively) were obtained. Substitutions of 19 with nucleic acid bases, amines and potassium salts (KSCN, KSeCN and KSAc), followed by cleavage of the protecting groups, gave $\mathbf{3 5}, \mathbf{3 6}$ and $\mathbf{3 7}$ as type A derivatives bearing thymine, uracil and 5-fluolouracil moieties, respec- 
tively. Compounds $\mathbf{5 1}-\mathbf{5 5}$ represent the same type of derivatives having amines (pyrrolidine, 1-methylpiperazine, morpholine, imidazole, theophylline or theobromine, respectively). Likewise compounds 65-67 are corresponding derivatives having - $\mathrm{SCN}$, $-\mathrm{SeCN}$ and -SAc groups, respectively. Similarly, from bromide $\mathbf{2 3}$, the type B naphthoquinone derivatives 38-41 having adenine, thymine, uracil and 5-fluorouracil, respectively, were synthesized. The same type derivatives 56-58 having morpholine, theophylline and theobromine, respectively, and the same type derivatives $68-70$ having $-\mathrm{SCN},-\mathrm{SeCN}$ and $-\mathrm{SAc}$, respectively, were also obtained.

The cytotoxic effects of each synthetic derivative was evaluated using the HCT 116 cell and Hep G2 cancer cell lines. These cell lines were chosen because MDR 1 (P-glycoprotein, P-gp $)^{2)}$ is known to be overexpressed in the Hep G2 cell lines but barely expressed in the HCT 116 cell lines. ${ }^{3)}$ The cytotoxic activity of each compound was then compared to that of 5-fluorouracil (5-FU). Among anthraquinones 9-17, 1,8-di- $O$-hexylchrysophanols $\mathbf{9}$ and $\mathbf{1 0}$ and chrysophanols 14, 16 and 17 showed potent effects both on HCT 116 and Hep G2 cells (Table 1). Interestingly, compounds $\mathbf{1 4}$ and $\mathbf{1 6}$ displayed enhanced activity using both Hep G2 cells and HCT 116 cells. Indeed, of all the anthraquinones, $\mathbf{1 4}$ and $\mathbf{1 6}$ seemed to be the strongest inhibitors of the efflux function of P-gp. Moreover, all the naphthoquinone derivatives synthesized in this study also displayed potent effects both on HCT 116 and Hep G2 cell lines (see Tables 2-4). We analized the structure-activity relationships between type A and B derivatives and the various substituents. However, no firm conclusions could be made from this analysis. Interestingly, however, many of the compounds had potent effects against Hep G2 cells, which overexpress P-gp. We anticipate these derivatives may help to overcome the problem of drug excretion from cancer cells stably expressing P-gp. Indeed, excretion of anticancer agents is a major cause of multidrug resistance. Further work is required to establish the precise structure-activity relationship for the various derivatives in terms of their affinity for the target proteins and the corresponding intracellular accumulation.

\section{Experimental}

General Methods Reagent-grade chemicals and solvents were obtained from commercial suppliers. The melting points $(\mathrm{mp})$ were determined using a Yanagimoto micromelting point apparatus and were uncorrected. Kieselgel $60 \mathrm{~F}_{254}$ (E. Merck, Germany) was used in thin-layer chromatography (TLC). Spots were detected by spraying plates with 1:9 $\mathrm{Ce}\left(\mathrm{SO}_{4}\right)_{2}-10 \% \mathrm{H}_{2} \mathrm{SO}_{4}$ reagent, followed by heating the plates at $200^{\circ} \mathrm{C}$ for $4-5 \mathrm{~min}$. Column chromatography was carried out using Kieselgel 60 (E. Merck), then the eluates were monitored by TLC. ${ }^{1} \mathrm{H}$ - and ${ }^{13} \mathrm{C}$-NMR spectroscopy investigations were carried out at 500 and $125 \mathrm{MHz}$, respectively, and ${ }^{1} \mathrm{H}-{ }^{1} \mathrm{H}$ and ${ }^{1} \mathrm{H}-{ }^{13} \mathrm{C}$ correlation spectroscopy (COSY) and HMBC spectra were obtained using a JEOL JNM-A500 FT-NMR spectrometer. Tetramethylsilane was used as an internal standard. The chemical shifts are given in ppm. The multiplicities of the ${ }^{1} \mathrm{H}-\mathrm{NMR}$ signals are indicated as s (singlet), $\mathrm{d}$ (doublet), dd (doublet of doublets), $\mathrm{t}$ (triplet), $\mathrm{q}$ (quartet) and $\mathrm{m}$ (multiplet). Electron impact mass spectra (EI-MS) were recorded using a JEOL JMS-DX 300 mass spectrometer. First-atom-bombardment mass spectra (FAB-MS) and high resolution mass (HR-MS) spectra were recorded using a JEOL JMS-700 mass spectrometer.

3-[(6-Amino-9H-purin-9-yl)methyl]-1,8-bis(hexyloxy)anthracene9,10-dione (9) A solution of $5(110 \mathrm{mg}, 0.19 \mathrm{mmol}), \mathrm{NaH}(42.5 \mathrm{mg}$, $1.8 \mathrm{mmol})$ and $6(118.5 \mathrm{mg}, 0.88 \mathrm{mmol})$ in DMF $(5 \mathrm{ml})$ was stirred at $85^{\circ} \mathrm{C}$ for $35 \mathrm{~h}$. The reaction mixture was poured into ice-water $(20 \mathrm{ml})$ and extracted with $\mathrm{CHCl}_{3}(30 \mathrm{ml} \times 2)$. The organic extracts were successively washed with brine and water, dried over absolute $\mathrm{MgSO}_{4}$, and then filtered.
The filtrate was evaporated to give a residue, which was subjected to silica gel column chromatography (a gradient of $0-10 \% \mathrm{MeOH}$ in $\mathrm{CHCl}_{3}$ ) to afford compound 9 (20.1 mg, 19.5\% yield) as yellowish needles (mp 194 $\left.196^{\circ} \mathrm{C}\right)$. FAB-MS: $m / z 556[\mathrm{M}+\mathrm{H}]^{+}$. HR-MS: $m / z$ Calcd for $\mathrm{C}_{32} \mathrm{H}_{38} \mathrm{~N}_{5} \mathrm{O}_{4}$ $[\mathrm{M}+\mathrm{H}]^{+} ; 556.2925$, Found; 556.2923. ${ }^{1} \mathrm{H}-\mathrm{NMR}\left(\mathrm{CDCl}_{3}\right) \delta: 8.40\left(1 \mathrm{H}, \mathrm{s}, 8^{\prime}-\right.$ H), $7.85\left(1 \mathrm{H}, \mathrm{s}, 2^{\prime}-\mathrm{H}\right), 7.77(1 \mathrm{H}, \mathrm{dd}, J=7.7,0.9 \mathrm{~Hz}, \mathrm{H}-5), 7.70(1 \mathrm{H}, \mathrm{d}$, $J=1.5 \mathrm{~Hz}, \mathrm{H}-4), 7.58(1 \mathrm{H}, \mathrm{dd}, J=8.2,7.7 \mathrm{~Hz}, \mathrm{H}-6), 7.28(1 \mathrm{H}, \mathrm{dd}, J=8.2$, $0.9 \mathrm{~Hz}, \mathrm{H}-7), 7.23(1 \mathrm{H}, \mathrm{d}, J=1.5 \mathrm{~Hz}, \mathrm{H}-2), 5.73\left(2 \mathrm{H}, \mathrm{br} \mathrm{s}, 6^{\prime}-\mathrm{NH}_{2}\right), 5.43(2 \mathrm{H}$, s, $\left.15-\mathrm{CH}_{2}\right), 4.11$ and 4.03 (each $2 \mathrm{H}, \mathrm{t}, J=6.6 \mathrm{~Hz}, 1-$ or $\left.8-\mathrm{OCH}_{2}\right), 1.88(4 \mathrm{H}$ $\left.\mathrm{m}, \mathrm{CH}_{2} \times 2\right), 1.54\left(4 \mathrm{H}, \mathrm{m}, \mathrm{CH}_{2} \times 2\right), 1.34\left(8 \mathrm{H}, \mathrm{m}, \mathrm{CH}_{2} \times 4\right), 0.91(6 \mathrm{H}, \mathrm{m}$, $\left.\mathrm{CH}_{3} \times 2\right) .{ }^{13} \mathrm{C}-\mathrm{NMR}\left(\mathrm{CDCl}_{3}\right): \delta 183.9(\mathrm{C}-10), 181.4(\mathrm{C}-9), 159.7$ (C-8), 159.0 (C-1), $155.6\left(\mathrm{C}-6^{\prime}\right), 153.4\left(\mathrm{C}-4^{\prime}\right), 150.2\left(\mathrm{C}-2^{\prime}\right), 141.3(\mathrm{C}-3), 140.2(\mathrm{C}-$ $8^{\prime}$ ), 135.4 (C-14), 134.7 (C-11), 133.6 (C-6), 124.5 (C-12), 124.4 (C-13), 119.8 (C-7), $119.6\left(\mathrm{C}-5^{\prime}\right), 118.9$ (C-5), $118.4(\mathrm{C}-2), 117.2(\mathrm{C}-4), 69.9$ and $70.0\left(\right.$ each $\left.\mathrm{OCH}_{2}\right), 47.1(\mathrm{C}-15), 22.6-31.6\left(\mathrm{CH}_{2} \times 8\right), 14.0\left(\mathrm{CH}_{3} \times 2\right)$.

1-([4,5-Bis(hexyloxy)-9,10-dioxo-9,10-dihydroanthracen-2-yl]methyl)5-methylpyrimidine-2,4(1H,3H)-dione (10) The same reaction and procedure using 5 (52.4 $\mathrm{mg}, 0.09 \mathrm{mmol}), 7(53.9 \mathrm{mg}, 0.43 \mathrm{mmol})$ and $\mathrm{NaH}$ (21.9 mg, $0.91 \mathrm{mmol})$ as described for 9 gave compound 10 (13.5 mg, 27.9\% yield) as yellowish needles (mp $194-196^{\circ} \mathrm{C}$ ). FAB-MS: $m / z 547[\mathrm{M}+\mathrm{H}]^{+}$ HR-MS: $m / z$ Calcd for $\mathrm{C}_{32} \mathrm{H}_{39} \mathrm{~N}_{2} \mathrm{O}_{6}[\mathrm{M}+\mathrm{H}]^{+}$; 547.2809, Found; 547.2808. ${ }^{1} \mathrm{H}-\mathrm{NMR}\left(\mathrm{CDCl}_{3}\right) \delta: 8.64(1 \mathrm{H}$, br s, 3'-H), $7.79(1 \mathrm{H}, \mathrm{dd}, J=7.6,0.9 \mathrm{~Hz}, \mathrm{H}-$ 5), $7.67(1 \mathrm{H}, \mathrm{d}, J=1.5 \mathrm{~Hz}, \mathrm{H}-4), 7.62(1 \mathrm{H}, \mathrm{dd}, J=8.2,7.6 \mathrm{~Hz}, \mathrm{H}-6), 7.29$ $(1 \mathrm{H}, \mathrm{dd}, J=8.2,0.9 \mathrm{~Hz}, \mathrm{H}-7), 7.23(1 \mathrm{H}, \mathrm{d}, J=1.5 \mathrm{~Hz}, \mathrm{H}-2), 7.03\left(1 \mathrm{H}, \mathrm{s}, 6^{\prime}-\right.$ $\mathrm{H}), 4.94\left(2 \mathrm{H}, \mathrm{s}, 15-\mathrm{CH}_{2}\right), 4.12$ and 4.10 (each $2 \mathrm{H}, \mathrm{t}, J=6.4 \mathrm{~Hz}, 1-$ or 8 $\left.\mathrm{OCH}_{2}\right), 1.92\left(3 \mathrm{H}, \mathrm{m}, 5^{\prime}-\mathrm{CH}_{3}\right), 1.92\left(4 \mathrm{H}, \mathrm{m}, \mathrm{CH}_{2} \times 2\right), 1.56\left(4 \mathrm{H}, \mathrm{m}, \mathrm{CH}_{2} \times 2\right)$, $1.37\left(8 \mathrm{H}, \mathrm{m}, \mathrm{CH}_{2} \times 4\right), 0.92\left(6 \mathrm{H}, \mathrm{m}, \mathrm{CH}_{3} \times 2\right) ;{ }^{13} \mathrm{C}-\mathrm{NMR}\left(\mathrm{CDCl}_{3}\right): \delta 184.0$ (C-10), 181.4 (C-9), 159.7 (C-8), 159.0 (C-1), 163.6 (C-4'), 150.9 (C-2'), 141.3 (C-3), 136.6 (C-11), 136.4 (C-6'), 135.5 (C-14), 133.7 (C-16), 124.6 (C-12), 124.5 (C-13), 119.8 (C-7), 118.9 (C-5), 118.6 (C-2), 117.4 (C-4), $111.9\left(\mathrm{C}-5^{\prime}\right), 69.9$ and $70.0\left(\right.$ each $\left.\mathrm{OCH}_{2}\right), 51.0(\mathrm{C}-15), 22.6-31.6$ $\left(\mathrm{CH}_{2} \times 8\right), 14.0\left(\mathrm{CH}_{3} \times 2\right), 12.4\left(5^{\prime}-\mathrm{CH}_{3}\right)$.

1-([4,5-Bis(hexyloxy)-9,10-dioxo-9,10-dihydroanthracen-2-yl]methyl)pyrimidine-2,4(1H,3H)-dione (11) The same reaction and procedure using 5 (64.4 $\mathrm{mg}, 0.11 \mathrm{mmol}), \mathbf{8}(16.7 \mathrm{mg}, 0.12 \mathrm{mmol})$ and $\mathrm{NaH}$ (5.5 mg, $0.23 \mathrm{mmol})$ as described for 9 gave compound $11(23.0 \mathrm{mg}, 39.7 \%$ yield) as yellowish needles (mp 196-198 $\left.{ }^{\circ} \mathrm{C}\right)$. FAB-MS: $m / z 533[\mathrm{M}+\mathrm{H}]^{+}$. HR-MS: $m / z$ Calcd for $\mathrm{C}_{31} \mathrm{H}_{37} \mathrm{~N}_{2} \mathrm{O}_{6}[\mathrm{M}+\mathrm{H}]^{+} ; 533.2630$, Found; 533.2652 . ${ }^{1} \mathrm{H}-\mathrm{NMR}\left(\mathrm{CDCl}_{3}\right) \delta: 8.50(1 \mathrm{H}$, br s, 3'-H), $7.81(1 \mathrm{H}, \mathrm{dd}, J=7.7,0.9 \mathrm{~Hz}, \mathrm{H}-$ 5), $7.69(1 \mathrm{H}, \mathrm{d}, J=1.6 \mathrm{~Hz}, \mathrm{H}-4), 7.62(1 \mathrm{H}, \mathrm{dd}, J=8.3,7.7 \mathrm{~Hz}, \mathrm{H}-6), 7.31$ $(1 \mathrm{H}, \mathrm{dd}, J=8.3,0.9 \mathrm{~Hz}, \mathrm{H}-7), 7.25\left(1 \mathrm{H}, \mathrm{d}, J=8.0 \mathrm{~Hz}, \mathrm{H}-6^{\prime}\right), 7.25(1 \mathrm{H}, \mathrm{s}, \mathrm{H}-$ 2), $5.77\left(1 \mathrm{H}, \mathrm{d}, J=8.0 \mathrm{~Hz}, \mathrm{H}-5^{\prime}\right), 4.98\left(2 \mathrm{H}, \mathrm{s}, 15-\mathrm{CH}_{2}\right), 4.14$ and 4.12 (each $2 \mathrm{H}, \mathrm{t}, J=6.4 \mathrm{~Hz}, 1-$ or $\left.8-\mathrm{OCH}_{2}\right), 1.92\left(4 \mathrm{H}, \mathrm{m}, \mathrm{CH}_{2} \times 2\right), 1.58(4 \mathrm{H}, \mathrm{m}$, $\left.\mathrm{CH}_{2} \times 2\right), 1.39\left(8 \mathrm{H}, \mathrm{m}, \mathrm{CH}_{2} \times 4\right), 0.94\left(6 \mathrm{H}, \mathrm{m}, \mathrm{CH}_{3} \times 2\right) .{ }^{13} \mathrm{C}-\mathrm{NMR}\left(\mathrm{CDCl}_{3}\right)$ $\delta$ : 183.9 (C-10), 181.4 (C-9), 162.8 (C-4'), 159.7 (C-8), 159.0 (C-1), 150.7 (C-2'), $143.6\left(\mathrm{C}-6^{\prime}\right), 140.8$ (C-3), 135.3 (C-14), 134.5 (C-11), 133.7 (C-6), 124.6 (C-12), 124.3 (C-13), 119.7 (C-7), 118.8 (C-5), 118.4 (C-2), 117.3 (C-

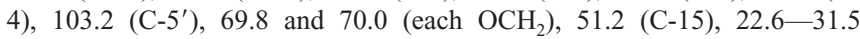
$\left(\mathrm{CH}_{2} \times 8\right), 14.0\left(\mathrm{CH}_{3} \times 2\right)$.

1-([4,5-Bis(hexyloxy)-9,10-dioxo-9,10-dihydroanthracen-2-yl]methyl)5-fluoropyrimidine-2,4(1H,3H)-dione (12) The same reaction and procedure using 5 (41.4 $\mathrm{mg}, 0.07 \mathrm{mmol}), 2(16.7 \mathrm{mg}, 0.12 \mathrm{mmol})$ and $\mathrm{NaH}$ (5.5 mg, $0.23 \mathrm{mmol})$ as described for 9 gave compound $12(21.5 \mathrm{mg}, 55.9 \%$ yield) as yellowish needles (mp $210-212^{\circ} \mathrm{C}$ ). FAB-MS: $m / z 551[\mathrm{M}+\mathrm{H}]^{+}$ HR-MS: $m / z$ Calcd for $\mathrm{C}_{31} \mathrm{H}_{36} \mathrm{O}_{6} \mathrm{~N}_{2} \mathrm{~F}[\mathrm{M}+\mathrm{H}]^{+}$; 551.2564, Found; 551.2552 . ${ }^{1} \mathrm{H}-\mathrm{NMR}\left(\mathrm{CDCl}_{3}\right) \delta: 8.66(1 \mathrm{H}$, br s, 3'-H), $7.80(1 \mathrm{H}, \mathrm{dd}, J=7.9,0.9 \mathrm{~Hz}, \mathrm{H}-$ 5), $7.69(1 \mathrm{H}, \mathrm{d}, J=1.5 \mathrm{~Hz}, \mathrm{H}-4), 7.62(1 \mathrm{H}, \mathrm{dd}, J=8.2,7.9 \mathrm{~Hz}, \mathrm{H}-6), 7.31$ $\left(1 \mathrm{H}, \mathrm{m}, \mathrm{H}-6^{\prime}\right), 7.31(1 \mathrm{H}, \mathrm{dd}, J=8.2,0.9 \mathrm{~Hz}, \mathrm{H}-7), 7.21(1 \mathrm{H}, \mathrm{d}, J=1.5 \mathrm{~Hz}, \mathrm{H}-$ 2), $4.93\left(2 \mathrm{H}, \mathrm{s}, 15-\mathrm{CH}_{2}\right), 4.12$ and 4.10 (each $2 \mathrm{H}, \mathrm{t}, J=6.4 \mathrm{~Hz}, 1-$ or 8 $\left.\mathrm{OCH}_{2}\right), 1.91\left(4 \mathrm{H}, \mathrm{m}, \mathrm{CH}_{2} \times 2\right), 1.56\left(4 \mathrm{H}, \mathrm{m}, \mathrm{CH}_{2} \times 2\right), 1.37\left(8 \mathrm{H}, \mathrm{m}, \mathrm{CH}_{2} \times 4\right)$, $0.92\left(6 \mathrm{H}, \mathrm{m}, \mathrm{CH}_{3} \times 2\right) .{ }^{13} \mathrm{C}-\mathrm{NMR}\left(\mathrm{CDCl}_{3}\right) \delta: 183.8(\mathrm{C}-10), 181.3(\mathrm{C}-9)$, $159.8(\mathrm{C}-8), 159.1\left(\mathrm{C}-4^{\prime}\right), 159.0(\mathrm{C}-1), 149.3\left(\mathrm{C}-2^{\prime}\right), 140.2(\mathrm{C}-3), 140.2(\mathrm{C}-$ 5'), 135.5 (C-14), 134.6 (C-11), 133.8 (C-6), 127.9 (C-6'), 124.9 (C-12), 124.4 (C-13), 119.9 (C-7), 118.9 (C-5), 118.6 (C-2), 117.5 (C-4), 69.8 and $70.1\left(\right.$ each $\left.\mathrm{OCH}_{2}\right), 51.5(\mathrm{C}-15), 22.6-31.6\left(\mathrm{CH}_{2} \times 8\right), 14.0\left(\mathrm{CH}_{3} \times 2\right)$.

3-[(6-Amino-9H-purin-9-yl)methyl]-1,8-dihydroxyanthracene-9,10dione (14) A solution of $13(96 \mathrm{mg}, 0.29 \mathrm{mmol}), \mathrm{NaH}(22.0 \mathrm{mg}, 0.9 \mathrm{mmol})$ and $6(77.4 \mathrm{mg}, 0.57 \mathrm{mmol})$ in DMF $(15 \mathrm{ml})$ was stirred at room temperature for $3 \mathrm{~h}$. The reaction mixture was poured into ice-water $(30 \mathrm{ml})$ and extracted with AcOEt $(100 \mathrm{ml} \times 3)$. The organic extracts were successively washed with brine and water, dried over absolute $\mathrm{MgSO}_{4}$, and then filtered. The filtrate was evaporated to give a residue, which was subjected to silica gel column chromatography (a gradient of $0-10 \% \mathrm{MeOH}$ in $\mathrm{CHCl}_{3}$ ) to afford compound 14 (20.2 $\mathrm{mg}, 18.1 \%$ yield) as yellowish needles (mp more than 
$300^{\circ} \mathrm{C}$ ). FAB-MS: $m / z 387[\mathrm{M}+\mathrm{H}]^{+}$. HR-MS: $m / z$ Calcd for $\mathrm{C}_{19} \mathrm{H}_{12} \mathrm{O}_{6} \mathrm{~N}_{2}$ $[\mathrm{M}+\mathrm{H}]^{+} ; 387.0968$, Found; 387.1002. ${ }^{1} \mathrm{H}-\mathrm{NMR}\left(\mathrm{DMSO}-d_{6}\right) \delta: 11.97(2 \mathrm{H}$, brs, 1- and $8-\mathrm{OH}), 8.34\left(1 \mathrm{H}, \mathrm{s}, \mathrm{H}-8^{\prime}\right), 8.15\left(1 \mathrm{H}, \mathrm{s}, \mathrm{H}-2^{\prime}\right), 7.78(1 \mathrm{H}, \mathrm{t}$, $J=8.1 \mathrm{~Hz}, \mathrm{H}-6), 7.67(1 \mathrm{H}, \mathrm{dd}, J=8.1,1.0 \mathrm{~Hz}, \mathrm{H}-7), 7.56(1 \mathrm{H}, \mathrm{d}, J=1.2 \mathrm{~Hz}$, $\mathrm{H}-2), 7.37(1 \mathrm{H}, \mathrm{dd}, J=8.1,1.0 \mathrm{~Hz}, \mathrm{H}-5), 7.32\left(2 \mathrm{H}, \mathrm{br} \mathrm{s}, 6^{\prime}-\mathrm{NH}_{2}\right), 7.22(1 \mathrm{H}$, d, $J=1.2 \mathrm{~Hz}, \mathrm{H}-4), 5.52(2 \mathrm{H}, \mathrm{s}, \mathrm{H}-15) .{ }^{13} \mathrm{C}-\mathrm{NMR}$ (DMSO-d $\left.d_{6}\right) \delta: 183.9(\mathrm{C}-$ 10), 181.2 (C-9), 161.6 (C-1), 161.4 (C-8), 156.0 (C-6'), 152.7 (C-2'), 149.4 (C-4'), 146.8 (C-8'), 140.8 (C-3), 137.2 (C-6), 133.7 (C-14), 133.2 (C-11), 124.4 (C-5), 122.5 (C-4), 119.2 (C-7), 118.6 (C'-6), 117.6 (C-2), 115.9 (C12), 115.4 (C-13), 45.7 (C-15)

1-[(4,5-Dihydroxy-9,10-dioxo-9,10-dihydroanthracen-2-yl)methyl]-5methylpyrimidine-2,4(1H,3H)-dione (15) The same reaction and procedure using $13(41.0 \mathrm{mg}, 0.12 \mathrm{mmol}), 7(32.0 \mathrm{mg}, 0.25 \mathrm{mmol})$ and $\mathrm{NaH}$ $(14.0 \mathrm{mg}, 0.58 \mathrm{mmol})$ as described for the preparation of 14 gave compound $15(26.6 \mathrm{mg}, 57.0 \%$ yield $)$ as yellowish needles ( $\mathrm{mp}$ more than $\left.300^{\circ} \mathrm{C}\right)$. EIMS: $m / z 378[\mathrm{M}]^{+}$. HR-MS: $m / z$ Calcd for $\mathrm{C}_{20} \mathrm{H}_{14} \mathrm{~N}_{2} \mathrm{O}_{6}[\mathrm{M}]^{+} ; 378.0852$, Found; 378.0857. ${ }^{1} \mathrm{H}-\mathrm{NMR}$ (pyridine- $d_{5}$ ) $\delta: 13.52\left(1 \mathrm{H}, \mathrm{brs}, \mathrm{H}-3^{\prime}\right), 12.12$ $(2 \mathrm{H}$, br s, 1 - and $8-\mathrm{OH}), 8.06(1 \mathrm{H}, \mathrm{d}, J=1.8 \mathrm{~Hz}, \mathrm{H}-2), 7.89(1 \mathrm{H}, \mathrm{dd}, J=8.2$, $0.9 \mathrm{~Hz}, \mathrm{H}-7), 7.64(1 \mathrm{H}, \mathrm{t}, J=8.2 \mathrm{~Hz}, \mathrm{H}-6), 7.56\left(1 \mathrm{H}, \mathrm{q}, J=1.2 \mathrm{~Hz}, \mathrm{H}-6^{\prime}\right)$, $7.54(1 \mathrm{H}, \mathrm{d}, J=1.8 \mathrm{~Hz}, \mathrm{H}-4), 7.37(1 \mathrm{H}, \mathrm{dd}, J=8.2,0.92 \mathrm{~Hz}, \mathrm{H}-5), 5.19(2 \mathrm{H}$, s, $\mathrm{H}-15), 1.96\left(3 \mathrm{H}, \mathrm{d}, J=1.2 \mathrm{~Hz}, 5^{\prime}-\mathrm{CH}_{3}\right)$.

1-[(4,5-Dihydroxy-9,10-dioxo-9,10-dihydroanthracen-2-yl)methyl]pyrimidine-2,4(1H,3H)-dione (16) The same reaction and procedure using $13(41.0 \mathrm{mg}, 0.12 \mathrm{mmol}), \mathbf{8}(39.1 \mathrm{mg}, 0.35 \mathrm{mmol})$ and $\mathrm{NaH}$ (15.1 $\mathrm{mg}, 0.63 \mathrm{mmol}$ ) as described for the preparation of $\mathbf{1 4}$ gave compound $16\left(30.6 \mathrm{mg}, 68.2 \%\right.$ yield) as yellowish needles $\left(\mathrm{mp} 282-283^{\circ} \mathrm{C}\right)$. EI-MS: $m / z 364[\mathrm{M}]^{+}$. HR-MS: $m / z$ Calcd for $\mathrm{C}_{19} \mathrm{H}_{12} \mathrm{~N}_{2} \mathrm{O}_{6}[\mathrm{M}]^{+} ; 364.0695$, Found; 364.0715. ${ }^{1} \mathrm{H}-\mathrm{NMR}$ (pyridine- $\left.d_{5}\right) \delta: 13.58\left(1 \mathrm{H}, \mathrm{br} \mathrm{s}, \mathrm{H}-3^{\prime}\right), 12.08(2 \mathrm{H}, \mathrm{br} \mathrm{s}$, 1 - and $8-\mathrm{OH}), 8.01(1 \mathrm{H}, \mathrm{d}, J=1.5 \mathrm{~Hz}, \mathrm{H}-2), 7.86(1 \mathrm{H}, \mathrm{dd}, J=8.2,0.9 \mathrm{~Hz}, \mathrm{H}-$ 7), $7.79\left(1 \mathrm{H}, \mathrm{d}, J=7.9 \mathrm{~Hz}, \mathrm{H}-6^{\prime}\right), 7.61(1 \mathrm{H}, \mathrm{t}, J=8.2 \mathrm{~Hz}, \mathrm{H}-6), 7.50(1 \mathrm{H}, \mathrm{d}$, $J=1.5 \mathrm{~Hz}, \mathrm{H}-4), 7.35(1 \mathrm{H}, \mathrm{dd}, J=8.2,0.9 \mathrm{~Hz}, \mathrm{H}-5), 5.91(1 \mathrm{H}, \mathrm{d}, J=7.9 \mathrm{~Hz}$, $\left.\mathrm{H}-5^{\prime}\right), 5.19(2 \mathrm{H}, \mathrm{s}, \mathrm{H}-15) .{ }^{13} \mathrm{C}-\mathrm{NMR}$ (pyridine- $\left.d_{5}\right) \delta: 192.6(\mathrm{C}-10), 181.5(\mathrm{C}-$ 9), 164.7 (C-4'), 163.0 (C-1), 162.9 (C-8), 152.3 (C-2'), 147.6 (C-3), 144.9 (C-6'), 137.6 (C-6), 134.5 (C-11), 134.0 (C-14), 124.8 (C-5), 123.0 (C-4) 120.0 (C-7), 118.9 (C-2), 116.3 (C-12), 115.8 (C-13), 103.0 (C-5'), 51.2 (C$15)$.

1-[(4,5-Dihydroxy-9,10-dioxo-9,10-dihydroanthracen-2-yl)methyl]-5fluoropyrimidine-2,4(1H,3H)-dione (17) The same reaction and procedure using $13(42.0 \mathrm{mg}, 0.13 \mathrm{mmol}), 2(34.5 \mathrm{mg}, 0.27 \mathrm{mmol})$ and $\mathrm{NaH}$ ( $20.4 \mathrm{mg}, 0.85 \mathrm{mmol}$ ) as described for the preparation of $\mathbf{1 4}$ gave compound

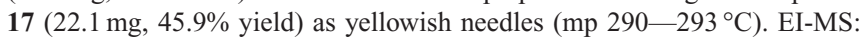
$m / z 382[\mathrm{M}]^{+}$. HR-MS: $m / z$ Calcd for $\mathrm{C}_{10} \mathrm{H}_{11} \mathrm{FN}_{2} \mathrm{O}_{6}[\mathrm{M}]^{+} ; 383.0601$, Found; 382.0587. ${ }^{1} \mathrm{H}-\mathrm{NMR}$ (pyridine- $\left.d_{5}\right) \delta$ : $13.69\left(3 \mathrm{H}, \mathrm{m}, 1-\right.$ and $8-\mathrm{OH}$ and $\mathrm{H}-3^{\prime}$ ), $8.27\left(1 \mathrm{H}, \mathrm{d}, J=6.1 \mathrm{~Hz}, \mathrm{H}-6^{\prime}\right), 8.07(1 \mathrm{H}, \mathrm{d}, J=1.8 \mathrm{~Hz}, \mathrm{H}-2), 7.88(2 \mathrm{H}, \mathrm{dd}$, $J=8.2,0.9 \mathrm{~Hz}, \mathrm{H}-7), 7.63(1 \mathrm{H}, \mathrm{t}, J=8.2 \mathrm{~Hz}, \mathrm{H}-6), 7.58(1 \mathrm{H}, \mathrm{d}, J=1.8 \mathrm{~Hz}, \mathrm{H}-$ 4), $7.36(1 \mathrm{H}, \mathrm{dd}, J=8.2,0.9 \mathrm{~Hz}, \mathrm{H}-5), 5.22(2 \mathrm{H}, \mathrm{s}, \mathrm{H}-15) .{ }^{13} \mathrm{C}-\mathrm{NMR}$ (pyridine- $\left.d_{5}\right) \delta: 192.6(\mathrm{C}-10), 181.5(\mathrm{C}-9), 163.1(\mathrm{C}-8), 162.7(\mathrm{C}-1), 158.5\left(\mathrm{C}^{\prime}\right.$ 4), $151.1\left(\mathrm{C}^{\prime}-2\right), 147.2$ (C-3), 140.6 (C'-5), 137.6 (C-6), 134.6 (C-11), 134.0 (C-14), 129.5 (C'-6), 124.9 (C-5), 123.1 (C-4), 120.0 (C-7), 119.0 (C-2), 116.4 (C-12), 116.0 (C-13), 51.4 (C-15).

1,4-Dimethoxy-2-methylnaphthalene (20) A solution of tin(II)chloride $(60.0 \mathrm{~g}, 0.32 \mathrm{mmol})$ in $12 \mathrm{M} \mathrm{HCl}(60.0 \mathrm{ml}, 0.72 \mathrm{mmol})$ was added dropwise over a period of $30 \mathrm{~min}$ to a solution of $\mathbf{1 8}(15.0 \mathrm{~g}, 87.1 \mathrm{mmol})$ in $\mathrm{MeOH}$ $(250 \mathrm{ml})$. The mixture was stirred for $30 \mathrm{~min}$, then $\mathrm{MeOH}$ was evaporated in vacuo and the residue was poured into water $(100 \mathrm{ml})$. The resulting precipitate was collected by filtration and dissolved in acetone $(200 \mathrm{ml})$. The solution was dried over $\mathrm{MgSO}_{4}$ and then filtered. To the acetone filtrate, $\mathrm{K}_{2} \mathrm{CO}_{3}$ $(90.0 \mathrm{~g}, 0.65 \mathrm{~mol})$ and dimethyl sulfate $(59.9 \mathrm{~g}, 0.48 \mathrm{~mol})$ were added, then refluxed for $4 \mathrm{~h}$ before being filtered. The filtrate was evaporated in vacuo and the residue was dissolved in ether $(200 \mathrm{ml})$ and aqueous $20 \% \mathrm{KOH}$ $(200 \mathrm{ml})$. After the mixture was stirred vigorously for $1 \mathrm{~h}$, the organic layer was separated and dried over $\mathrm{MgSO}_{4}$. The solvent was evaporated to give a residue, which was subjected to column chromatography (toluene) to obtain compound 20 (12.6g, 71.5\% yield). EI-MS: $m / z 202[\mathrm{M}]^{+}$. HR-MS: $m / z$ Calcd for $\mathrm{C}_{13} \mathrm{H}_{14} \mathrm{O}_{2}[\mathrm{M}]^{+} ; 202.0994$, Found; 202.1005. ${ }^{1} \mathrm{H}-\mathrm{NMR}\left(\mathrm{CDCl}_{3}\right) \delta$ : 8.19 and 8.02 (each $1 \mathrm{H}, \mathrm{m}, \mathrm{H}-5$ or 8 ), 7.50 and 7.42 (each $1 \mathrm{H}, \mathrm{m}, \mathrm{H}-6$ or 7 ), $6.60(1 \mathrm{H}, \mathrm{s}, \mathrm{H}-3), 3.96$ and 3.86 (each $3 \mathrm{H}, \mathrm{s}, 1-$ or $\left.4-\mathrm{OCH}_{3}\right), 2.44(3 \mathrm{H}, \mathrm{s}, 2-$ $\left.\mathrm{CH}_{3}\right) .{ }^{13} \mathrm{C}-\mathrm{NMR}\left(\mathrm{CDCl}_{3}\right) \delta: 151.5(\mathrm{C}-4), 147.0(\mathrm{C}-1), 128.6(\mathrm{C}-9), 126.5(\mathrm{C}-$ 10), 125.6 (C-7), 125.2 (C-6), 124.6 (C-5), 122.2 (C-8), 121.5 (C-2), 106.8 $(\mathrm{C}-3), 61.2\left(\mathrm{OCH}_{3}\right), 55.6\left(\mathrm{OCH}_{3}\right), 16.3(\mathrm{C}-11)$.

1,4-Dimethoxynaphthalene-2-carboxylic Acid (21) $\mathrm{KMnO}_{4}(63.4 \mathrm{~g}$, $0.4 \mathrm{~mol})$ was added to a solution of compound $20(16.2 \mathrm{~g}, 80.1 \mathrm{mmol})$ in pyridine $(250 \mathrm{ml})$ and water $(250 \mathrm{ml})$ before stirring the mixture at $100{ }^{\circ} \mathrm{C}$ for $24 \mathrm{~h}$. The reaction mixture was filtered and half the filtrate was removed by distillation at reduced pressure. Water $(250 \mathrm{ml})$ was then added to the mixture before extracting with $\mathrm{Et}_{2} \mathrm{O}(100 \mathrm{ml} \times 3)$. The organic extracts were successively washed with brine and water, dried over $\mathrm{MgSO}_{4}$, and filtered. The filtrate was evaporated to give a residue, which was subjected to column chromatography (a gradient of $0-50 \% \mathrm{MeOH}$ in $\mathrm{CHCl}_{3}$ ) to obtain compound $21\left(6.0 \mathrm{~g}, 32.3 \%\right.$ yield) as colorless needles (mp 160-162 $\left.{ }^{\circ} \mathrm{C}\right)$. EIMS: $m / z 232[\mathrm{M}]^{+}$. HR-MS: $m / z$ Calcd for $\mathrm{C}_{13} \mathrm{H}_{12} \mathrm{O}_{4}[\mathrm{M}]^{+} ; 232.0736$, Found; 232.0734. ${ }^{1} \mathrm{H}-\mathrm{NMR}\left(\mathrm{CDCl}_{3}\right) \delta: 11.05(1 \mathrm{H}, \mathrm{br} \mathrm{s}, \mathrm{OH}), 8.31$ and 8.11 (each $1 \mathrm{H}, \mathrm{m}, \mathrm{H}-5$ or 8$), 7.65(2 \mathrm{H}, \mathrm{m}, \mathrm{H}-6$ and 7$), 7.37(1 \mathrm{H}, \mathrm{s}, \mathrm{H}-3), 4.12$ and 4.05 (each $3 \mathrm{H}, \mathrm{s}, 1-$ or $\left.4-\mathrm{OCH}_{3}\right) .{ }^{13} \mathrm{C}-\mathrm{NMR}\left(\mathrm{CDCl}_{3}\right) \delta: 166.2(\mathrm{COOH})$, 152.6 (C-1), 151.1 (C-4), 129.6 (C-10), 128.4 (C-6), 127.7 (C-9), 127.3 (C7), 123.0 (C-8), 122.7 (C-5), 117.4 (C-3), $103.2(\mathrm{C}-2), 64.3\left(\mathrm{OCH}_{3}\right), 56.0$ $\left(\mathrm{OCH}_{3}\right)$.

(1,4-Dimethoxynaphthlen-2-yl)methanol (22) $\quad \mathrm{LiAlH}_{4} \quad(3.8 \mathrm{~g}, \quad 100$ $\mathrm{mmol})$ was added to a solution of $21(5.8 \mathrm{~g}, 25.0 \mathrm{mmol})$ in THF $(150 \mathrm{ml})$ and the mixture was stirred at room temperature for $12 \mathrm{~h}$. The reaction mixture was neutralized by dropwise addition of $10 \%$ aqueous $\mathrm{H}_{2} \mathrm{SO}_{4}$. After pouring into water $(100 \mathrm{ml})$ the mixture was extracted with $\mathrm{Et}_{2} \mathrm{O}(50 \mathrm{ml} \times 3)$. The organic extracts were washed with water and dried over $\mathrm{MgSO}_{4}$, and filtered. The filtrate was evaporated to give a residue, which was subjected to column chromatography (a gradient of $0-5 \%$ acetone in toluene) to obtain compound $22\left(3.1 \mathrm{~g}, 57.1 \%\right.$ yield) as colorless needles (mp 59-65 $\left.{ }^{\circ} \mathrm{C}\right)$. EI-MS: $m / z 218[\mathrm{M}]^{+}$. HR-MS: $m / z$ Calcd for $\mathrm{C}_{13} \mathrm{H}_{14} \mathrm{O}_{3}[\mathrm{M}]^{+} ; 218.0943$, Found; 218.0919. ${ }^{1} \mathrm{H}-\mathrm{NMR}\left(\mathrm{CDCl}_{3}\right) \delta: 8.23$ and 8.03 (each $1 \mathrm{H}, \mathrm{m}, \mathrm{H}-5$ or 8$), 7.54$ and 7.48 (each $1 \mathrm{H}, \mathrm{m}, \mathrm{H}-6$ or 7$), 6.81(1 \mathrm{H}, \mathrm{s}, \mathrm{H}-3), 4.88(2 \mathrm{H}, \mathrm{s}, \mathrm{H}-11), 3.98$ and 3.91 (each $3 \mathrm{H}, \mathrm{s}, 1-$ or $\left.4-\mathrm{OCH}_{3}\right), 2.03(1 \mathrm{H}, \mathrm{br} \mathrm{s}, \mathrm{OH}) .{ }^{13} \mathrm{C}-\mathrm{NMR}\left(\mathrm{CDCl}_{3}\right)$ $\delta: 145.0$ (C-4), 139.8 (C-1), 121.4 (C-2), 121.3 (C-9), 119.6 (C-10), 119.1 (C-7), 118.4 (C-6), 115.3 (C-5), 114.6 (C-8), 96.6 (C-3), 55.5 (C-11), 53.9 $\left(\mathrm{OCH}_{3}\right), 48.5\left(\mathrm{OCH}_{3}\right)$

2-(Bromomethyl)-1,4-dimethoxynaphthalene (19) $\mathrm{CBr}_{4}(13.2 \mathrm{~g}, 39.9$ $\mathrm{mmol})$ and $\mathrm{PPh}_{3}(10.5 \mathrm{~g}, 39.9 \mathrm{mmol})$ were added to a solution of $22(2.9 \mathrm{~g}$, $13.3 \mathrm{mmol})$ in $\mathrm{Et}_{2} \mathrm{O}(100 \mathrm{ml})$. The reaction mixture was stirred at room temperature for $4 \mathrm{~h}$, then filtered. The filtrate was evaporated to give a residue, which was subjected to column chromatography $\left(\mathrm{CHCl}_{3}\right)$ to obtain compound $19(1.88 \mathrm{~g}, 50.3 \%$ yield $)$ as colorless needles (mp $\left.89-91^{\circ} \mathrm{C}\right)$. EI-MS: $m / z 280[\mathrm{M}]^{+}$and $282[\mathrm{M}+2]^{+}$. HR-MS: $m / z$ Calcd for $\mathrm{C}_{13} \mathrm{H}_{13} \mathrm{BrO}_{2}[\mathrm{M}]^{+}$; 280.0099, Found; 280.0081. ${ }^{1} \mathrm{H}-\mathrm{NMR}\left(\mathrm{CDCl}_{3}\right) \delta: 8.22$ and 8.05 (each $1 \mathrm{H}$ $\mathrm{m}, \mathrm{H}-5$ or 8 ), 7.55 and 7.50 (each $1 \mathrm{H}, \mathrm{m}, \mathrm{H}-6$ or 7$), 6.72(1 \mathrm{H}, \mathrm{s}, \mathrm{H}-3), 4.77$ $(2 \mathrm{H}, \mathrm{s}, \mathrm{H}-11), 4.01$ and 4.00 (each $3 \mathrm{H}, \mathrm{s}, 1-$ or $\left.4-\mathrm{OCH}_{3}\right) \cdot{ }^{13} \mathrm{C}-\mathrm{NMR}\left(\mathrm{CDCl}_{3}\right)$ $\delta: 152.2(\mathrm{C}-4), 147.9(\mathrm{C}-1), 128.4(\mathrm{C}-9), 127.01(\mathrm{C}-10), 126.98(\mathrm{C}-7), 126.2$ (C-6), 125.7 (C-5), 122.5 (C-8), $122.3(\mathrm{C}-2), 104.7(\mathrm{C}-3), 62.4\left(\mathrm{OCH}_{3}\right), 55.7$ $\left(\mathrm{OCH}_{3}\right), 29.1(\mathrm{C}-11)$

1-(5,8-Dimethoxy-7-methylnaphthalen-2-yl)ethanone (24) To a solution of compound $20(100 \mathrm{mg}, 0.49 \mathrm{mmol})$ in $\mathrm{CH}_{2} \mathrm{Cl}_{2}(15 \mathrm{ml}), \mathrm{CH}_{3} \mathrm{COCl}$ $(0.17 \mathrm{ml}, 1.69 \mathrm{mmol})$ and $\mathrm{AlCl}_{3}(220 \mathrm{mg}, 1.69 \mathrm{mmol})$ were added. The mixture was stirred at room temperature for $40 \mathrm{~min}$, then poured into ice-water $(50 \mathrm{ml})$, neutralized with $\mathrm{NaHCO}_{3}$ and extracted with $\mathrm{CHCl}_{3}(30 \mathrm{ml} \times 3)$. The organic extracts were washed with water, dried over $\mathrm{MgSO}_{4}$, and filtered. The filtrate was evaporated to give a residue which was subjected to column chromatography (a gradient of $0-5 \%$ acetone in toluene) to obtain compound $24\left(78.8 \mathrm{mg}, 65.2 \%\right.$ yield) as colorless solid $\left(\mathrm{mp} 115-116^{\circ} \mathrm{C}\right)$. EI-MS: $m / z 244[\mathrm{M}]^{+}$. HR-MS: $m / z$ Calcd for $\mathrm{C}_{15} \mathrm{H}_{16} \mathrm{O}_{3}[\mathrm{M}]^{+} ; 244.1099$, Found; $244.1089 .{ }^{1} \mathrm{H}-\mathrm{NMR}\left(\mathrm{CDCl}_{3}\right) \delta: 8.83\left(1 \mathrm{H}, \mathrm{H}-8^{*}\right), 8.06\left(2 \mathrm{H}, \mathrm{H}-5^{*}\right.$ and $\left.6^{*}\right)$ (peaks with an asterisk show virtual coupling) ${ }^{20)} 6.66(1 \mathrm{H}, \mathrm{s}, \mathrm{H}-3), 4.01$ $\left(3 \mathrm{H}, \mathrm{s}, 4-\mathrm{OCH}_{3}\right), 3.86\left(3 \mathrm{H}, \mathrm{s}, 1-\mathrm{OCH}_{3}\right), 2.73\left(3 \mathrm{H}, \mathrm{s}, \mathrm{COCH}_{3}\right), 2.47(3 \mathrm{H}, \mathrm{s}$, $\mathrm{H}-11) .{ }^{13} \mathrm{C}-\mathrm{NMR}\left(\mathrm{CDCl}_{3}\right) \delta: 198.1\left(\mathrm{COCH}_{3}\right), 152.5(\mathrm{C}-4), 147.0(\mathrm{C}-1)$, 133.2 (C-7), 130.7 (C-10), 129.5 (C-9), 124.9 (C-5), 124.5 (C-8), 124.2 (C2), $122.0(\mathrm{C}-6), 107.7(\mathrm{C}-3), 61.3\left(\mathrm{OCH}_{3}\right), 55.6\left(\mathrm{OCH}_{3}\right), 26.6\left(\mathrm{COCH}_{3}\right)$, $16.3(\mathrm{C}-11)$

5,8-Dimethoxy-7-methylnaphthalene-2-carboxylic Acid (25) Finely powdered $\mathrm{KOH}(130 \mathrm{mg}, 2.3 \mathrm{mmol})$ was added to a solution of $\mathbf{2 4}(100 \mathrm{mg}$, $0.41 \mathrm{mmol})$ in DMF $(10 \mathrm{ml})$ and the mixture was then stirred at $68^{\circ} \mathrm{C}$ for $3 \mathrm{~h}$. After a second addition of finely powderd $\mathrm{KOH}(130 \mathrm{mg}, 2.3 \mathrm{mmol})$ the mixture was stirred at the same temperature for a further $12 \mathrm{~h}$. The reaction mixture was then poured into ice-water $(100 \mathrm{ml})$ and extracted with $\mathrm{CHCl}_{3}$ $(50 \mathrm{ml} \times 3)$. The chloroform extracts were acidified by addition of $5 \%$ aqueous $\mathrm{HCl}$ and extracted with $\mathrm{CHCl}_{3}(50 \mathrm{ml} \times 3)$. The extracts were washed with water, dried over $\mathrm{MgSO}_{4}$, and filtered. The filtrate was evaporated to give a residue, which was subjected to column chromatography (a gradient of $0-3 \% \mathrm{MeOH}$ in $\mathrm{CHCl}_{3}$ ) to obtain compound 25 ( $43.5 \mathrm{mg}, 43.2 \%$ yield) as needles (mp 197-199 ${ }^{\circ} \mathrm{C}$ ). EI-MS: $m / z 246[\mathrm{M}]^{+}$. HR-MS: $m / z$ Calcd for $\mathrm{C}_{14} \mathrm{H}_{14} \mathrm{O}_{4}[\mathrm{M}]^{+} ; 246.0892$, Found; 246.0879. ${ }^{1} \mathrm{H}-\mathrm{NMR}\left(\mathrm{CDCl}_{3}\right) \delta: 13.01$ $(1 \mathrm{H}$, br s, $\mathrm{COOH}), 8.77\left(1 \mathrm{H}, \mathrm{H}-8^{*}\right), 8.02\left(2 \mathrm{H}, \mathrm{H}-5^{*}\right.$ and $\left.6^{*}\right)$ (peaks with an asterisk show virtual coupling), ${ }^{20)} 6.95(1 \mathrm{H}, \mathrm{s}, \mathrm{H}-3), 4.04\left(3 \mathrm{H}, \mathrm{s}, 4-\mathrm{OCH}_{3}\right)$, 
$3.84\left(3 \mathrm{H}, \mathrm{s}, 1-\mathrm{OCH}_{3}\right), 2.47(3 \mathrm{H}, \mathrm{s}, \mathrm{H}-11) .{ }^{13} \mathrm{C}-\mathrm{NMR}\left(\mathrm{CDCl}_{3}\right) \delta: 167.4$ (COOH), 151.6 (C-4), 146.3 (C-1), 129.9 (C-10), 129.1 (C-6), 126.7 (C-9), 125.9 (C-7), 124.6 (C-8), 123.5 (C-2), 121.8 (C-5), 108.2 (C-3), 61.0 $\left(\mathrm{OCH}_{3}\right), 55.8\left(\mathrm{OCH}_{3}\right), 16.2(\mathrm{C}-11)$.

(5,8-Dimethoxy-7-methylnaphthalen-2-yl)methanol (26) $\mathrm{LiAlH}_{4}$ $(62.3 \mathrm{mg}, 1.64 \mathrm{mmol})$ was added to a solution of $25(100 \mathrm{mg}, 0.41 \mathrm{mmol})$ in THF $(10 \mathrm{ml})$ and the mixture was then stirred at room temperature for $12 \mathrm{~h}$ The reaction mixture was neutralized by addition of $10 \%$ aqueous $\mathrm{H}_{2} \mathrm{SO}_{4}$, poured into ice-water $(100 \mathrm{ml})$ and extracted with $\mathrm{CHCl}_{3}(50 \mathrm{ml} \times 3)$. The organic extracts were washed with water, dried over $\mathrm{MgSO}_{4}$, and filtered. The filtrate was evaporated to give a residue, which was subjected to column chromatography (a gradient of $0-5 \%$ acetone in toluene) to obtain compound $26(61.2 \mathrm{mg}, 64.7 \%$ yield $)$ as colorless needles $\left(\mathrm{mp} 99-100^{\circ} \mathrm{C}\right)$. EIMS: $m / z 232[\mathrm{M}]^{+}$. HR-MS: $m / z$ Calcd for $\mathrm{C}_{14} \mathrm{H}_{16} \mathrm{O}_{3}[\mathrm{M}]^{+} ; 232.1099$, Found; 232.1091. ${ }^{1} \mathrm{H}-\mathrm{NMR}\left(\mathrm{CDCl}_{3}\right) \delta: 8.15(1 \mathrm{H}, \mathrm{d}, J=1.8 \mathrm{~Hz}, \mathrm{H}-8), 8.00$ $(1 \mathrm{H}, \mathrm{d}, J=8.6 \mathrm{~Hz}, \mathrm{H}-5), 7.52(1 \mathrm{H}, \mathrm{dd}, J=8.6,1.8 \mathrm{~Hz}, \mathrm{H}-6), 6.60(1 \mathrm{H}, \mathrm{s}, \mathrm{H}-$ 3), $4.83(2 \mathrm{H}, \mathrm{s}, \mathrm{H}-12), 3.96\left(3 \mathrm{H}, \mathrm{s}, 4-\mathrm{OCH}_{3}\right), 3.85\left(3 \mathrm{H}, \mathrm{s}, 1-\mathrm{OCH}_{3}\right), 2.44$ $(3 \mathrm{H}, \mathrm{s}, \mathrm{H}-11), 1.76(1 \mathrm{H}, \mathrm{br} \mathrm{s}, \mathrm{OH}){ }^{13} \mathrm{C}-\mathrm{NMR}\left(\mathrm{CDCl}_{3}\right) \delta: 151.5(\mathrm{C}-4), 147.0$ (C-1), 137.1 (C-7), 128.1 (C-10), 125.9 (C-5), 125.7 (C-9), 125.0 (C-2), $122.1(\mathrm{C}-8), 120.1(\mathrm{C}-6), 107.2(\mathrm{C}-3), 65.7\left(7-\mathrm{CH}_{2} \mathrm{OH}\right), 61.2\left(\mathrm{OCH}_{3}\right), 55.6$ $\left(\mathrm{OCH}_{3}\right), 16.3(\mathrm{C}-11)$.

7-(Bromomethyl)-1,4-dimethoxy-2-methylnaphthalene (23) $\mathrm{CBr}_{4}$ (554 mg, $1.67 \mathrm{mmol})$ and $\mathrm{PPh}_{3}(438 \mathrm{mg}, 1.67 \mathrm{mmol})$ were added to a solution of $26(100 \mathrm{mg}, 0.43 \mathrm{mmol})$ in $\mathrm{Et}_{2} \mathrm{O}(100 \mathrm{ml})$ and the mixture was stirred at room temperature for $4 \mathrm{~h}$. The reaction mixture was filtered and the filtrate was evaporated to give a residue, which was subjected to column chromatography $\left(\mathrm{CHCl}_{3}\right)$ to obtain compound $\mathbf{2 3}(83.3 \mathrm{mg}, 65.8 \%$ yield). EI-MS: $\mathrm{m} / \mathrm{z}$ $294[\mathrm{M}]^{+}$and $296[\mathrm{M}+2]^{+}$. HR-MS: $m / z$ Calcd for $\mathrm{C}_{14} \mathrm{H}_{15} \mathrm{BrO}_{2}[\mathrm{M}]^{+}$; 294.0255, Found; 294.0247. ${ }^{1} \mathrm{H}-\mathrm{NMR}\left(\mathrm{CDCl}_{3}\right) \delta: 8.19(1 \mathrm{H}, \mathrm{d}, J=1.8 \mathrm{~Hz}, \mathrm{H}-$ 8), $8.00(1 \mathrm{H}, \mathrm{d}, J=8.6 \mathrm{~Hz}, \mathrm{H}-5), 7.54(1 \mathrm{H}, \mathrm{dd}, J=8.6,1.8 \mathrm{~Hz}, \mathrm{H}-6), 6.61$ $\left(2 \mathrm{H}, \mathrm{s}, \mathrm{CH}_{2} \mathrm{Br}\right), 3.96\left(3 \mathrm{H}, \mathrm{s}, 4-\mathrm{OCH}_{3}\right), 3.84\left(3 \mathrm{H}, \mathrm{s}, 1-\mathrm{OCH}_{3}\right), 2.44(3 \mathrm{H}, \mathrm{s}$, $\left.11-\mathrm{CH}_{3}\right) .{ }^{13} \mathrm{C}-\mathrm{NMR}\left(\mathrm{CDCl}_{3}\right) \delta: 151.5(\mathrm{C}-4), 147.0(\mathrm{C}-1), 133.8(\mathrm{C}-7), 128.3$ (C-10), 127.3 (C-6), 126.7 (C-9), 124.9 (C-2), 122.6 (C-8), 122.5 (C-5), $107.5(\mathrm{C}-3), 61.3\left(\mathrm{OCH}_{3}\right), 55.6\left(\mathrm{OCH}_{3}\right), 34.5\left(7-\mathrm{CH}_{2} \mathrm{Br}\right), 16.3(\mathrm{C}-11)$.

9-[(1,4-Dimethoxynaphthalen-2-yl)methyl]-9H-purin-6-amine (27) Compound $6(220 \mathrm{mg}, 1.62 \mathrm{mmol})$ and $\mathrm{NaH}(12.8 \mathrm{mg}, 0.53 \mathrm{mmol})$ were added to a solution of $19(150 \mathrm{mg}, 0.53 \mathrm{mmol})$ in DMF $(20 \mathrm{ml})$ and the mixture was then stirred at $80^{\circ} \mathrm{C}$ for $5 \mathrm{~h}$. The reaction mixture was poured into ice-water $(100 \mathrm{ml})$, neutralized with $5 \%$ aqueous $\mathrm{NaHCO}_{3}$, and extracted with $\mathrm{CHCl}_{3}(50 \mathrm{ml} \times 3)$. The organic extracts were washed with water, dried over $\mathrm{MgSO}_{4}$, and filtered. The filtrate was evaporated to give a residue, which was subjected to column chromatography (a gradient of $0-10 \%$ $\mathrm{MeOH}$ in $\mathrm{CHCl}_{3}$ ) to obtain compound $27(50.6 \mathrm{mg}, 28.3 \%$ yield) as a solid (mp 233-236 ${ }^{\circ} \mathrm{C}$ ). EI-MS: $\mathrm{m} / z \quad 335[\mathrm{M}]^{+}$. HR-MS: $\mathrm{m} / \mathrm{z}$ Calcd for $\mathrm{C}_{18} \mathrm{H}_{17} \mathrm{~N}_{5} \mathrm{O}_{2}[\mathrm{M}]^{+}$; 335.1382, Found; 335.1372. ${ }^{1} \mathrm{H}-\mathrm{NMR}$ (DMSO- $d_{6}$ ) $\delta$ : $8.45\left(1 \mathrm{H}, \mathrm{s}, \mathrm{H}-8^{\prime}\right), 8.12$ and 8.02 (each $1 \mathrm{H}, \mathrm{m}, \mathrm{H}-5$ or 8$), 7.91\left(2 \mathrm{H}, \mathrm{brs}, 6^{\prime}-\right.$ $\left.\mathrm{NH}_{2}\right), 7.77\left(1 \mathrm{H}, \mathrm{s}, \mathrm{H}-2^{\prime}\right), 7.61$ and 7.54 (each $1 \mathrm{H}, \mathrm{m}, \mathrm{H}-6$ or 7$), 6.94(1 \mathrm{H}, \mathrm{s}$, $\mathrm{H}-3), 5.69(2 \mathrm{H}, \mathrm{s}, \mathrm{H}-11), 3.94$ and 3.84 (each $3 \mathrm{H}, \mathrm{s}, 1-$ or $\left.4-\mathrm{OCH}_{3}\right) \cdot{ }^{13} \mathrm{C}-$ NMR (DMSO- $\left.d_{6}\right) \delta: 154.8\left(\mathrm{C}^{\prime}-6\right), 152.4\left(\mathrm{C}-2^{\prime}\right), 151.1\left(\mathrm{C}-4^{\prime}\right), 149.9(\mathrm{C}-4)$, 147.4 (C-1), 143.6 (C-8'), 127.7 (C-9), 127.0 (C-10), 126.1 (C-7), 125.8 (C6), 123.7 (C-5'), 121.9 (C-5), 121.9 (C-8), 120.3 (C-2), 105.0 (C-3), 62.3 $\left(\mathrm{OCH}_{3}\right), 55.6\left(\mathrm{OCH}_{3}\right), 47.9(\mathrm{C}-11)$.

1-[(1,4-Dimethoxynaphthalen-2-yl)methyl]-5-methylpyrimidine$\mathbf{2 , 4}(\mathbf{1 H}, \mathbf{3 H})$-dione $(\mathbf{2 8})$ The same reaction and procedure using 19 ( $80.0 \mathrm{mg}, 0.29 \mathrm{mmol}), 7$ (72.0 mg, $0.57 \mathrm{mmol})$ and $\mathrm{NaH}(6.9 \mathrm{mg}, 0.29 \mathrm{mmol})$ as for the preparation of $\mathbf{2 7}$ gave a residue, which was subjected to column chromatography (a gradient of $0-20 \%$ acetone in toluene) to afford compound $28\left(49.9 \mathrm{mg}, 53.7 \%\right.$ yield) as a solid $\left(\mathrm{mp} 208-210^{\circ} \mathrm{C}\right)$. EI-MS: $\mathrm{m} / \mathrm{z}$ $326[\mathrm{M}]^{+}$. HR-MS: $m / z$ Calcd for $\mathrm{C}_{18} \mathrm{H}_{18} \mathrm{~N}_{2} \mathrm{O}_{4}[\mathrm{M}]^{+}$; 326.1267, Found; 326.1275. ${ }^{1} \mathrm{H}-\mathrm{NMR}$ (pyridine- $\left.d_{5}\right) \delta: 13.35\left(1 \mathrm{H}, \mathrm{brs}, \mathrm{H}-3{ }^{\prime}\right), 8.39$ and 8.18 (each $1 \mathrm{H}, \mathrm{m}, \mathrm{H}-5$ or 8$), 7.60$ and 7.55 (each $1 \mathrm{H}, \mathrm{m}, \mathrm{H}-6$ or 7$), 7.44(1 \mathrm{H}, \mathrm{q}$, $\left.J=0.9 \mathrm{~Hz}, \mathrm{H}-6^{\prime}\right), 7.05(1 \mathrm{H}, \mathrm{s}, \mathrm{H}-3), 5.29(2 \mathrm{H}, \mathrm{s}, \mathrm{H}-11), 3.94$ and 3.78 (each $3 \mathrm{H}, \mathrm{s}, 1-$ or $\left.4-\mathrm{OCH}_{3}\right), 1.91\left(3 \mathrm{H}, \mathrm{d}, J=0.9 \mathrm{~Hz}, 5^{\prime}-\mathrm{CH}_{3}\right) .{ }^{13} \mathrm{C}-\mathrm{NMR}$ (pyridine$\left.d_{5}\right) \delta: 165.3\left(\mathrm{C}-4^{\prime}\right), 152.7\left(\mathrm{C}-2^{\prime}\right), 152.6(\mathrm{C}-4), 148.3(\mathrm{C}-1), 140.8\left(\mathrm{C}-6^{\prime}\right)$, 128.9 (C-9), 127.4 (C-10), 127.0 (C-7), 126.3 (C-6), 125.4 (C-5), 123.0 (C8), $122.5(\mathrm{C}-2), 110.6\left(\mathrm{C}-5^{\prime}\right), 104.9(\mathrm{C}-3), 62.6\left(\mathrm{OCH}_{3}\right), 55.6\left(\mathrm{OCH}_{3}\right), 46.0$ (C-11), $12.5\left(5^{\prime}-\mathrm{CH}_{3}\right)$.

1-[(1,4-Dimethoxynaphthalen-2-yl)methyl]pyrimidine-2,4(1H,3H)dione (29) The same reaction and procedure using 19 (150 mg, $0.53 \mathrm{mmol}), 8(178 \mathrm{mg}, 1.60 \mathrm{mmol})$ and $\mathrm{NaH}(12.8 \mathrm{mg}, 0.54 \mathrm{mmol})$ as the preparation of $\mathbf{2 7}$ gave a residue, which was subjected to column chromatography (a gradient of $0-15 \%$ acetone in toluene) to afford compound 29 (69.8 $\mathrm{mg}, 41.9 \%$ yield) as a solid ( $\left.\mathrm{mp} 224-227^{\circ} \mathrm{C}\right)$. EI-MS: $\mathrm{m} / z 312[\mathrm{M}]^{+}$. HR-MS: $m / z$ Calcd for $\mathrm{C}_{17} \mathrm{H}_{16} \mathrm{~N}_{2} \mathrm{O}_{4}[\mathrm{M}]^{+}$; 312.1110, Found; 312.1127. ${ }^{1} \mathrm{H}-$
NMR (pyridine- $d_{5}$ ) $\delta: 13.43(1 \mathrm{H}$, br s, H-3') 8.40 and 8.18 (each $1 \mathrm{H}, \mathrm{m}, \mathrm{H}-$ 5 or 8$), 7.65\left(1 \mathrm{H}, \mathrm{d}, J=7.9 \mathrm{~Hz}, \mathrm{H}-6^{\prime}\right), 7.61$ and 7.56 (each $1 \mathrm{H}, \mathrm{m}, \mathrm{H}-6$ or 7 ), $7.01(1 \mathrm{H}, \mathrm{s}, \mathrm{H}-3), 5.86\left(1 \mathrm{H}, \mathrm{d}, J=7.9 \mathrm{~Hz}, \mathrm{H}-5^{\prime}\right), 5.26(2 \mathrm{H}, \mathrm{s}, \mathrm{H}-11), 3.92$ and 3.78 (each $3 \mathrm{H}, \mathrm{s}, 1-$ or $\left.4-\mathrm{OCH}_{3}\right) .{ }^{13} \mathrm{C}-\mathrm{NMR}$ (pyridine- $\left.d_{5}\right) \delta: 164.8\left(\mathrm{C}-4^{\prime}\right)$, 152.63 (C-2'), 152.60 (C-4), 148.5 (C-1), 145.1 (C-6'), 128.9 (C-9), 127.4 (C-10), 127.1 (C-7), 126.3 (C-6), 125.0 (C-5), 123.0 (C-8), 122.6 (C-2), $105.0(\mathrm{C}-3), 102.4\left(\mathrm{C}-5^{\prime}\right), 62.6\left(\mathrm{OCH}_{3}\right), 55.6\left(\mathrm{OCH}_{3}\right), 46.5(\mathrm{C}-11)$.

1-[(1,4-Dimethoxynaphthalen-2-yl)methyl]-5-fluoropyrimidine2,4(1H,3H)-dione (30) The same reaction and procedure using 19 (150 mg, $0.53 \mathrm{mmol}), 2$ (277 mg, $2.13 \mathrm{mmol})$ and $\mathrm{NaH}(18.8 \mathrm{mg}, 0.78 \mathrm{mmol})$ as the preparation of $\mathbf{2 7}$ gave a residue, which was subjected to column chromatography (a gradient of $0-10 \% \mathrm{MeOH}$ in $\mathrm{CHCl}_{3}$ ) to afford compound 30 $\left(95.0 \mathrm{mg}, 54.7 \%\right.$ yield) as a solid (mp $\left.191-193^{\circ} \mathrm{C}\right)$. EI-MS: $\mathrm{m} / z 330[\mathrm{M}]^{+}$ HR-MS: $m / z$ Calcd for $\mathrm{C}_{17} \mathrm{H}_{15} \mathrm{FN}_{2} \mathrm{O}_{4}[\mathrm{M}]^{+} ; 330.1016$, Found; 3301.005. ${ }^{1} \mathrm{H}-$ NMR (pyridine- $d_{5}$ ) $\delta: 14.12(1 \mathrm{H}$, br s, H-3'), 8.41 and 8.19 (each $1 \mathrm{H}, \mathrm{m}, \mathrm{H}-$ 5 or 8 ), $8.00\left(1 \mathrm{H}, \mathrm{d}, J=6.4 \mathrm{~Hz}, \mathrm{H}-6^{\prime}\right), 7.62$ and 7.57 (each $1 \mathrm{H}, \mathrm{m}, \mathrm{H}-6$ or 7 ), $7.06(1 \mathrm{H}, \mathrm{s}, \mathrm{H}-3), 5.28(2 \mathrm{H}, \mathrm{s}, \mathrm{H}-11), 3.94$ and 3.80 (each $3 \mathrm{H}, \mathrm{s}, 1-$ or $4-$ $\left.\mathrm{OCH}_{3}\right) .{ }^{13} \mathrm{C}-\mathrm{NMR}$ (pyridine- $\left.d_{5}\right) \delta$ : $158.5\left(\mathrm{C}-4^{\prime}\right), 152.7\left(\mathrm{C}-2^{\prime}\right), 151.2(\mathrm{C}-4)$ $148.6(\mathrm{C}-1), 142.1\left(\mathrm{C}-5^{\prime}\right), 129.5\left(\mathrm{C}-6^{\prime}\right), 129.2$ (C-9), 127.5 (C-10), 127.2 (C-7), 126.4 (C-6), 124.6 (C-5), 123.0 (C-8), 122.6 (C-2), 105.1 (C-3), 62.7 $\left(\mathrm{OCH}_{3}\right), 55.7\left(\mathrm{OCH}_{3}\right), 46.7(\mathrm{C}-11)$

9-[(5,8-Dimethoxy-7-methylnaphthalen-2-yl)methyl]-9H-purin-6amine (31) The same reaction and procedure using 23 (200 mg, $0.68 \mathrm{mmol}), 6(276 \mathrm{mg}, 2.13 \mathrm{mmol})$ and $\mathrm{NaH}(54.6 \mathrm{mg}, 1.36 \mathrm{mmol})$ as the preparation of $\mathbf{2 7}$ gave a residue, which was subjected to column chromatography (a gradient of $0-7 \% \mathrm{MeOH}$ in $\mathrm{CHCl}_{3}$ ) to give compound 31 (135.1 $\mathrm{mg}, 57.0 \%$ yield) as a solid (mp $134-136{ }^{\circ} \mathrm{C}$ ). EI-MS: $\mathrm{m} / \mathrm{z} 349$ $[\mathrm{M}]^{+}$. HR-MS: $m / z$ Calcd for $\mathrm{C}_{19} \mathrm{H}_{19} \mathrm{~N}_{5} \mathrm{O}_{2}[\mathrm{M}]^{+} ; 349.1539$, Found; 349.1541. ${ }^{1} \mathrm{H}-\mathrm{NMR}$ (DMSO- $\left.d_{6}\right) \delta: 8.31\left(1 \mathrm{H}, \mathrm{s}, \mathrm{H}-8^{\prime}\right), 8.17\left(1 \mathrm{H}, \mathrm{s}, \mathrm{H}-2^{\prime}\right)$, $8.01(1 \mathrm{H}, \mathrm{d}, J=1.8 \mathrm{~Hz}, \mathrm{H}-8), 7.91(1 \mathrm{H}, \mathrm{d}, J=8.9 \mathrm{~Hz}, \mathrm{H}-5), 7.51(1 \mathrm{H}, \mathrm{dd}$ $J=8.9,1.8 \mathrm{~Hz}, \mathrm{H}-6), 7.22\left(2 \mathrm{H}, \mathrm{br} \mathrm{s}, 6^{\prime}-\mathrm{NH}_{2}\right), 6.80(1 \mathrm{H}, \mathrm{s}, \mathrm{H}-3), 5.53(2 \mathrm{H}, \mathrm{s}$, $\left.7-\mathrm{CH}_{2}-\right), 4.01\left(3 \mathrm{H}, \mathrm{s}, 4-\mathrm{OCH}_{3}\right), 3.91\left(3 \mathrm{H}, \mathrm{s}, 1-\mathrm{OCH}_{3}\right), 2.37(3 \mathrm{H}, \mathrm{s}, \mathrm{H}-11)$ ${ }^{13} \mathrm{C}-\mathrm{NMR}$ (DMSO- $\left.d_{6}\right) \delta$ : $156.0\left(\mathrm{C}-6^{\prime}\right), 152.6\left(\mathrm{C}-2^{\prime}\right), 150.6$ (C-4), $149.5(\mathrm{C}-$ $4^{\prime}$ ), 146.4 (C-1), 140.8 (C-8'), 133.4 (C-7), 127.4 (C-9), 126.1 (C-6), 125.9 (C-2), 124.1 (C-10), 122.0 (C-5), 120.5 (C-8), 118.7 (C-5'), 107.8 (C-3), $60.8\left(\mathrm{OCH}_{3}\right), 55.5\left(\mathrm{OCH}_{3}\right), 46.4\left(7-\mathrm{CH}_{2}-\right), 15.9(\mathrm{C}-11)$.

1-[(5,8-Dimethoxy-7-methylnaphthalen-2-yl)methyl]-5-methylpyrimidine-2,4(1H,3H)-dione (32) The same reaction and procedure using 23 (100 mg, $0.34 \mathrm{mmol}), 7$ (130 mg, $1.0 \mathrm{mmol})$ and $\mathrm{NaH}(13.6 \mathrm{mg}, 0.34 \mathrm{mmol})$ as described for the preparation of $\mathbf{2 7}$ gave a residue, which was subjected to column chromatography (a gradient of $0-5 \% \mathrm{MeOH}$ in $\mathrm{CHCl}_{3}$ ) to afford compound $32(63.1 \mathrm{mg}, 54.7 \%$ yield $)$ as a solid ( $\left.\mathrm{mp} 234-237^{\circ} \mathrm{C}\right)$. EI-MS: $m / z 340[\mathrm{M}]^{+}$. HR-MS: $m / z$ Calcd for $\mathrm{C}_{19} \mathrm{H}_{20} \mathrm{~N}_{2} \mathrm{O}_{4}[\mathrm{M}]^{+} ; 340.1423$, Found; 340.1415. ${ }^{1} \mathrm{H}-\mathrm{NMR}$ (DMSO- $\left.d_{6}\right) \delta: 11.36\left(1 \mathrm{H}, \mathrm{brs}, \mathrm{H}-3^{\prime}\right), 8.01(1 \mathrm{H}, \mathrm{d}$, $J=1.8 \mathrm{~Hz}, \mathrm{H}-8), 7.94(1 \mathrm{H}, \mathrm{d}, J=8.9 \mathrm{~Hz}, \mathrm{H}-5), 7.69\left(1 \mathrm{H}, \mathrm{s}, \mathrm{H}-6^{\prime}\right), 7.50(1 \mathrm{H}$, dd, $J=8.9,1.8 \mathrm{~Hz}, \mathrm{H}-6), 6.82(1 \mathrm{H}, \mathrm{s}, \mathrm{H}-3), 4.99\left(2 \mathrm{H}, \mathrm{s}, 7-\mathrm{CH}_{2}-\right), 3.93(3 \mathrm{H}, \mathrm{s}$, $\left.4-\mathrm{OCH}_{3}\right), 3.75\left(3 \mathrm{H}, \mathrm{s}, 1-\mathrm{OCH}_{3}\right), 2.38(3 \mathrm{H}, \mathrm{s}, \mathrm{H}-11), 1.75\left(3 \mathrm{H}, \mathrm{s}, 5^{\prime}-\mathrm{CH}_{3}\right)$. ${ }^{13} \mathrm{C}-\mathrm{NMR}$ (DMSO- $d_{6}$ ) $\delta: 164.2\left(\mathrm{C}-4^{\prime}\right), 151.1\left(\mathrm{C}-2^{\prime}\right), 150.7(\mathrm{C}-4), 146.4(\mathrm{C}-$ 1), 141.3 (C-6'), 133.3 (C-7), 127.4 (C-10), 126.2 (C-5), 125.9 (C-9), 124.2 (C-2), 122.1 (C-6), $120.7(\mathrm{C}-8), 109.1\left(\mathrm{C}-5^{\prime}\right), 107.8(\mathrm{C}-3), 60.9\left(\mathrm{OCH}_{3}\right)$, $55.6\left(\mathrm{OCH}_{3}\right), 50.3\left(7-\mathrm{CH}_{2}-\right), 16.0(\mathrm{C}-11), 11.9\left(5^{\prime}-\mathrm{CH}_{3}\right)$.

1-[(5,8-Dimethoxy-7-methylnaphthalen-2-yl)methyl]pyrimidine2,4(1H,3H)-dione (33) The same reaction and procedure using 23 (300 mg, $1.01 \mathrm{mmol}), 8$ (330 mg, $3.00 \mathrm{mmol})$ and $\mathrm{NaH}(120 \mathrm{mg}, 3.00 \mathrm{mmol})$ as the preparation of $\mathbf{2 7}$ gave a residue, which was subjected to column chromatography (a gradient of $0-15 \% \mathrm{MeOH}$ in toluene) to afford compound $33\left(187.7 \mathrm{mg}, 56.6 \%\right.$ yield) as a solid (mp more than $300^{\circ} \mathrm{C}$ ). EI-MS: $\mathrm{m} / z$ $326[\mathrm{M}]^{+}$. HR-MS: $m / z$ Calcd for $\mathrm{C}_{18} \mathrm{H}_{18} \mathrm{~N}_{2} \mathrm{O}_{4}[\mathrm{M}]^{+}$; 326.1267, Found; 326.1260. ${ }^{1} \mathrm{H}-\mathrm{NMR}$ (DMSO- $\left.d_{6}\right) \delta: 11.36\left(1 \mathrm{H}, \mathrm{brs}, \mathrm{H}-3^{\prime}\right), 7.99(1 \mathrm{H}, \mathrm{d}$, $J=1.8 \mathrm{~Hz}, \mathrm{H}-8), 7.92(1 \mathrm{H}, \mathrm{d}, J=8.9 \mathrm{~Hz}, \mathrm{H}-5), 7.82\left(1 \mathrm{H}, \mathrm{d}, J=7.9 \mathrm{~Hz}, \mathrm{H}-6^{\prime}\right)$, $7.48(1 \mathrm{H}, \mathrm{dd}, J=8.9,1.8 \mathrm{~Hz}, \mathrm{H}-6), 6.81(1 \mathrm{H}, \mathrm{s}, \mathrm{H}-3), 5.61(1 \mathrm{H}, \mathrm{d}, J=7.9 \mathrm{~Hz}$, H-5') $5.01\left(2 \mathrm{H}, \mathrm{s}, 7-\mathrm{CH}_{2}-\right), 3.91\left(3 \mathrm{H}, \mathrm{s}, 4-\mathrm{OCH}_{3}\right), 3.74\left(3 \mathrm{H}, \mathrm{s}, 1-\mathrm{OCH}_{3}\right)$, $2.36(3 \mathrm{H}, \mathrm{s}, \mathrm{H}-11) .{ }^{13} \mathrm{C}-\mathrm{NMR}\left(\mathrm{DMSO}-d_{6}\right) \delta: 163.7\left(\mathrm{C}-4^{\prime}\right), 151.1\left(\mathrm{C}-2^{\prime}\right)$, 152.6 (C-4), 146.4 (C-1), 145.7 (C-6'), 133.2 (C-7), 127.4 (C-10), 126.3 (C5), 126.0 (C-9), 124.2 (C-2), 122.1 (C-8), 120.6 (C-6), 107.8 (C-3), 101.4 $\left(\mathrm{C}-5^{\prime}\right), 60.9\left(\mathrm{OCH}_{3}\right), 55.6\left(\mathrm{OCH}_{3}\right), 50.5\left(7-\mathrm{CH}_{2}\right), 16.0(\mathrm{C}-11)$.

1-[(5,8-Dimethoxy-7-methylnaphthalen-2-yl)methyl]-5-fluoropyrimidine-2,4(1H,3H)-dione (34) The same reaction and procedure using 23 (170 mg, $0.58 \mathrm{mmol}), 2$ (222 mg, $1.73 \mathrm{mmol})$ and $\mathrm{NaH}$ (46.2 mg, $1.15 \mathrm{mmol})$ as the preparation of $\mathbf{2 7}$ gave a residue, which was subjected to column chromatography (a gradient of $0-10 \% \mathrm{MeOH}$ in toluene) to afford compound $34(94.0 \mathrm{mg}, 47.8 \%$ yield $)$ as a solid $\left(\mathrm{mp} 257-260^{\circ} \mathrm{C}\right)$. EI-MS: $\mathrm{m} / \mathrm{z} 344$ $[\mathrm{M}]^{+}$. HR-MS: $m / z$ Calcd for $\mathrm{C}_{18} \mathrm{H}_{17} \mathrm{FN}_{2} \mathrm{O}_{4}[\mathrm{M}]^{+}$; 344.1172, Found; 344.1158. ${ }^{1} \mathrm{H}-\mathrm{NMR}$ (DMSO- $\left.d_{6}\right) \delta: 12.81\left(1 \mathrm{H}, \mathrm{brs}, \mathrm{H}-3^{\prime}\right), 8.31(1 \mathrm{H}, \mathrm{d}$, 
$\left.J=6.7 \mathrm{~Hz}, \mathrm{H}-6^{\prime}\right), 8.04(1 \mathrm{H}, \mathrm{d}, J=1.8 \mathrm{~Hz}, \mathrm{H}-8), 7.95(1 \mathrm{H}, \mathrm{d}, J=8.9 \mathrm{~Hz}, \mathrm{H}-5)$, $7.60(1 \mathrm{H}, \mathrm{dd}, J=8.9,1.8 \mathrm{~Hz}, \mathrm{H}-6), 6.83(1 \mathrm{H}, \mathrm{s}, \mathrm{H}-3), 4.98\left(2 \mathrm{H}, \mathrm{s}, 7-\mathrm{CH}_{2}-\right)$, $3.94\left(3 \mathrm{H}, \mathrm{s}, 4-\mathrm{OCH}_{3}\right), 3.76\left(3 \mathrm{H}, \mathrm{s}, 1-\mathrm{OCH}_{3}\right), 2.37(3 \mathrm{H}, \mathrm{s}, \mathrm{H}-11) .{ }^{13} \mathrm{C}-\mathrm{NMR}$ $\left(\mathrm{DMSO}-d_{6}\right) \delta$ : $157.5\left(\mathrm{C}-4^{\prime}\right), 157.3\left(\mathrm{C}-2^{\prime}\right), 150.7$ (C-4), $149.7(\mathrm{C}-1), 146.4$ (C-5'), 132.8 (C'-6), 130.2 (C-7), 127.5 (C-9), 126.3 (C-6), 126.0 (C-2), 124.2 (C-10), 121.6 (C-5), 120.8 (C-8), $107.5(\mathrm{C}-3), 60.7\left(\mathrm{OCH}_{3}\right), 55.6$ $\left(\mathrm{OCH}_{3}\right), 50.9\left(7-\mathrm{CH}_{2}\right), 16.0(\mathrm{C}-11)$.

1-[(1,4-Dioxo-1,4-dihydronaphthalen-2-yl)methyl]-5-methylpyrimidine-2,4(1H,3H)-dione (35) To a solution of $\mathbf{2 8}(45.0 \mathrm{mg}, 0.14 \mathrm{mmol})$ in $\mathrm{AcOH}(5 \mathrm{ml}), \mathrm{HNO}_{3}(0.28 \mathrm{~g}, 2.90 \mathrm{mmol})$ was added, and the mixture was stirred at room temperature for $1 \mathrm{~h}$. The reaction mixture was poured into ice-water $(50 \mathrm{ml})$ and extracted with $\mathrm{CHCl}_{3}(50 \mathrm{ml} \times 3)$. The organic extracts were neutralized with $5 \%$ aqueous $\mathrm{NaHCO}_{3}$, washed with water, dried over $\mathrm{MgSO}_{4}$, and filtered. The filtrate was evaporated to give compound 35 $\left(21.7 \mathrm{mg}, 53.2 \%\right.$ yield) as a solid ( $\left.\mathrm{mp} 206-207^{\circ} \mathrm{C}\right)$. EI-MS: $\mathrm{m} / z 296[\mathrm{M}]^{+}$. HR-MS: $m / z$ Calcd for $\mathrm{C}_{16} \mathrm{H}_{12} \mathrm{~N}_{2} \mathrm{O}_{4}[\mathrm{M}]^{+} ; 296.0797$, Found; 296.0792. ${ }^{1} \mathrm{H}-$ $\operatorname{NMR}\left(\mathrm{CDCl}_{3}\right) \delta: 9.05\left(1 \mathrm{H}, \mathrm{br} \mathrm{s}, \mathrm{H}-3^{\prime}\right), 8.09(2 \mathrm{H}, \mathrm{m}, \mathrm{H}-5$ and 8$), 7.78(2 \mathrm{H}$, $\mathrm{m}, \mathrm{H}-6$ and 7), $7.24\left(1 \mathrm{H}, \mathrm{q}, J=1.2 \mathrm{~Hz}, \mathrm{H}-6^{\prime}\right), 6.94(1 \mathrm{H}, \mathrm{t}, J=1.2 \mathrm{~Hz}, \mathrm{H}-3)$, $4.80(2 \mathrm{H}, \mathrm{d}, J=1.2 \mathrm{~Hz}, \mathrm{H}-11), 1.95\left(3 \mathrm{H}, \mathrm{d}, J=1.2 \mathrm{~Hz}, 5^{\prime}-\mathrm{CH}_{3}\right) .{ }^{13} \mathrm{C}-\mathrm{NMR}$ $\left(\mathrm{CDCl}_{3}\right) \delta: 184.8(\mathrm{C}-1), 184.4(\mathrm{C}-4), 163.9\left(\mathrm{C}-4^{\prime}\right), 150.7\left(\mathrm{C}-2^{\prime}\right), 143.1(\mathrm{C}-$ 2), 140.5 (C-6'), 136.8 (C-3), 134.4 (C-7), 134.1 (C-6), 132.0 (C-9), 131.7 (C-10), 126.6 (C-8), 126.5 (C-5), $111.5\left(\mathrm{C}-5^{\prime}\right), 46.7$ (C-11), $12.4\left(5^{\prime}-\mathrm{CH}_{3}\right)$.

1-[(1,4-Dioxo-1,4-dihydronaphthalen-2-yl)methyl]pyrimidine$\mathbf{2 , 4}(\mathbf{1 H}, \mathbf{3 H})$-dione (36) The same reaction and preparation using 29 (700 $\mathrm{mg}, 0.22 \mathrm{mmol}$ ) as described for the preparation of $\mathbf{3 5}$ gave compound 36 (302.4 mg, 47.8\%yield) as solid (mp 236-237 $\left.{ }^{\circ} \mathrm{C}\right)$. EI-MS: $\mathrm{m} / \mathrm{z} 282$ $[\mathrm{M}]^{+}$. HR-MS: $m / z$ Calcd for $\mathrm{C}_{15} \mathrm{H}_{10} \mathrm{~N}_{2} \mathrm{O}_{4}[\mathrm{M}]^{+} ; 282.0641$, Found; 282.0643. ${ }^{1} \mathrm{H}-\mathrm{NMR}$ (DMSO- $\left.d_{6}\right) \delta: 11.37\left(1 \mathrm{H}, \mathrm{brs}, \mathrm{H}-3{ }^{\prime}\right), 8.04$ and 7.99 (each $1 \mathrm{H}, \mathrm{m}, \mathrm{H}-5$ or 8$), 7.90(2 \mathrm{H}, \mathrm{m}, \mathrm{H}-6$ and 7$), 7.67(1 \mathrm{H}, \mathrm{d}, J=7.9 \mathrm{~Hz}, \mathrm{H}-$ $\left.6^{\prime}\right), 6.70(1 \mathrm{H}, \mathrm{t}, J=1.5 \mathrm{~Hz}, \mathrm{H}-3), 5.65\left(1 \mathrm{H}, \mathrm{d}, J=7.9 \mathrm{~Hz}, \mathrm{H}-5^{\prime}\right), 4.81(2 \mathrm{H}, \mathrm{d}$, $J=1.5 \mathrm{~Hz}, \mathrm{H}-11) .{ }^{13} \mathrm{C}-\mathrm{NMR}$ (DMSO- $\left.d_{6}\right) \delta: 184.3$ (C-1), 184.0 (C-4), 163.7 (C-4'), 150.9 (C-2'), 145.6 (C-2), 145.0 (C-6'), 134.4 (C-7), 134.3 (C-6), 134.0 (C-3), 131.6 (C-9), 131.5 (C-10), 126.1 (C-8), 125.8 (C-5), 101.6 (C$\left.5^{\prime}\right), 46.0(\mathrm{C}-11)$.

1-[(1,4-Dioxo-1,4-dihydronaphthalen-2-yl)methyl]-5-fluoropyrimidine-2,4(1H,3H)-dione (37) The same reaction and procedure using 30 $(80.0 \mathrm{mg}, 0.24 \mathrm{mmol})$ as described for the preparation of $\mathbf{3 5}$ gave compound $37\left(37.6 \mathrm{mg}, 51.7 \%\right.$ yield) as solid $\left(\mathrm{mp} 90-92{ }^{\circ} \mathrm{C}\right)$. EI-MS: $\mathrm{m} / z 300[\mathrm{M}]^{+}$. HR-MS: $m / z$ Calcd for $\mathrm{C}_{15} \mathrm{H}_{9} \mathrm{FN}_{2} \mathrm{O}_{4}[\mathrm{M}]^{+} ; 300.0546$, Found; $300.0543 .{ }^{1} \mathrm{H}-$ NMR (DMSO- $d_{6}$ ) $\delta: 11.87(1 \mathrm{H}$, br s, H-3'), 8.05 and 8.00 (each $1 \mathrm{H}, \mathrm{m}, \mathrm{H}-5$ or 8), $8.04\left(1 \mathrm{H}, \mathrm{d}, J=6.7 \mathrm{~Hz}, \mathrm{H}-6^{\prime}\right), 7.90(2 \mathrm{H}, \mathrm{m}, \mathrm{H}-6$ and 7$), 6.89(1 \mathrm{H}, \mathrm{t}$, $J=1.5 \mathrm{~Hz}, \mathrm{H}-3), 4.77(2 \mathrm{H}, \mathrm{d}, J=1.5 \mathrm{~Hz}, \mathrm{H}-11) .{ }^{13} \mathrm{C}-\mathrm{NMR}$ (DMSO- $\left.d_{6}\right) \delta$ : 184.4 (C-1), 184.1 (C-4), 157.7 (C-4'), 1489.7 (C-2'), 144.6 (C-2), 139.1 (C-5'), 134.4 (C-3), 134.3 (C-7), 134.2 (C-6), 131.6 (C-6'), 130.0 (C-10), 129.8 (C-9), 126.1 (C-8), 125.8 (C-5), 46.3 (C-11).

7-[(6-Amino-9H-purin-9-yl)methyl]-2-methylnaphthalene-1,4-dione (38) The same reaction and procedure using $\mathbf{3 1}(100 \mathrm{mg}, 0.29 \mathrm{mmol})$ as described for the preparation of $\mathbf{3 5}$ gave a residue, which was subjected to column chromatography (a gradient of $0-5 \% \mathrm{MeOH}$ in toluene) to afford compound 38 (20.0 mg, 21.9\% yield) as a pale yellowish solid (mp 134$135^{\circ} \mathrm{C}$ ). EI-MS: $m / z 319[\mathrm{M}]^{+}$. HR-MS: $m / z$ Calcd for $\mathrm{C}_{17} \mathrm{H}_{13} \mathrm{~N}_{5} \mathrm{O}_{2}[\mathrm{M}]^{+}$; 319.1069, Found; $319.1064 .{ }^{1} \mathrm{H}-\mathrm{NMR}$ (DMSO- $\left.d_{6}\right) \delta: 8.33\left(1 \mathrm{H}, \mathrm{s}, \mathrm{H}-8^{\prime}\right.$ ), $8.14\left(1 \mathrm{H}, \mathrm{s}, \mathrm{H}-2^{\prime}\right), 7.98(1 \mathrm{H}, \mathrm{d}, J=8.2 \mathrm{~Hz}, \mathrm{H}-5), 7.83(1 \mathrm{H}, \mathrm{d}, J=1.8 \mathrm{~Hz}, \mathrm{H}-$ 8), $7.74(1 \mathrm{H}, \mathrm{dd}, J=8.2,1.8 \mathrm{~Hz}, \mathrm{H}-6), 7.30\left(2 \mathrm{H}, \mathrm{br} \mathrm{s}, 6^{\prime}-\mathrm{NH}_{2}\right), 6.95(1 \mathrm{H}, \mathrm{q}$, $J=1.2 \mathrm{~Hz}, \mathrm{H}-3), 5.53(2 \mathrm{H}, \mathrm{s}, \mathrm{H}-12), 2.09(3 \mathrm{H}, \mathrm{d}, J=1.2 \mathrm{~Hz}, \mathrm{H}-11) .{ }^{13} \mathrm{C}-\mathrm{NMR}$ $\left(\right.$ DMSO- $\left.d_{6}\right) \delta: 184.5(\mathrm{C}-1), 184.2(\mathrm{C}-4), 156.0\left(\mathrm{C}-6^{\prime}\right), 152.7\left(\mathrm{C}-2^{\prime}\right), 149.4$ (C-4'), 148.0 (C-8'), 143.2 (C-7), 135.1 (C-9), 133.2 (C-3), 132.6 (C-6), 131.9 (C-10), 131.0 (C-2), 126.6 (C-5), 124.2 (C-8), 118.6 (C-5'), 45.7 (C12), 15.8 (C-11).

5-Methyl-1-[(7-methyl-5,8-dioxo-5,8-dihydronaphthalen-2yl)methyl]pyrimidine-2,4(1H,3H)-dione (39) The same reaction and procedure using $32(65.0 \mathrm{mg}, 0.19 \mathrm{mmol})$ as described for the preparation of $\mathbf{3 5}$ gave a residue, which was subjected to column chromatography (a gradient of $0-3 \% \mathrm{MeOH}$ in $\left.\mathrm{CHCl}_{3}\right)$ to give compound $39(38.0 \mathrm{mg}, 64.1 \%$ yield $)$ as a solid (mp $\left.267-269^{\circ} \mathrm{C}\right)$. EI-MS: $m / z 310[\mathrm{M}]^{+}$. HR-MS: $m / z$ Calcd for $\mathrm{C}_{17} \mathrm{H}_{14} \mathrm{~N}_{2} \mathrm{O}_{4}[\mathrm{M}]^{+} ; 310.0954$, Found; 310.0953 . ${ }^{1} \mathrm{H}-\mathrm{NMR}$ (DMSO- $d_{6}$ ) $\delta$ : $11.41(1 \mathrm{H}$, br s, H-3'), $8.00(1 \mathrm{H}, \mathrm{d}, J=8.2 \mathrm{~Hz}, \mathrm{H}-5), 7.85(1 \mathrm{H}, \mathrm{d}, J=1.8 \mathrm{~Hz}$, $\mathrm{H}-8), 7.73(1 \mathrm{H}, \mathrm{dd}, J=8.2,1.8 \mathrm{~Hz}, \mathrm{H}-6), 7.71\left(1 \mathrm{H}, \mathrm{q}, J=1.2 \mathrm{~Hz}, \mathrm{H}-6^{\prime}\right), 6.97$ $(1 \mathrm{H}, \mathrm{q}, J=1.53 \mathrm{~Hz}, \mathrm{H}-3), 5.00(2 \mathrm{H}, \mathrm{s}, \mathrm{H}-12), 2.11(3 \mathrm{H}, \mathrm{d}, J=1.5 \mathrm{~Hz}, \mathrm{H}-11)$, $1.73\left(3 \mathrm{H}, \mathrm{d}, J=1.2 \mathrm{~Hz}, 5^{\prime}-\mathrm{CH}_{3}\right) .{ }^{13} \mathrm{C}-\mathrm{NMR}$ (DMSO- $\left.d_{6}\right) \delta: 184.6(\mathrm{C}-1), 184.3$ (C-4), 164.1 (C-4'), 150.9 (C-2'), 148.0 (C-2), 143.2 (C-7), 141.2 (C-6'), 135.1 (C-3), 132.6 (C-6), 131.9 (C-9), 130.1 (C-10), 126.6 (C-5), 124.2 (C8), 109.2 (C-5'), 49.9 (C-12), $15.8(\mathrm{C}-11), 11.9\left(5^{\prime}-\mathrm{CH}_{3}\right)$.

1-[(7-Methyl-5,8-dioxo-5,8-dihydronaphthalen-2-yl)methyl]pyrimi-
dine-2,4(1H,3H)-dione (40) The same reaction and procedure using 33 ( $70.0 \mathrm{mg}, 0.21 \mathrm{mmol}$ ) as described for the preparation of $\mathbf{3 5}$ gave a residue, which was subjected to column chromatography (a gradient of $0-5 \%$ $\mathrm{MeOH}$ in $\mathrm{CHCl}_{3}$ ) to afford compound $\mathbf{4 0}(40.4 \mathrm{mg}, 63.5 \%$ yield $)$ as a solid (mp more than $300^{\circ} \mathrm{C}$ ). EI-MS: $\mathrm{m} / z 296[\mathrm{M}]^{+}$. HR-MS: $\mathrm{m} / z$ Calcd for $\mathrm{C}_{16} \mathrm{H}_{12} \mathrm{~N}_{2} \mathrm{O}_{4}[\mathrm{M}]^{+} ; 296.0797$, Found; 296.0790. ${ }^{1} \mathrm{H}-\mathrm{NMR}$ (DMSO- $d_{6}$ ) $\delta$ : $11.41(1 \mathrm{H}$, br s, H-3'), $8.01(1 \mathrm{H}, \mathrm{d}, J=7.9 \mathrm{~Hz}, \mathrm{H}-5), 7.86(1 \mathrm{H}, \mathrm{d}, J=7.6 \mathrm{~Hz}$, H-6'), $7.84(1 \mathrm{H}, \mathrm{d}, J=1.8 \mathrm{~Hz}, \mathrm{H}-8), 7.76(1 \mathrm{H}, \mathrm{dd}, J=7.9,1.8 \mathrm{~Hz}, \mathrm{H}-6), 6.98$ $(1 \mathrm{H}, \mathrm{q}, J=1.5 \mathrm{~Hz}, \mathrm{H}-3), 5.66\left(1 \mathrm{H}, \mathrm{d}, J=7.6 \mathrm{~Hz}, \mathrm{H}-5^{\prime}\right), 5.04(2 \mathrm{H}, \mathrm{s}, \mathrm{H}-12)$, $2.11(3 \mathrm{H}, \mathrm{d}, J=1.5 \mathrm{~Hz}, \mathrm{H}-11) .{ }^{13} \mathrm{C}-\mathrm{NMR}$ (DMSO- $\left.d_{6}\right) \delta: 184.7$ (C-1), 184.4 (C-4), 163.7 (C-4'), 151.0 (C-2'), 148.1 (C-2), 145.6 (C-7), $143.2\left(\mathrm{C}-6^{\prime}\right)$, 135.2 (C-3), 132.7 (C-6), 131.9 (C-9), 131.1 (C-10), 126.7 (C-5), 124.2 (C8), $101.6\left(\mathrm{C}-5^{\prime}\right), 50.2$ (C-12), 15.9 (C-11).

5-Fluoro-1-[(7-methyl-5,8-dioxo-5,8-dihydronapphthalen-2-yl)methyl]pyrimidine-2,4(1H,3H)-dione (41) The same reaction and procedure using $34(80.0 \mathrm{mg}, 0.23 \mathrm{mmol})$ as described for the preparation of $\mathbf{3 5}$ gave a residue, which was subjected to column chromatography (a gradient of $0-5 \% \mathrm{MeOH}$ in $\mathrm{CHCl}_{3}$ ) to afford compound $41(41.0 \mathrm{mg}, 56.1 \%$ yield $)$ as a solid (mp $155-157^{\circ} \mathrm{C}$ ). EI-MS: $m / z 314[\mathrm{M}]^{+}$. HR-MS: $m / z$ Calcd for $\mathrm{C}_{16} \mathrm{H}_{11} \mathrm{FN}_{2} \mathrm{O}_{4}[\mathrm{M}]^{+}$; 314.0703, Found; 314.0703. ${ }^{1} \mathrm{H}-\mathrm{NMR}$ (DMSO- $d_{6}$ ) $\delta$ : $11.92\left(1 \mathrm{H}, \mathrm{br} \mathrm{s}, \mathrm{H}-3^{\prime}\right), 8.30\left(1 \mathrm{H}, \mathrm{d}, J=6.7 \mathrm{~Hz}, \mathrm{H}-6^{\prime}\right), 8.00(1 \mathrm{H}, \mathrm{d}, J=7.9 \mathrm{~Hz}$, H-5), $7.89(1 \mathrm{H}, \mathrm{d}, J=1.8 \mathrm{~Hz}, \mathrm{H}-8), 7.79(1 \mathrm{H}, \mathrm{dd}, J=7.9,1.8 \mathrm{~Hz}, \mathrm{H}-6), 6.98$ $(1 \mathrm{H}, \mathrm{q}, J=1.5 \mathrm{~Hz}, \mathrm{H}-3), 4.98(2 \mathrm{H}, \mathrm{s}, \mathrm{H}-12), 2.11(3 \mathrm{H}, \mathrm{d}, J=1.5 \mathrm{~Hz}, \mathrm{H}-11)$. ${ }^{13} \mathrm{C}-\mathrm{NMR}$ (DMSO- $d_{6}$ ) $\delta$ : 184.6 (C-1), 184.4 (C-4), 157.5 (C-4'), 149.7 (C2'), 148.1 (C-2), 142.7 (C-7), 135.2 (C-5'), 132.8 (C-3), 132.7 (C-6), 131.9 (C-6), 131.1 (C-5), 130.1 (C-9), 129.9 (C-10), 126.6 (C-8), 124.4 (C-6'), $50.5(\mathrm{C}-12), 15.9(\mathrm{C}-11)$

1-[(1,4-Dimethoxynaphthalen-2-yl)methyl]pyrrolidine (42) Pyrrolidine $(91 \mu \mathrm{l}, 1.1 \mathrm{mmol})$ was added to a solution of $19(50 \mathrm{mg}, 0.18 \mathrm{mmol})$ in DMF $(10 \mathrm{ml})$ and the mixture was then stirred at room temperature for $30 \mathrm{~min}$. The reaction mixture was poured into ice-water $(100 \mathrm{ml})$, neutralized with $5 \%$ aqueous $\mathrm{NaHCO}_{3}$, and extracted with $\mathrm{Et}_{2} \mathrm{O}(50 \mathrm{ml} \times 3)$. The organic extracts were washed with water, dried over $\mathrm{MgSO}_{4}$, and filtered. The filtrate was evaporated to give a residue, which was subjected to column chromatography (a gradient of $0-5 \% \mathrm{MeOH}$ in toluene) to obtain compound $\mathbf{4 2}$ (31.2 mg, 64.7\% yield). EI-MS: $m / z 271[\mathrm{M}]^{+}$. HR-MS: $m / z$ Calcd for $\mathrm{C}_{17} \mathrm{H}_{21} \mathrm{NO}_{2}[\mathrm{M}]^{+} ; 271.1572$, Found; 271.1571. ${ }^{1} \mathrm{H}-\mathrm{NMR}\left(\mathrm{CDCl}_{3}\right) \delta: 8.20$ $(1 \mathrm{H}, \mathrm{d}, J=8.2 \mathrm{~Hz}, \mathrm{H}-5) 8.00(1 \mathrm{H}, \mathrm{d}, J=8.2 \mathrm{~Hz}, \mathrm{H}-8), 7.52(1 \mathrm{H}, \mathrm{ddd}, J=8.2$, $7.0,1.2 \mathrm{~Hz}, \mathrm{H}-6)$ or $7.46(1 \mathrm{H}$, ddd, $J=8.2,7.0,1.2 \mathrm{~Hz}, \mathrm{H}-7), 6.98(1 \mathrm{H}, \mathrm{s}, \mathrm{H}-$ 3), 4.00 and 3.89 (each $3 \mathrm{H}, \mathrm{s}, 1-$ or $\left.4-\mathrm{OCH}_{3}\right), 3.88(2 \mathrm{H}, \mathrm{s}, \mathrm{H}-11), 2.64(4 \mathrm{H}$, $\left.\mathrm{s},-\mathrm{NCH}_{2}-\times 2\right)$ and $4.12\left(4 \mathrm{H}, \mathrm{s},-\mathrm{NCH}_{2}-\times 2\right) ;{ }^{13} \mathrm{C}-\mathrm{NMR}\left(\mathrm{CDCl}_{3}\right) \delta: 151.8$ (C-4), 147.2 (C-1), 128.5 (C-9), 126.4 (C-10), 125.9 (C-7), 125.1 (C-6), $122.3(\mathrm{C}-5), 121.9(\mathrm{C}-8), 105.4(\mathrm{C}-2), 96.1(\mathrm{C}-3), 62.2\left(1-\mathrm{OCH}_{3}\right), 55.8$ (4$\left.\mathrm{OCH}_{3}\right), 54.3\left(-\mathrm{NCH}_{2} \mathrm{CH}_{2}-\times 2\right), 54.1(\mathrm{C}-11), 23.6\left(-\mathrm{NCH}_{2} \mathrm{CH}_{2}-\times 2\right)$.

1-[(1,4-Dimethoxynaphthalen-2-yl)methyl]-4-methylpiperazine (43) The same reaction and preparation using $19(100.0 \mathrm{mg}, 0.36 \mathrm{mmol})$ and $1-$ methylpiperazine $(280 \mu \mathrm{l}, 2.3 \mathrm{mmol})$ as described for the preparation of $\mathbf{4 2}$ gave compound 43 (57.0 mg, 51.4\% yield). EI-MS: $m / z 300[\mathrm{M}]^{+}$. HR-MS: $m / z$ Calcd for $\mathrm{C}_{18} \mathrm{H}_{24} \mathrm{~N}_{2} \mathrm{O}_{2}[\mathrm{M}]^{+}$; 300.1838, Found; 300.1829. ${ }^{1} \mathrm{H}-\mathrm{NMR}$ $\left(\mathrm{CDCl}_{3}\right) \delta: 8.21(1 \mathrm{H}, \mathrm{d}, J=8.2 \mathrm{~Hz}, \mathrm{H}-5) 8.03(1 \mathrm{H}, \mathrm{d}, J=8.2 \mathrm{~Hz}, \mathrm{H}-8), 7.50$ $(1 \mathrm{H}, \mathrm{ddd}, J=8.2,7.0,1.2 \mathrm{~Hz}, \mathrm{H}-6)$ or $7.43(1 \mathrm{H}, \mathrm{ddd}, J=8.2,7.0,1.2 \mathrm{~Hz}, \mathrm{H}-$ 7), $6.90(1 \mathrm{H}, \mathrm{s}, \mathrm{H}-3), 3.97$ and 3.86 (each $3 \mathrm{H}, \mathrm{s}, 1-$ or $\left.4-\mathrm{OCH}_{3}\right), 3.34(2 \mathrm{H}, \mathrm{s}$, $\mathrm{H}-11), 2.50\left(8 \mathrm{H}, \mathrm{m}, \mathrm{NC}_{2} \times 4\right)$ and $2.27\left(3 \mathrm{H}, \mathrm{s}, \mathrm{N}-\mathrm{CH}_{3}\right) \cdot{ }^{13} \mathrm{C}-\mathrm{NMR}\left(\mathrm{CDCl}_{3}\right)$ $\delta: 151.8$ (C-4), $148.0(\mathrm{C}-1), 128.4(\mathrm{C}-9), 126.5(\mathrm{C}-10), 126.0(\mathrm{C}-7), 125.7$ (C-6), 125.3 (C-5), 122.2 (C-8), 121.8 (C-2), 105.2 (C-3), $56.4\left(1-\mathrm{OCH}_{3}\right)$, $55.7\left(4-\mathrm{OCH}_{3}\right), 55.3\left(-\mathrm{NCH}_{2} \mathrm{CH}_{2} \times 2\right), 53.2(\mathrm{C}-11), 46.1\left(-\mathrm{NCH}_{3}\right)$.

4-[(1,4-Dimethoxynaphthalen-2-yl)methyl]morpholine (44) The same reaction and procedure fusing $19(100.0 \mathrm{mg}, 0.36 \mathrm{mmol})$ and $1-$ methylpiperazine $(217 \mu \mathrm{l}, 2.5 \mathrm{mmol})$ as described for the preparation of $\mathbf{4 2}$ gave compound $44\left(64.0 \mathrm{mg}, 62.6 \%\right.$ yield) as a solid $\left(\mathrm{mp} 56-58^{\circ} \mathrm{C}\right)$. EIMS: $m / z 287[\mathrm{M}]^{+}$. HR-MS: $m / z$ Calcd for $\mathrm{C}_{18} \mathrm{H}_{24} \mathrm{~N}_{2} \mathrm{O}_{2}[\mathrm{M}]^{+} ; 287.1521$, Found; 287.1526. ${ }^{1} \mathrm{H}-\mathrm{NMR}\left(\mathrm{CDCl}_{3}\right) \delta: 8.22(1 \mathrm{H}, \mathrm{d}, J=8.2 \mathrm{~Hz}, \mathrm{H}-5) 8.04$ $(1 \mathrm{H}, \mathrm{d}, J=8.2 \mathrm{~Hz}, \mathrm{H}-8), 7.52(1 \mathrm{H}$, ddd, $J=8.2,7.0,1.2 \mathrm{~Hz}, \mathrm{H}-6)$ or $7.46(1 \mathrm{H}$, ddd, $J=8.2,7.0,1.2 \mathrm{~Hz}, \mathrm{H}-7), 6.91(1 \mathrm{H}, \mathrm{s}, \mathrm{H}-3) 3.99$ and 3.89 (each $3 \mathrm{H}, \mathrm{s}$, 1- or $\left.4-\mathrm{OCH}_{3}\right), 3.71(2 \mathrm{H}, \mathrm{s}, \mathrm{H}-11), 3.72\left(4 \mathrm{H}, \mathrm{s},-\mathrm{NCH}_{2} \times 2\right)$ and $2.53(4 \mathrm{H}, \mathrm{m}$, $\left.-\mathrm{CH}_{2} \mathrm{OCH}_{2}-\right) .{ }^{13} \mathrm{C}-\mathrm{NMR}\left(\mathrm{CDCl}_{3}\right) \delta: 151.8(\mathrm{C}-4), 148.0(\mathrm{C}-1), 128.4(\mathrm{C}-9)$, 126.5 (C-10), 126.0 (C-7), 125.7 (C-6), 125.3 (C-5), 122.2 (C-8), 121.8 (C2), $105.2(\mathrm{C}-3), 67.1\left(-\mathrm{CH}_{2} \mathrm{OCH}_{2}-\right), 62.4\left(1-\mathrm{OCH}_{3}\right), 56.8\left(4-\mathrm{OCH}_{3}\right), 55.7$ $\left(-\mathrm{NCH}_{2} \times 2\right), 53.7(\mathrm{C}-11)$

1-[(1,4-Dimethoxynaphthalen-2-yl)methyl]-1H-imidazole (45) The same reaction and procedure using $19(100.0 \mathrm{mg}, 0.36 \mathrm{mmol})$ and imidazol $(120 \mathrm{mg}, 1.78 \mathrm{mmol})$ as described for the preparation of $\mathbf{4 2}$ gave compound 45 (44.6 mg, 46.7\% yield) as a solid ( $\left.\mathrm{mp} 88-90^{\circ} \mathrm{C}\right)$. EI-MS: $\mathrm{m} / \mathrm{z} 268[\mathrm{M}]^{+}$ HR-MS: $m / z$ Calcd for $\mathrm{C}_{16} \mathrm{H}_{16} \mathrm{~N}_{2} \mathrm{O}_{2}[\mathrm{M}]^{+} ; 268.1212$, Found; $268.1220 .{ }^{1} \mathrm{H}-$ 
NMR $\left(\mathrm{CDCl}_{3}\right) \delta: 8.23(1 \mathrm{H}, \mathrm{d}, J=8.2 \mathrm{~Hz}, \mathrm{H}-5) 8.05(1 \mathrm{H}, \mathrm{d}, J=8.2 \mathrm{~Hz}, \mathrm{H}-8)$, $7.58(1 \mathrm{H}$, ddd, $J=8.2,7.0,1.2 \mathrm{~Hz}, \mathrm{H}-6)$ and $7.52(1 \mathrm{H}$, ddd, $J=8.2,7.0$, $1.2 \mathrm{~Hz}, \mathrm{H}-7), 7.63,7.08$ and 6.96 (each $1 \mathrm{H}$, proton on the imidazol group), $6.39(1 \mathrm{H}, \mathrm{s}, \mathrm{H}-3), 3.71(2 \mathrm{H}, \mathrm{s}, \mathrm{H}-11), 3.89$ and 3.86 (each $3 \mathrm{H}, \mathrm{s}, 1-$ or $4-$ $\left.\mathrm{OCH}_{3}\right) \cdot{ }^{13} \mathrm{C}-\mathrm{NMR}\left(\mathrm{CDCl}_{3}\right) \delta: 152.5(\mathrm{C}-4), 147.5(\mathrm{C}-1), 137.5(-\mathrm{NC}=\mathrm{N}-)$, $129.7(-\mathrm{NC}=\underline{\mathrm{C}}-), 128.3(\mathrm{C}-9), 127.1(\mathrm{C}-10), 126.7(\mathrm{C}-7), 126.1(\mathrm{C}-6)$, 123.5 (C-5), $122.6(\mathrm{C}-8), 122.0(-\mathrm{NC}=\mathrm{C}-), 119.3(\mathrm{C}-2), 103.4(\mathrm{C}-3), 62.6$ (C-11), $55.7\left(1-\mathrm{OCH}_{3}\right), 45.8\left(4-\mathrm{OCH}_{3}\right)$.

7-[(1,4-Dimethoxynaphthalen-2-yl)methyl]1,3-dimethyl-3,7-dihydro$\mathbf{1 H}$-purine-2,6-dione (46) $\quad \mathrm{K}_{2} \mathrm{CO}_{3}(50 \mathrm{mg}, 0.36 \mathrm{mmol})$ was added to a solution of $19(50.0 \mathrm{mg}, 0.18 \mathrm{mmol})$ and theophylline $(64.0 \mathrm{mg}, 0.36 \mathrm{mmol})$ in DMF $(10 \mathrm{ml})$ and the mixture was then stirred at room temperature for $12 \mathrm{~h}$. The mixture was poured into ice-water and neutralized with $5 \% \mathrm{NaHCO}_{3}$ and extracted with $\mathrm{Et}_{2} \mathrm{O}(50 \mathrm{ml} \times 3)$. The organic extracts was washed with water, dried over $\mathrm{MgSO}_{4}$, and filtered. The filtrate was evaporated to give a residue which was subjected to column chromatography (a gradient of 0 $10 \%$ acetone in toluene) to obtain compound $\mathbf{4 6}(22.1 \mathrm{mg}, 32.6 \%$ yield $)$ as a solid (mp $170-172{ }^{\circ} \mathrm{C}$ ). EI-MS: $m / z 380[\mathrm{M}]^{+}$. HR-MS: $\mathrm{m} / z$ Calcd for $\mathrm{C}_{20} \mathrm{H}_{20} \mathrm{~N}_{4} \mathrm{O}_{4}[\mathrm{M}]^{+}$; 380.1485, Found; 380.1471. ${ }^{1} \mathrm{H}-\mathrm{NMR}\left(\mathrm{CDCl}_{3}\right) \delta: 8.23$ $(1 \mathrm{H}, \mathrm{dd}, J=8.2,1.2 \mathrm{~Hz}, \mathrm{H}-5)$ or $8.05(1 \mathrm{H}, \mathrm{dd}, J=8.2,1.2 \mathrm{~Hz}, \mathrm{H}-8), 7.64(1 \mathrm{H}$, s, H-8') $7.58(1 \mathrm{H}$, ddd, $J=8.24,7.0,1.2 \mathrm{~Hz}, \mathrm{H}-6)$ or $7.52(1 \mathrm{H}$, ddd, $J=8.2$, $7.0,1.2 \mathrm{~Hz}, \mathrm{H}-7), 6.83(1 \mathrm{H}, \mathrm{s}, \mathrm{H}-3) 5.68(2 \mathrm{H}, \mathrm{s}, \mathrm{H}-11), 3.98$ and 3.93 (each $3 \mathrm{H}, \mathrm{s}, 1-$ or $4-\mathrm{OCH}_{3}$ ), 3.59 and 3.44 (each $3 \mathrm{H}, \mathrm{s}, 1^{\prime}-$ or $\left.3^{\prime}-\mathrm{NCH}_{3}\right) \cdot{ }^{13} \mathrm{C}-\mathrm{NMR}$ $\left(\mathrm{CDCl}_{3}\right) \delta: 155.5\left(\mathrm{C}^{\prime}-6\right), 152.5\left(\mathrm{C}-2^{\prime}\right), 151.7\left(\mathrm{C}-4^{\prime}\right), 148.7(\mathrm{C}-4), 148.1(\mathrm{C}-$ 8'), 141.7 (C-1), 128.2 (C-9), 127.1 (C-10), 126.9 (C-7), 126.2 (C-6), 123.1 (C-5), $122.6(\mathrm{C}-8), 122.1(\mathrm{C}-2), 107.0\left(\mathrm{C}-5^{\prime}\right) 104.2(\mathrm{C}-3), 62.8\left(1-\mathrm{OCH}_{3}\right)$, $55.8\left(4-\mathrm{OCH}_{3}\right), 45.3(\mathrm{C}-11), 29.8\left(7-\mathrm{N}^{\prime} \mathrm{CH}_{3}\right), 28.0\left(3-\mathrm{N}^{\prime} \mathrm{CH}_{3}\right)$.

1-I(1,4-Dimethoxynaphthalen-2-yl)methyl-3,7-dimethyl-3,7-dihydro$\mathbf{1 H}$-purine-2,6-dione (47) The same reaction and procedure using 9 $(50 \mathrm{mg}, 0.18 \mathrm{mmol})$, theobromine $(250 \mathrm{mg}, 1.42 \mathrm{mmol})$ and $\mathrm{K}_{2} \mathrm{CO}_{3}(50 \mathrm{mg}$, $0.36 \mathrm{mmol}$ ) as described for the preparation of $\mathbf{4 6}$ gave compound $\mathbf{4 7}$ (36.4 mg, $55.5 \%$ yield) as a solid (mp $159-161{ }^{\circ} \mathrm{C}$ ). EI-MS: $m / z 380[\mathrm{M}]^{+}$. HR-MS: $m / z$ Calcd for $\mathrm{C}_{20} \mathrm{H}_{20} \mathrm{~N}_{4} \mathrm{O}_{4}[\mathrm{M}]^{+} ; 380.1485$, Found; 380.1475. ${ }^{1} \mathrm{H}-$ $\operatorname{NMR}\left(\mathrm{CDCl}_{3}\right) \delta: 8.17(1 \mathrm{H}, \mathrm{dd}, J=8.2,1.2 \mathrm{~Hz}, \mathrm{H}-5)$ or $8.04(1 \mathrm{H}, \mathrm{dd}, J=8.2$, $1.2 \mathrm{~Hz}, \mathrm{H}-8), 7.52\left(1 \mathrm{H}, \mathrm{s}, \mathrm{H}-8^{\prime}\right), 7.51(1 \mathrm{H}, \mathrm{ddd}, J=8.2,7.0,1.2 \mathrm{~Hz}, \mathrm{H}-6)$ or $7.44(1 \mathrm{H}$, ddd, $J=8.2,7.0,1.2 \mathrm{~Hz}, \mathrm{H}-7), 6.63(1 \mathrm{H}, \mathrm{s}, \mathrm{H}-3) 5.45(2 \mathrm{H}, \mathrm{s}, \mathrm{H}-$ 11), 4.03 and 3.99 (each $3 \mathrm{H}, \mathrm{s}, 1-$ or $4-\mathrm{OCH}_{3}$ ), 3.89 and 3.60 (each $3 \mathrm{H}, \mathrm{s}, 3^{\prime}-$ or $\left.7^{\prime}-\mathrm{NCH}_{3}\right) .{ }^{13} \mathrm{C}-\mathrm{NMR}\left(\mathrm{CDCl}_{3}\right) \delta: 155.4\left(\mathrm{C}-6^{\prime}\right), 152.0\left(\mathrm{C}-2^{\prime}\right), 151.9(\mathrm{C}-$ $\left.4^{\prime}\right), 149.0$ (C-4), 146.98 (C-8'), 141.6 (C-1), 128.5 (C-9), 126.7 (C-10), 126.5 (C-7), 125.3 (C-6), 122.3 (C-5), 122.1 (C-8), 107.7 (C-2), 103.8 (C-3), $103.4\left(\mathrm{C}-5^{\prime}\right), 62.3\left(1-\mathrm{OCH}_{3}\right), 55.7\left(4-\mathrm{OCH}_{3}\right), 40.0(\mathrm{C}-11), 30.7\left(7^{\prime}-\mathrm{NCH}_{3}\right)$, $30.0\left(3^{\prime}-\mathrm{NCH}_{3}\right)$.

4-[(5,8-Dimethoxy-7-methylnaphthalen-2-yl)methyl]morpholine (48) The same reaction and procedure using $23(330.0 \mathrm{mg}, 1.12 \mathrm{mmol})$ and morpholine $(1.59 \mathrm{mg}, 18.3 \mathrm{mmol})$ as described for the preparation of $\mathbf{4 2}$ gave compound 48 (167.8 $\mathrm{mg}, 49.8 \%$ yield) as a solid (mp 91-93 $\left.{ }^{\circ} \mathrm{C}\right)$. EI-MS: $\mathrm{m} / \mathrm{z} 301[\mathrm{M}]^{+}$. HR-MS: $\mathrm{m} / \mathrm{z}$ Calcd for $\mathrm{C}_{18} \mathrm{H}_{23} \mathrm{NO}_{3}[\mathrm{M}]^{+}$; 301.1678, Found; 301.1671. ${ }^{1} \mathrm{H}-\mathrm{NMR}\left(\mathrm{CDCl}_{3}\right) \delta: 8.05(1 \mathrm{H}, \mathrm{s}, \mathrm{H}-8), 7.98(1 \mathrm{H}, \mathrm{d}, J=8.9 \mathrm{~Hz}, \mathrm{H}-$ 5), $7.52(1 \mathrm{H}, \mathrm{d}, J=8.9 \mathrm{~Hz}, \mathrm{H}-6), 6.59(1 \mathrm{H}, \mathrm{s}, \mathrm{H}-3), 3.96$ and 3.85 (each $3 \mathrm{H}$, $\mathrm{s}, 1-$ or $\left.4-\mathrm{OCH}_{3}\right), 3.72\left(4 \mathrm{H}, \mathrm{m},-\mathrm{CH}_{2} \mathrm{OCH}_{2}-\right)$ and $3.65\left(2 \mathrm{H}, \mathrm{s}, 7-\mathrm{CH}_{2}-\right), 2.48$ $\left(4 \mathrm{H}, \mathrm{m},-\mathrm{CH}_{2} \mathrm{NCH}_{2}-\right) 2.43(3 \mathrm{H}, \mathrm{s}, \mathrm{H}-11) .{ }^{13} \mathrm{C}-\mathrm{NMR}\left(\mathrm{CDCl}_{3}\right) \delta: 151.3(\mathrm{C}-4)$, 147.0 (C-1), 134.0 (C-7), 128.0 (C-9), 125.4 (C-6), 124.9 (C-10), 122.3 (C2), 121.7 (C-8), 107.0 (C-5), $96.1(\mathrm{C}-3), 67.2\left(-\mathrm{CH}_{2} \mathrm{OCH}_{2}-\right), 66.4(\mathrm{C}-12)$, $63.8\left(\mathrm{OCH}_{3}\right), 61.2\left(\mathrm{OCH}_{3}\right), 55.5\left(-\mathrm{CH}_{2} \mathrm{NCH}_{2}-\right), 16.2(\mathrm{C}-11)$.

7-[(5,8-Dimethoxy-7-methylnaphthalen-2-yl)methyl]-1,3-dimethyl-3,7dihydro-1 $\boldsymbol{H}$-purine-2,6-dione (49) To a solution of 23 (330.0 mg, $1.12 \mathrm{mmol})$ in DMF $(20 \mathrm{ml})$, theophylline $(540 \mathrm{mg}, 3.36 \mathrm{mmol})$ and $\mathrm{NaH}$ $(135 \mathrm{mg}, 3.36 \mathrm{mmol})$ was added. The mixture was stirred at $80^{\circ} \mathrm{C}$ for $2 \mathrm{~h}$. The reaction mixture was poured into ice-water $(100 \mathrm{ml})$, neutralized with $5 \%$ aqueous $\mathrm{NaHCO}_{3}$ and extracted with $\mathrm{CHCl}_{3}(50 \mathrm{ml} \times 3)$. The organic extracts were washed with water, dried over $\mathrm{MgSO}_{4}$, and then filtered. The filtrate was subjected to column chromatography (a gradient of $0-3 \% \mathrm{MeOH}$ in toluene) to obtain compound $\mathbf{4 9}(169.3 \mathrm{mg}, 38.4 \%$ yield) as a solid (mp 182-184 ${ }^{\circ} \mathrm{C}$ ). EI-MS: $m / z 394[\mathrm{M}]^{+}$. HR-MS: $m / z$ Calcd for $\mathrm{C}_{21} \mathrm{H}_{22} \mathrm{~N}_{4} \mathrm{O}_{4}$ $[\mathrm{M}]^{+}$; 394.1641, Found; 394.1639. ${ }^{1} \mathrm{H}-\mathrm{NMR}\left(\mathrm{CDCl}_{3}\right) \delta: 8.13(1 \mathrm{H}, \mathrm{d}$, $J=1.8 \mathrm{~Hz}, \mathrm{H}-8), 8.02(1 \mathrm{H}, \mathrm{d}, J=8.9 \mathrm{~Hz}, \mathrm{H}-5), 7.56\left(1 \mathrm{H}, \mathrm{s}, \mathrm{H}-8^{\prime}\right), 7.46(1 \mathrm{H}$, dd, $J=8.9,1.8 \mathrm{~Hz}, \mathrm{H}-6), 6.62(1 \mathrm{H}, \mathrm{s}, \mathrm{H}-3), 5.65\left(2 \mathrm{H}, \mathrm{s}, 7-\mathrm{CH}_{2}-\right), 3.95$ and 3.82 (each $3 \mathrm{H}, \mathrm{s}, 1-$ or $\left.4-\mathrm{OCH}_{3}\right), 3.82$ and 3.59 (each $3 \mathrm{H}, \mathrm{s}, 3^{\prime}-\mathrm{CH}_{3}$ or $7^{\prime}-$ $\left.\mathrm{CH}_{3}\right), 2.43(3 \mathrm{H}, \mathrm{s}, \mathrm{H}-11) .{ }^{13} \mathrm{C}-\mathrm{NMR}\left(\mathrm{CDCl}_{3}\right) \delta: 155.3\left(\mathrm{C}-6^{\prime}\right), 151.7\left(\mathrm{C}-2^{\prime}\right)$, 151.4 (C-4'), 148.8 (C-4), 147.0 (C-1), 141.0 (C-8'), 132.2 (C-7), 128.5 (C9), 126.7 (C-6), 126.1 (C-5), 125.0 (C-10), 122.9 (C-8), 122.0 (C-2), 107.6 $\left(\mathrm{C}-5^{\prime}\right), 96.1(\mathrm{C}-3), 61.2\left(\mathrm{OCH}_{3}\right), 55.6\left(\mathrm{OCH}_{3}\right), 50.6\left(7^{\prime}-\mathrm{CH}_{2}-\right), 29.8$ and 28.0 $\left(1^{\prime}-\right.$ and $\left.3^{\prime}-\mathrm{CH}_{3}\right), 16.3(\mathrm{C}-11)$.

1-[(5,8-Dimethoxy-7-methylnaphthalen-2-yl)methyl]-1,3-dimethyl-3,7-
dihydro-1H-purine-2,6-dione (50) The same reaction and procedure uisng $23(250 \mathrm{mg}, 0.85 \mathrm{mmol})$, theobromine $(460 \mathrm{mg}, 2.56 \mathrm{mmol})$ and $\mathrm{NaH}$ (102 $\mathrm{mg}, 2.56 \mathrm{mmol})$ as described for the preparation of $\mathbf{4 9}$ gave compound $50\left(232.7 \mathrm{mg}, 69.8 \%\right.$ yield) as a solid (mp $\left.155-156^{\circ} \mathrm{C}\right)$. EI-MS: $\mathrm{m} / \mathrm{z} 394$ $[\mathrm{M}]^{+}$. HR-MS: $m / z$ Calcd for $\mathrm{C}_{21} \mathrm{H}_{22} \mathrm{~N}_{4} \mathrm{O}_{4}[\mathrm{M}]^{+}$; 394.1641, Found; 394.1646. ${ }^{1} \mathrm{H}-\mathrm{NMR}\left(\mathrm{CDCl}_{3}\right) \delta: 8.27\left(1 \mathrm{H}, \mathrm{s}, \mathrm{H}-8^{\prime}\right), 7.95(1 \mathrm{H}, \mathrm{d}, J=8.6 \mathrm{~Hz}$, $\mathrm{H}-5), 7.63(1 \mathrm{H}, \mathrm{dd}, J=8.6,1.8 \mathrm{~Hz}, \mathrm{H}-6), 7.48(1 \mathrm{H}, \mathrm{d}, J=1.8 \mathrm{~Hz}, \mathrm{H}-8), 6.55$ $(1 \mathrm{H}, \mathrm{s}, \mathrm{H}-3), 5.35\left(2 \mathrm{H}, \mathrm{s},-\mathrm{CH}_{2}-\right), 3.98$ and 3.85 (each $3 \mathrm{H}, \mathrm{s}, 1-$ or $\left.4-\mathrm{OCH}_{3}\right)$, 3.80 and 3.57 (each $3 \mathrm{H}, \mathrm{s}, 1^{\prime}-$ or $\left.3^{\prime}-\mathrm{CH}_{3}\right), 2.38(3 \mathrm{H}, \mathrm{s}, \mathrm{H}-11) .{ }^{13} \mathrm{C}-\mathrm{NMR}$ $\left(\mathrm{CDCl}_{3}\right) \delta: 157.9\left(\mathrm{C}-6^{\prime}\right), 155.3\left(\mathrm{C}-2^{\prime}\right), 151.4\left(\mathrm{C}-4^{\prime}\right), 148.9$ (C-4), 146.1 (C1), 141.5 (C-8'), 133.5 (C-7), 128.0 (C-9), 127.2 (C-5), 125.1 (C-6), 125.1 (C-10), 122.2 (C-8), 121.9 (C-2), 107.7 (C-5'), $107.0(\mathrm{C}-3), 61.2\left(\mathrm{OCH}_{3}\right)$, $55.5\left(\mathrm{OCH}_{3}\right), 44.8\left(7^{\prime}-\mathrm{CH}_{2}-\right), 33.6$ and $29.8\left(3^{\prime}-\right.$ and $\left.7^{\prime}-\mathrm{CH}_{3}\right), 16.2(\mathrm{C}-11)$.

2-[(Pyrrolidin-1-yl)methyl]naphthalene-1,4-dione (51) To a solution of $42(100 \mathrm{mg}, 0.37 \mathrm{mmol})$ in THF $(25 \mathrm{ml})$ and $\mathrm{H}_{2} \mathrm{O}(5 \mathrm{ml})$, NBS $(72.2 \mathrm{mg}$, $0.41 \mathrm{mmol})$ and $0.1 \mathrm{M}$ aqueous $\mathrm{H}_{2} \mathrm{SO}_{4}(0.05 \mathrm{ml})$ were added, and the mixture was then stirred at room temperature for $5 \mathrm{~min}$. The reaction mixture was poured into ice-water $(100 \mathrm{ml})$, neutralized with $5 \%$ aqueous $\mathrm{NaHCO}_{3}$, and extracted with $\mathrm{Et}_{2} \mathrm{O}(50 \mathrm{ml} \times 3)$. The organic extracts were washed with water, dried over $\mathrm{MgSO}_{4}$, and filtered. The filtrate was evaporated to give a residue, which was subjected to column chromatography (a gradient of 0 $3 \% \mathrm{MeOH}$ in $\mathrm{CHCl}_{3}$ ) to obtain compound $\mathbf{5 1}(52.9 \mathrm{mg}, 59.0 \%$ yield). EIMS: $m / z 241[\mathrm{M}]^{+}$. HR-MS: $m / z$ Calcd for $\mathrm{C}_{15} \mathrm{H}_{15} \mathrm{NO}_{2}[\mathrm{M}]^{+} ; 270.1103$, Found; 270.1099. ${ }^{1} \mathrm{H}-\mathrm{NMR}\left(\mathrm{CDCl}_{3}\right) \delta: 8.09$ (each $1 \mathrm{H}, \mathrm{m}, \mathrm{H}-5$ or 8$), 7.73$ (each $1 \mathrm{H}, \mathrm{m}, \mathrm{H}-6$ or 7$), 7.05(1 \mathrm{H}, \mathrm{t}, J=1.8 \mathrm{~Hz}, \mathrm{H}-3), 3.65(2 \mathrm{H}, \mathrm{d}, J=1.8 \mathrm{~Hz}$, $\mathrm{H}-11), 2.63\left(4 \mathrm{H}, \mathrm{m},-\mathrm{CH}_{2} \mathrm{NCH}_{2}-\right)$ and $2.52\left(4 \mathrm{H}, \mathrm{m},-\mathrm{CH}_{2} \mathrm{CH}_{2}-\right) .{ }^{13} \mathrm{C}-\mathrm{NMR}$ $\left(\mathrm{CDCl}_{3}\right) \delta: 185.3(\mathrm{C}-1), 185.3$ (C-4), 148.5 (C-2), 135.3 (C-3), 133.7 (C-7), 133.6 (C-6), 132.4 (C-9), 132.1 (C-10), 126.4 (C-8), 126.1 (C-5), 53.4 (C$11), 54.5$ and 23.7 (signals on the pyrrolidinyl group).

2-[(4-Methylpyrerazin-1-yl)methyl]naphthalene-1,4-dione (52) The same reaction and procedure using $43(62 \mathrm{mg}, 0.21 \mathrm{mmol})$ and NBS (120 $\mathrm{mg}, 0.62 \mathrm{mmol}$ ) as described for the preparation of $\mathbf{5 1}$ gave compound 52 (30.6mg, 54.8\% yield). EI-MS: $m / z 270[\mathrm{M}]^{+}$. HR-MS: $m / z$ Calcd for $\mathrm{C}_{16} \mathrm{H}_{18} \mathrm{~N}_{2} \mathrm{O}_{2}[\mathrm{M}]^{+} ; 270.1368$, Found; 270.1364. ${ }^{1} \mathrm{H}-\mathrm{NMR}\left(\mathrm{CDCl}_{3}\right) \delta: 8.08$ (each $1 \mathrm{H}, \mathrm{m}, \mathrm{H}-5$ or 8$), 7.74$ (each $1 \mathrm{H}, \mathrm{m}, \mathrm{H}-6$ or 7$), 7.06(1 \mathrm{H}, \mathrm{t}, J=1.8 \mathrm{~Hz}$, $\mathrm{H}-3) 3.45(2 \mathrm{H}, \mathrm{d}, J=1.8 \mathrm{~Hz}, \mathrm{H}-11), 2.61$ and $2.52\left(8 \mathrm{H}, \mathrm{m},-\mathrm{NCH}_{2} \mathrm{CH}_{2}-\times 2\right)$ and $2.27\left(3 \mathrm{H}, \mathrm{s},-\mathrm{NCH}_{3}\right) .{ }^{13} \mathrm{C}-\mathrm{NMR}\left(\mathrm{CDCl}_{3}\right) \delta: 185.4(\mathrm{C}-1), 185.3(\mathrm{C}-4)$, 147.4 (C-2), 135.3 (C-3), 133.8 (C-7), 133.7 (C-6), 132.3 (C-9), 132.1 (C10), 126.4 (C-8), 126.1 (C-5), 55.7 (C-11), $55.1\left(-\mathrm{N}^{-} \mathrm{H}_{2} \mathrm{CH}_{2}-\times 2\right), 53.3$ $\left(-\mathrm{NCH}_{2} \mathrm{CH}_{2}-\times 2\right), 45.9\left(-\mathrm{NCH}_{3}\right)$.

2-[(Morpholin-4-yl)methyl] naphthalene-1,4-dione (53) A solution of $44(70 \mathrm{mg}, 0.34 \mathrm{mmol})$ and CAN $(400 \mathrm{mg}, 0.73 \mathrm{mmol})$ in acetonitrile $(25 \mathrm{ml})$ and $\mathrm{H}_{2} \mathrm{O}(25 \mathrm{ml})$ was stirred at room temperature for $1 \mathrm{~h}$. The reaction mixture was poured into ice-water $(100 \mathrm{ml})$, and extracted with $\mathrm{Et}_{2} \mathrm{O}(50 \mathrm{ml} \times 3)$. The organic extracts were washed with water, dried over $\mathrm{MgSO}_{4}$, and filtered. The filtrate was evaporated to give a residue, which was subjected to column chromatography (a gradient of $0-3 \% \mathrm{MeOH}$ in $\mathrm{CHCl}_{3}$ ) to obtain compound $\mathbf{5 3}$ (39.8 mg, 63.5\% yield). EI-MS: $m / z 257\left[\mathrm{M}^{+}\right.$. HR-MS: $\mathrm{m} / z$ Calcd for $\mathrm{C}_{16} \mathrm{H}_{18} \mathrm{~N}_{2} \mathrm{O}_{2}[\mathrm{M}]^{+} ; 257.1052$, Found; 270.1042. ${ }^{1} \mathrm{H}-\mathrm{NMR}\left(\mathrm{CDCl}_{3}\right)$ $\delta: 8.04$ (each $1 \mathrm{H}, \mathrm{m}, \mathrm{H}-5$ or 8$), 7.70$ (each $1 \mathrm{H}, \mathrm{m}, \mathrm{H}-6$ or 7$), 7.04(1 \mathrm{H}, \mathrm{s}, \mathrm{H}-$ 3), $3.47(2 \mathrm{H}, \mathrm{s}, \mathrm{H}-11), 3.72\left(4 \mathrm{H}, \mathrm{t}, J=4.6 \mathrm{~Hz},-\mathrm{CH}_{2} \mathrm{OCH}_{2}-\right), 2.52(4 \mathrm{H}, \mathrm{t}$, $\left.J=4.6 \mathrm{~Hz},-\mathrm{NCH}_{2} \times 2\right) .{ }^{13} \mathrm{C}-\mathrm{NMR}\left(\mathrm{CDCl}_{3}\right) \delta: 185.2(\mathrm{C}-1), 185.2(\mathrm{C}-4)$, 147.0 (C-2), 135.3 (C-3), 133.8 (C-7), 133.7 (C-6), 132.3 (C-9), 132.0 (C10), 126.4 (C-8), 126.1 (C-5), $66.9\left(-\underline{\mathrm{CH}}_{2} \mathrm{O}^{\mathrm{CH}}{ }_{2}-\right), 55.7$ (C-11), 29.9 and $28.0\left(-\mathrm{CH}_{2} \mathrm{NCH}_{2}-\right)$.

7-[(1,4-Dioxo-1,4-dihydronaphthalen-2-yl)methyl]-1,3-dimethyl-3,7dihydro-1 $H$-purine-2,6-dione (54) The same reaction and procedure using $46(60 \mathrm{mg}, 0.16 \mathrm{mmol})$ and $\mathrm{CAN}(400 \mathrm{mg}, 0.73 \mathrm{mmol})$ as described for the preparation of $\mathbf{5 3}$ gave compound $\mathbf{5 4}(29.6 \mathrm{mg}, 53.7 \%$ yield) as a solid (mp 183-185 ${ }^{\circ} \mathrm{C}$ ). EI-MS: $m / z 350[\mathrm{M}]^{+}$. HR-MS: $m / z$ Calcd for $\mathrm{C}_{18} \mathrm{H}_{14} \mathrm{~N}_{4} \mathrm{O}_{4}[\mathrm{M}]^{+}$; 350.1015, Found; 350.1016. ${ }^{1} \mathrm{H}-\mathrm{NMR}\left(\mathrm{CDCl}_{3}\right) \delta: 8.11$ and 8.07 (each $1 \mathrm{H}, \mathrm{m}, \mathrm{H}-5$ or 8$), 7.80\left(1 \mathrm{H}, \mathrm{s}, \mathrm{H}-8^{\prime}\right), 7.77(2 \mathrm{H}, \mathrm{m}, \mathrm{H}-6$ and 7), $6.84(1 \mathrm{H}, \mathrm{s}, \mathrm{H}-3), 5.46(2 \mathrm{H}, \mathrm{s}, \mathrm{H}-11), 3.60$ and 3.38 (each $3 \mathrm{H}, \mathrm{s}, 1^{\prime}-$ or $\left.3^{\prime}-\mathrm{NCH}_{3}\right) .{ }^{13} \mathrm{C}-\mathrm{NMR}\left(\mathrm{CDCl}_{3}\right) \delta$ : $184.4(\mathrm{C}-1), 184.1(\mathrm{C}-4), 155.01\left(\mathrm{C}-6^{\prime}\right)$, 151.6 (C-2'), 148.9 (C-2), 144.0 (C-4'), 142.2 (C-8'), 136.1 (C-3), 134.4 (C7), 134.1 (C-6), 132.0 (C-9), 131.6 (C-10), 126.7 (C-8), 126.5 (C-5), 106.7 $\left(\mathrm{C}-5^{\prime}\right), 44.5(\mathrm{C}-11), 29.9$ and $28.0\left(1^{\prime}-\right.$ and $\left.3^{\prime}-\mathrm{NCH}_{3}\right)$.

7-[(1,4-Dioxo-1,4-dihydronaphthalen-2-yl)methyl]-3,7-dimethyl-3,7dihydro-1H-purine-2,6-dione (55) A solution of $47(100 \mathrm{mg}, 0.26 \mathrm{mmol})$ and $\mathrm{HNO}_{3}(0.28 \mathrm{~g}, 2.9 \mathrm{mmol})$ in $\mathrm{AcOH}(10 \mathrm{ml})$ was stirred at room temperature for $1 \mathrm{~h}$. The reaction mixture was poured into ice-water $(50 \mathrm{ml})$, and the mixture was neutralized with $5 \%$ aqueous $\mathrm{NaHCO}_{3}$, and extracted with $\mathrm{CHCl}_{3}(50 \mathrm{ml} \times 3)$. The extracts were evaporated to give a residue which was subjected to column chromatography (a gradient of $0-3 \% \mathrm{MeOH}$ in 
$\mathrm{CHCl}_{3}$ ) to obtain compound $\mathbf{5 5}$ (44.8 $\mathrm{mg}, 58.6 \%$ yield) as a solid (mp 168 $170{ }^{\circ} \mathrm{C}$ ). EI-MS: $m / z 350[\mathrm{M}]^{+}$. HR-MS: $m / z$ Calcd for $\mathrm{C}_{18} \mathrm{H}_{14} \mathrm{~N}_{4} \mathrm{O}_{4}[\mathrm{M}]^{+}$; 350.1015, Found; $350.1034 .{ }^{1} \mathrm{H}-\mathrm{NMR}\left(\mathrm{CDCl}_{3}\right) \delta: 8.14$ and 8.04 (each $1 \mathrm{H}$, m, H-5 or 8), 7.77 (2H, m, H-6 and 7), 7.59 (1H, s, H-8'), 6.44 (1H, s, H-3), $5.20(2 \mathrm{H}, \mathrm{s}, \mathrm{H}-11), 4.00$ and 3.61 (each $3 \mathrm{H}, \mathrm{s}, 1^{\prime}-$ or $\left.3^{\prime}-\mathrm{NCH}_{3}\right) \cdot{ }^{13} \mathrm{C}-\mathrm{NMR}$ $\left(\mathrm{CDCl}_{3}\right) \delta: 184.7(\mathrm{C}-1), 184.3(\mathrm{C}-4), 154.6\left(\mathrm{C}-6^{\prime}\right), 151.1(\mathrm{C}-2), 149.3(\mathrm{C}-$ $\left.2^{\prime}\right), 145.9$ (C-4'), 142.1 (C-8'), 135.2 (C-3), 134.0 (C-7), 133.9 (C-6), 132.2 (C-9), 132.1 (C-10), 126.6 (C-8), 126.3 (C-5), 107.5 (C-5'), 39.5 (C-11), 33.7 and $30.0\left(3^{\prime}-\right.$ and $\left.7^{\prime}-\mathrm{NCH}_{3}\right)$.

2-Methyl-7-[(morpholin-4-yl)methyl]naphthalene-1,4-dione (56) A solution of $48(80 \mathrm{mg}, 0.27 \mathrm{mmol})$ and $\mathrm{HNO}_{3}(0.28 \mathrm{~g}, 2.9 \mathrm{mmol})$ in $\mathrm{AcOH}$ $(50 \mathrm{ml})$ was stirred at room temperature for $1 \mathrm{~h}$. The reaction mixture was poured into ice-water $(50 \mathrm{ml})$, and extracted with $\mathrm{CHCl}_{3}(50 \mathrm{ml} \times 3)$. The organic extracts were washed with $5 \% \mathrm{NaHCO}_{3}$ and water, dried over $\mathrm{MgSO}_{4}$, and filtered. The filtrate was evaporated to give a residue which was subjected to column chromatography (toluene) to obtain compound $\mathbf{5 6}$ (57.3 $\mathrm{mg}, 49.5 \%$ yield) as a solid ( $\mathrm{mp} 115-117^{\circ} \mathrm{C}$ ). EI-MS: $\mathrm{m} / z 271[\mathrm{M}]^{+}$. HR-MS: $m / z$ Calcd for $\mathrm{C}_{16} \mathrm{H}_{17} \mathrm{NO}_{3}[\mathrm{M}]^{+} ; 271.1208$, Found; 271.1209. ${ }^{1} \mathrm{H}-$ $\operatorname{NMR}\left(\mathrm{CDCl}_{3}\right) \delta: 8.01(1 \mathrm{H}, \mathrm{d}, J=7.9 \mathrm{~Hz}, \mathrm{H}-5), 8.00(1 \mathrm{H}, \mathrm{d}, J=1.8 \mathrm{~Hz}, \mathrm{H}-8)$, $7.74(1 \mathrm{H}, \mathrm{dd}, J=7.9,1.8 \mathrm{~Hz}, \mathrm{H}-6), 6.83(1 \mathrm{H}, \mathrm{d}, J=1.5 \mathrm{~Hz}, \mathrm{H}-3), 3.73(4 \mathrm{H}$, $\left.\mathrm{m},-\mathrm{CH}_{2} \mathrm{OCH}_{2}-\right), 3.61\left(2 \mathrm{H}, \mathrm{s}, 7^{\prime}-\mathrm{CH}_{2}-\right), 3.47\left(4 \mathrm{H}, \mathrm{m},-\mathrm{CH}_{2} \mathrm{NCH}_{2}-\right), 2.20$ $(3 \mathrm{H}, \mathrm{s}, \mathrm{H}-11) .{ }^{13} \mathrm{C}-\mathrm{NMR}\left(\mathrm{CDCl}_{3}\right) \delta: 185.3(\mathrm{C}-1), 185.1(\mathrm{C}-4), 148.2(\mathrm{C}-2)$, 144.7 (C-7), 135.6 (C-3), 134.0 (C-6), 132.2 (C-9), 131.3 (C-10), 126.8 (C5), $126.4(\mathrm{C}-8), 66.9\left(-\underline{\mathrm{CH}}_{2} \mathrm{OCH}_{2}-\right), 62.8\left(7^{\prime}-\mathrm{CH}_{2}-\right), 53.6\left(-\underline{\mathrm{CH}}_{2} \mathrm{NCH}_{2}-\right)$, $16.4(\mathrm{C}-11)$.

1,3-Dimethyl-7-[(7-methyl-5,8-diox 0-5,8-dihydronaphthalen-2yl)methyl]-3,7-dihydro-1 $\boldsymbol{H}$-purine-2,6-dione (57) The same reaction and procedure using $49(80 \mathrm{mg}, 0.20 \mathrm{mmol})$ as described for the preparation of 56 gave compound $57\left(28.8 \mathrm{mg}, 41.2 \%\right.$ yield) as a solid $\left(\mathrm{mp} 238-240{ }^{\circ} \mathrm{C}\right)$. EI-MS: $m / z 364[\mathrm{M}]^{+}$. HR-MS: $m / z$ Calcd for $\mathrm{C}_{19} \mathrm{H}_{16} \mathrm{~N}_{4} \mathrm{O}_{4}[\mathrm{M}]^{+} ; 364.1172$, Found; 364.1185. ${ }^{1} \mathrm{H}-\mathrm{NMR}\left(\mathrm{CDCl}_{3}\right) \delta: 8.35(1 \mathrm{H}, \mathrm{d}, J=1.8 \mathrm{~Hz}, \mathrm{H}-8), 7.97$ $(1 \mathrm{H}, \mathrm{d}, J=7.9 \mathrm{~Hz}, \mathrm{H}-5), 7.87\left(1 \mathrm{H}, \mathrm{s}, \mathrm{H}-6^{\prime}\right), 7.74(1 \mathrm{H}, \mathrm{dd}, J=7.9,1.8 \mathrm{~Hz}, \mathrm{H}-$ 6), $6.96(1 \mathrm{H}, \mathrm{q}, J=1.5 \mathrm{~Hz}, \mathrm{H}-3), 5.64\left(2 \mathrm{H}, \mathrm{s}, 7-\mathrm{CH}_{2}-\right), 3.43$ and 3.17 (each $3 \mathrm{H}, \mathrm{s}, 1^{\prime}-$ or $\left.3^{\prime}-\mathrm{CH}_{3}\right), 2.10(3 \mathrm{H}, \mathrm{d}, J=1.5 \mathrm{~Hz}, \mathrm{H}-11) .{ }^{13} \mathrm{C}-\mathrm{NMR}\left(\mathrm{CDCl}_{3}\right) \delta$ : 184.5 (C-1), 184.2 (C-4), 154.2 (C-6'), 150.9 (C-2'), 148.5 (C-4'), 148.0 (C2), 142.9 (C-7), 142.7 (C-8'), 135.1 (C-3), 132.6 (C-9), 131.9 (C-6), 131.2 (C-5), $126.6(\mathrm{C}-8), 124.3(\mathrm{C}-10), 105.7\left(\mathrm{C}-5^{\prime}\right), 48.6\left(7-\mathrm{CH}_{2}-\right), 29.4$ and 27.4 $\left(1^{\prime}-\right.$ and $\left.3^{\prime}-\mathrm{CH}_{3}\right), 15.8(\mathrm{C}-11)$.

3,7-Dimethyl-1-[(7-methyl-5,8-diox o-5,8-dihydronaphthalen-2yl)methyl]-3,7-dihydro-1 $\boldsymbol{H}$-purine-2,6-dione (58) The same reaction and procedure using $\mathbf{5 0}(100 \mathrm{mg}, 0.25 \mathrm{mmol})$ as described for the preparation of $\mathbf{5 7}$ gave compound $\mathbf{5 8}\left(84.0 \mathrm{mg}, 92.0 \%\right.$ yield) as a solid $\left(\mathrm{mp} 224-225^{\circ} \mathrm{C}\right)$. EI-MS: $m / z 364[\mathrm{M}]^{+}$. HR-MS: $m / z$ Calcd for $\mathrm{C}_{19} \mathrm{H}_{16} \mathrm{~N}_{4} \mathrm{O}_{4}[\mathrm{M}]^{+} ; 364.1172$, Found; 364.1189. ${ }^{1} \mathrm{H}-\mathrm{NMR}\left(\mathrm{CDCl}_{3}\right) \delta: 8.05(1 \mathrm{H}, \mathrm{d}, J=7.9 \mathrm{~Hz}, \mathrm{H}-5), 8.02$ $\left(1 \mathrm{H}, \mathrm{s}, \mathrm{H}-8^{\prime}\right), 7.76(1 \mathrm{H}, \mathrm{dd}, J=7.9,1.8 \mathrm{~Hz}, \mathrm{H}-6), 7.55(1 \mathrm{H}, \mathrm{d}, J=1.8 \mathrm{~Hz}, \mathrm{H}-$ 8), $6.80(1 \mathrm{H}, \mathrm{q}, J=1.5 \mathrm{~Hz}, \mathrm{H}-3), 5.30\left(2 \mathrm{H}, \mathrm{s}, 7-\mathrm{CH}_{2}-\right), 4.00\left(3 \mathrm{H}, \mathrm{s}, 7^{\prime}-\mathrm{CH}_{3}\right)$, $3.61\left(3 \mathrm{H}, \mathrm{s}, 3^{\prime}-\mathrm{CH}_{3}\right), 2.17(3 \mathrm{H}, \mathrm{d}, J=1.5 \mathrm{~Hz}, \mathrm{H}-11) \cdot{ }^{13} \mathrm{C}-\mathrm{NMR}\left(\mathrm{CDCl}_{3}\right) \delta$ : 185.3 (C-1), 184.9 (C-4), 167.8 (C-6'), 155.0 (C-2'), $151.4\left(\mathrm{C}-4^{\prime}\right), 143.7$ (C7), 141.9 (C-8'), 135.1 (C-3), 133.3 (C-6), 132.4 (C-2), 131.3 (C-10), 130.9 (C-9), $127.0(\mathrm{C}-5), 125.5(\mathrm{C}-8), 107.6\left(\mathrm{C}-5^{\prime}\right), 44.2\left(7^{\prime}-\mathrm{CH}_{2}-\right), 33.7$ and 29.7 ( $3^{\prime}$ - and $\left.7^{\prime}-\mathrm{CH}_{3}\right), 16.4(\mathrm{C}-11)$

1,4-Dimethoxynaphthalen-2-yl)methyl Thiocyanate (59) KSCN $(430 \mathrm{mg}, 4.28 \mathrm{mmol})$ was added to a solution of $19(300 \mathrm{mg}, 1.07 \mathrm{mmol})$ in DMF $(50 \mathrm{ml})$ and the mixture was then stirred at $60^{\circ} \mathrm{C}$ for $2 \mathrm{~h}$. The reaction mixture was poured into ice-water $(100 \mathrm{ml})$ and extracted with $\mathrm{CHCl}_{3}$ $(50 \mathrm{ml} \times 3)$. The organic extracts were washed successively with brine and water, dried over $\mathrm{MgSO}_{4}$, and filtered. The filtrate was evaporated to give a residue, which was subjected to column chromatography (a gradient of 0 $5 \%$ acetone in toluene) to obtain compound $\mathbf{5 9}(203.7 \mathrm{mg}, 73.6 \%$ yield $)$ as a solid (mp 94-97 ${ }^{\circ} \mathrm{C}$ ). EI-MS: $m / z 259[\mathrm{M}]^{+}$. HR-MS: $m / z$ Calcd for $\mathrm{C}_{14} \mathrm{H}_{13} \mathrm{NO}_{2} \mathrm{~S}[\mathrm{M}]^{+} ; 259.0667$, Found; 259.0658. ${ }^{1} \mathrm{H}-\mathrm{NMR}\left(\mathrm{CDCl}_{3}\right) \delta: 8.25$ and 8.03 (each $1 \mathrm{H}, \mathrm{m}, \mathrm{H}-5$ or 8 ), 7.58 and 7.52 (each $1 \mathrm{H}, \mathrm{m}, \mathrm{H}-6$ or 7 ), 6.72 $(1 \mathrm{H}, \mathrm{s}, \mathrm{H}-3), 4.43(2 \mathrm{H}, \mathrm{s}, \mathrm{H}-11), 4.01$ and 3.97 (each $3 \mathrm{H}, \mathrm{s}, 1-$ or $\left.4-\mathrm{OCH}_{3}\right)$. ${ }^{13} \mathrm{C}-\mathrm{NMR}\left(\mathrm{CDCl}_{3}\right) \delta: 152.4(\mathrm{C}-4), 148.2(\mathrm{C}-1), 128.2$ (C-9), $127.2(\mathrm{C}-10)$, 127.1 (C-7), 126.3 (C-6), 122.7 (C-5), 122.3 (C-8), 122.2 (C-2), 112.5 $(\mathrm{SCN}), 104.0(\mathrm{C}-3), 63.1\left(\mathrm{OCH}_{3}\right), 55.8\left(\mathrm{OCH}_{3}\right), 33.7(\mathrm{C}-11)$.

(1,4-Dimethoxynaphthalen-2-yl)methyl Selenocyanate (60) The same reaction and preparation using $19(286 \mathrm{mg}, 0.95 \mathrm{mmol})$ and $\mathrm{KSeCN}$ (548 $\mathrm{mg}, 3.81 \mathrm{mmol}$ ) as described for the preparation of $\mathbf{5 9}$ gave compound $60\left(238.0 \mathrm{mg}, 76.4 \%\right.$ yield) as a solid $\left(\mathrm{mp} 95-96{ }^{\circ} \mathrm{C}\right)$. EI-MS: $\mathrm{m} / \mathrm{z} 307$ $[\mathrm{M}]^{+}$. HR-MS: $m / z$ Calcd for $\mathrm{C}_{14} \mathrm{H}_{13} \mathrm{NO}_{2} \mathrm{Se}[\mathrm{M}]^{+}$; 307.0112, Found; 307.0120. ${ }^{1} \mathrm{H}-\mathrm{NMR}\left(\mathrm{CDCl}_{3}\right) \delta: 8.24$ and 8.02 (each $1 \mathrm{H}, \mathrm{m}, \mathrm{H}-5$ or 8 ), 7.55 and 7.51 (each $1 \mathrm{H}, \mathrm{m}, \mathrm{H}-6$ or 7$), 6.71(1 \mathrm{H}, \mathrm{s}, \mathrm{H}-3), 4.55(2 \mathrm{H}, \mathrm{s}, \mathrm{H}-11), 4.01$ and 3.97 (each $3 \mathrm{H}, \mathrm{s}, 1-$ or $\left.4-\mathrm{OCH}_{3}\right) .{ }^{13} \mathrm{C}-\mathrm{NMR}\left(\mathrm{CDCl}_{3}\right) \delta: 152.3(\mathrm{C}-4)$,
148.0 (C-1), 128.3 (C-9), 127.2 (C-10), 127.0 (C-7), 126.2 (C-6), 123.4 (C5), 122.7 (C-8), 122.0 (C-2), $104.2(\mathrm{C}-3), 102.5(\mathrm{SeCN}), 62.7\left(\mathrm{OCH}_{3}\right), 55.8$ $\left(\mathrm{OCH}_{3}\right), 28.3(\mathrm{C}-11)$

$S$-[(1,4-Dimethoxynaphthalin-2-yl)methyl] Ethanethionate (61) The same reaction and procedure using $19(300 \mathrm{mg}, 1.07 \mathrm{mmol})$ and $\mathrm{KSeAc}$ (430 $\mathrm{mg}, 3.78 \mathrm{mmol}$ ) as described for the preparation of $\mathbf{5 9}$ gave compound $61\left(163.1 \mathrm{mg}, 55.3 \%\right.$ yield). EI-MS: $\mathrm{m} / z 276[\mathrm{M}]^{+}$. HR-MS: $\mathrm{m} / z$ Calcd for $\mathrm{C}_{15} \mathrm{H}_{16} \mathrm{O}_{3} \mathrm{~S}[\mathrm{M}]^{+} ; 276.0820$, Found; $276.0828 .{ }^{1} \mathrm{H}-\mathrm{NMR}\left(\mathrm{CDCl}_{3}\right) \delta: 8.20$ and 8.01 (each $1 \mathrm{H}, \mathrm{m}, \mathrm{H}-5$ or 8 ), 7.53 and 7.46 (each $1 \mathrm{H}, \mathrm{m}, \mathrm{H}-6$ or 7 ), 6.70 $(1 \mathrm{H}, \mathrm{s}, \mathrm{H}-3), 4.35(2 \mathrm{H}, \mathrm{s}, \mathrm{H}-11), 3.96$ and 3.92 (each $3 \mathrm{H}, \mathrm{s}, 1-$ or $4-\mathrm{OCH}_{3}$ ), $2.38\left(3 \mathrm{H}, \mathrm{s}, \mathrm{COCH}_{3}\right) .{ }^{13} \mathrm{C}-\mathrm{NMR}\left(\mathrm{CDCl}_{3}\right) \delta: 195.7\left(11-\mathrm{SCOCH}_{3}\right), 152.1(\mathrm{C}-$ 4), 147.6 (C-1), 128.4 (C-9), 126.8 (C-10), 126.3 (C-7), 125.5 (C-6), 125.2 (C-5), $122.4(\mathrm{C}-8), 121.9(\mathrm{C}-2), 105.1(\mathrm{C}-3), 62.5\left(\mathrm{OCH}_{3}\right), 55.7\left(\mathrm{OCH}_{3}\right)$, 30.4 (C-11), $28.4\left(11-\mathrm{SCOCH}_{3}\right)$.

(5,8-Dimethoxynaphthalen-2-yl)methyl Thiocyanate (62) The same reaction and procedure using $\mathbf{2 3}(300 \mathrm{mg}, 1.02 \mathrm{mmol})$ and $\mathrm{KSCN}(430 \mathrm{mg}$, $4.28 \mathrm{mmol}$ ) as described for the preparation of $\mathbf{5 9}$ gave compound $\mathbf{6 2}$ (181.4 mg, 65.3\% yield) as a solid (mp 58-60 ${ }^{\circ} \mathrm{C}$ ). EI-MS: $\mathrm{m} / z 273[\mathrm{M}]^{+}$. HR-MS: $m / z$ Calcd for $\mathrm{C}_{15} \mathrm{H}_{15} \mathrm{NO}_{2} \mathrm{~S}[\mathrm{M}]^{+} ; 273.0824$, Found; 273.0825. ${ }^{1} \mathrm{H}-$ NMR $\left(\mathrm{CDCl}_{3}\right) \delta: 8.16(1 \mathrm{H}, \mathrm{d}, J=1.8 \mathrm{~Hz}, \mathrm{H}-8), 8.04(1 \mathrm{H}, \mathrm{d}, J=8.6 \mathrm{~Hz}, \mathrm{H}-5)$, $7.48(1 \mathrm{H}, \mathrm{dd}, J=8.6,1.8 \mathrm{~Hz}, \mathrm{H}-6), 6.63(1 \mathrm{H}, \mathrm{s}, \mathrm{H}-3), 4.34\left(2 \mathrm{H}, \mathrm{s}, 7-\mathrm{CH}_{2}-\right)$, $3.98\left(3 \mathrm{H}, \mathrm{s}, 4-\mathrm{OCH}_{3}\right), 3.85\left(3 \mathrm{H}, \mathrm{s}, 1-\mathrm{OCH}_{3}\right), 2.44(3 \mathrm{H}, \mathrm{s}, \mathrm{H}-11) .{ }^{13} \mathrm{C}-\mathrm{NMR}$ $\left(\mathrm{CDCl}_{3}\right) \delta: 151.4(\mathrm{C}-4), 147.0(\mathrm{C}-1), 130.2(\mathrm{C}-7), 128.5(\mathrm{C}-9), 127.0(\mathrm{C}-$ 10), 126.7 (C-6), 125.0 (C-2), 123.1 (C-5), 122.9 (C-8), 112.0 (SCN), 107.7 (C-3), $61.3\left(\mathrm{OCH}_{3}\right), 55.6\left(\mathrm{OCH}_{3}\right), 39.1\left(7-\mathrm{CH}_{2}-\right), 16.8(\mathrm{C}-11)$.

(5,8-Dimethoxy-7-methylnaphthalen-2-yl)methyl Selenocyanate (63) The same reaction and procedure using $23(260 \mathrm{mg}, 0.89 \mathrm{mmol})$ and $\mathrm{KSeCN}$ $(548 \mathrm{mg}, 3.81 \mathrm{mmol})$ as described for the preparation of $\mathbf{6 2}$ gave compound $63\left(147.2 \mathrm{mg}, 52.2 \%\right.$ yield) as a solid $\left(\mathrm{mp} 105-108^{\circ} \mathrm{C}\right)$. EI-MS: $\mathrm{m} / \mathrm{z} 321$ $[\mathrm{M}]^{+}$. HR-MS: $m / z$ Calcd for $\mathrm{C}_{15} \mathrm{H}_{15} \mathrm{NO}_{2} \mathrm{Se}[\mathrm{M}]^{+}$; 321.0268, Found; 321.0264. ${ }^{1} \mathrm{H}-\mathrm{NMR}\left(\mathrm{CDCl}_{3}\right) \delta: 8.16(1 \mathrm{H}, \mathrm{d}, J=1.8 \mathrm{~Hz}, \mathrm{H}-8), 8.03(1 \mathrm{H}, \mathrm{d}$, $J=8.6 \mathrm{~Hz}, \mathrm{H}-5), 7.48(1 \mathrm{H}, \mathrm{dd}, J=8.6,1.8 \mathrm{~Hz}, \mathrm{H}-6), 6.62(1 \mathrm{H}, \mathrm{s}, \mathrm{H}-3), 4.51$ $\left(2 \mathrm{H}, \mathrm{s}, 7-\mathrm{CH}_{2}-\right), 3.96\left(3 \mathrm{H}, \mathrm{s}, 4-\mathrm{OCH}_{3}\right), 3.85\left(3 \mathrm{H}, \mathrm{s}, 1-\mathrm{OCH}_{3}\right), 2.44(3 \mathrm{H}, \mathrm{s}$, $\mathrm{H}-11) .{ }^{13} \mathrm{C}-\mathrm{NMR}\left(\mathrm{CDCl}_{3}\right) \delta: 151.4(\mathrm{C}-4), 147.0(\mathrm{C}-1), 131.1(\mathrm{C}-7), 128.4$ (C-9), 127.0 (C-10), 126.9 (C-6), 125.0 (C-2), 123.0 (C-5), 107.7 (C-8), $102.0(\mathrm{C}-3), 96.1(\mathrm{SeCN}), 61.3\left(\mathrm{OCH}_{3}\right), 55.7\left(\mathrm{OCH}_{3}\right), 33.7\left(7-\mathrm{CH}_{2}-\right), 16.4$ $(\mathrm{C}-11)$.

$S$-[(5,8-Dimethoxy-7-methylnaphthalen-2-yl)methyl Ethanethioate (64) The same reaction and procedure using $\mathbf{2 3}(300 \mathrm{mg}, 1.02 \mathrm{mmol})$ and $\mathrm{KSAc}$ (468 $\mathrm{mg}, 4.06 \mathrm{mmol}$ ) as described for the preparation of $\mathbf{5 9}$ gave compound $64\left(142.5 \mathrm{mg}, 48.3 \%\right.$ yield). EI-MS: $m / z 290[\mathrm{M}]^{+}$. HR-MS: $m / z$ Calcd for $\mathrm{C}_{16} \mathrm{H}_{18} \mathrm{O}_{3} \mathrm{~S}[\mathrm{M}]^{+} ; 290.0977$, Found; 290.0980. ${ }^{1} \mathrm{H}-\mathrm{NMR}\left(\mathrm{CDCl}_{3}\right) \delta: 8.09$ $(1 \mathrm{H}, \mathrm{d}, J=1.8 \mathrm{~Hz}, \mathrm{H}-8), 7.96(1 \mathrm{H}, \mathrm{d}, J=8.5 \mathrm{~Hz}, \mathrm{H}-5), 7.42(1 \mathrm{H}, \mathrm{dd}, J=8.5$, $1.8 \mathrm{~Hz}, \mathrm{H}-6), 6.59(1 \mathrm{H}, \mathrm{s}, \mathrm{H}-3), 4.23\left(2 \mathrm{H}, \mathrm{s}, 7-\mathrm{CH}_{2}-\right), 3.95\left(3 \mathrm{H}, \mathrm{s}, 4-\mathrm{OCH}_{3}\right)$, $3.83\left(3 \mathrm{H}, \mathrm{s}, 1-\mathrm{OCH}_{3}\right), 2.42(3 \mathrm{H}, \mathrm{s}, \mathrm{H}-11) 2.36\left(3 \mathrm{H}, \mathrm{s}, \mathrm{SCOCH}_{3}\right) .{ }^{13} \mathrm{C}-\mathrm{NMR}$ $\left(\mathrm{CDCl}_{3}\right) \delta: 151.7$ (C-4), 146.9 (C-1), 131.1 (C-7), 128.6 (C-9), 127.4 (C-6), 125.8 (C-10), 125.1 (C-2), 122.3 (C-8), 122.0 (C-5), 107.3 (C-3), $102.0(\mathrm{SeCN}), 61.2\left(\mathrm{OCH}_{3}\right), 55.6\left(\mathrm{OCH}_{3}\right), 33.9\left(7-\mathrm{CH}_{2}-\right), 30.3$ $\left.\mathrm{SCOCH}_{3}\right), 16.3(\mathrm{C}-11)$.

(1,4-Dioxo-1,4-dihydronaphthalen-2-yl)methyl Thiocyanate (65) A solution of compound $\mathbf{5 9}(50 \mathrm{mg}, 0.19 \mathrm{mmol})$ and $\mathrm{HNO}_{3}(0.28 \mathrm{~g}, 2.90 \mathrm{mmol})$ in $\mathrm{AcOH}(10 \mathrm{ml})$ was stirred at room temperature for $1 \mathrm{~h}$. The mixture was poured into ice-water $(50 \mathrm{ml})$ and extracted with $\mathrm{Et}_{2} \mathrm{O}(50 \mathrm{ml} \times 3)$. The organic extracts were washed successively with $5 \%$ aqueous $\mathrm{NaHCO}_{3}$ and water, dried over $\mathrm{MgSO}_{4}$, and filtered. The filtrate was evaporated to give a residue which was subjected to column chromatography (a gradient of 0 $10 \%$ acetone in toluene) to obtain compound $\mathbf{6 5}(20.6 \mathrm{mg}, 46.6 \%$ yield $)$ as a solid (mp 79-81 ${ }^{\circ} \mathrm{C}$ ). EI-MS: $229[\mathrm{M}]^{+}$. HR-MS: $m / z$ Calcd for $\mathrm{C}_{12} \mathrm{H}_{7} \mathrm{NO}_{2} \mathrm{~S}$ $[\mathrm{M}]^{+} ; 229.0197$, Found; 229.0201. ${ }^{1} \mathrm{H}-\mathrm{NMR}\left(\mathrm{CDCl}_{3}\right) \delta: 8.13(2 \mathrm{H}, \mathrm{m}, \mathrm{H}-5$ and 8$), 7.80(2 \mathrm{H}, \mathrm{m}, \mathrm{H}-6$ and 7$), 7.07(1 \mathrm{H}, \mathrm{s}, \mathrm{H}-3), 3.99(2 \mathrm{H}, \mathrm{s}, \mathrm{H}-11) .{ }^{13} \mathrm{C}-$ NMR $\left(\mathrm{CDCl}_{3}\right) \delta: 183.9(\mathrm{C}-4), 183.2(\mathrm{C}-1), 143.3(\mathrm{C}-2), 136.7$ (C-3), 134.5 (C-7), 134.2 (C-6), 132.2 (C-9), 131.6 (C-10), 126.9 (C-5), 126.6 (C-8), $111.3(11-\mathrm{SCN}), 31.9$ (C-11).

(1,4-Dioxo-1,4-dihydronaphthalen-2-yl)methyl Selenocyanate (66) The same reaction and procedure using $\mathbf{6 0}(50.0 \mathrm{mg}, 0.16 \mathrm{mmol})$ as described for the preparation of $\mathbf{6 5}$ gave compound $\mathbf{6 6}(17.5 \mathrm{mg}, 38.9 \%$ yield $)$ as a solid $\left(\mathrm{mp} 121-123^{\circ} \mathrm{C}\right)$. EI-MS: $m / z 276[\mathrm{M}]^{+}$. HR-MS: $\mathrm{m} / z$ Calcd for $\mathrm{C}_{12} \mathrm{H}_{7} \mathrm{O}_{2} \mathrm{NSe}[\mathrm{M}]^{+} ; 276.9642$, Found; 276.9662. ${ }^{1} \mathrm{H}-\mathrm{NMR}\left(\mathrm{CDCl}_{3}\right) \delta: 8.12$ $(2 \mathrm{H}, \mathrm{m}, \mathrm{H}-5$ and 8$), 7.80(2 \mathrm{H}, \mathrm{m}, \mathrm{H}-6$ and 7$), 7.03(1 \mathrm{H}, \mathrm{s}, \mathrm{H}-3), 4.03(2 \mathrm{H}, \mathrm{s}$, $\mathrm{H}-11),{ }^{13} \mathrm{C}-\mathrm{NMR}\left(\mathrm{CDCl}_{3}\right) \delta: 183.9(\mathrm{C}-1), 183.8(\mathrm{C}-4), 145.0(\mathrm{C}-2), 135.6$ (C-3), 134.6 (C-7), 134.1 (C-6), 132.3 (C-9), 131.6 (C-10), 126.9 (C-8), 126.7 (C-5), 101.7 (11-SeCN), 25.7 (C-11).

$S$-[(1,4-Dioxo-1,4-dihydronaphthalen-2-yl)methyl] Ethanethioate (67) The same reaction and procedure using $61(80 \mathrm{mg}, 0.29 \mathrm{mmol})$ as described 
for the preparation of $\mathbf{6 6}$ gave compound $\mathbf{6 7}(32.3 \mathrm{mg}, 45.3 \%$ yield) as a solid (mp 75-78 ${ }^{\circ} \mathrm{C}$ ). EI-MS: $m / z 246[\mathrm{M}]^{+}$. HR-MS: $m / z$ Calcd for $\mathrm{C}_{13} \mathrm{H}_{10} \mathrm{O}_{3} \mathrm{~S}[\mathrm{M}]^{+} ; 246.0351$, Found; 246.0353. ${ }^{1} \mathrm{H}-\mathrm{NMR}\left(\mathrm{CDCl}_{3}\right) \delta: 8.11$ and 8.07 (each $1 \mathrm{H}, \mathrm{m}, \mathrm{H}-5$ or 8$), 7.75(2 \mathrm{H}, \mathrm{m}, \mathrm{H}-6$ and 7$), 7.05(1 \mathrm{H}, \mathrm{t}, J=0.9 \mathrm{~Hz}$, $\mathrm{H}-3), 4.00(2 \mathrm{H}, \mathrm{d}, J=0.9 \mathrm{~Hz}, \mathrm{H}-11), 2.36\left(3 \mathrm{H}, \mathrm{s}, \mathrm{SCOCH}_{3}\right) .{ }^{13} \mathrm{C}-\mathrm{NMR}$ $\left(\mathrm{CDCl}_{3}\right) \delta$ : $194.3\left(11-\mathrm{SCOCH}_{3}\right), 184.9(\mathrm{C}-1), 184.3$ (C-4), 146.4 (C-2), 135.9 (C-3), 134.0 (C-7), 133.8 (C-6), 132.1 (C-9), 131.9 (C-10), 126.7 (C8), 126.3 (C-5), 30.3 (C-11), $27.3\left(11-\mathrm{SCOCH}_{3}\right)$.

(7-Methyl-5,8-dioxo-5,8-dihydronaphthalen-2-yl)methyl Thiocyanate (68) The same reaction and procedure fusing $62(70.0 \mathrm{mg}, 0.26 \mathrm{mmol})$ as described for the preparation of $\mathbf{5 9}$ gave compound $\mathbf{6 8}$ (26.4 mg, 42.3\% yield) as a solid (mp 135-136 $\left.{ }^{\circ} \mathrm{C}\right)$. EI-MS: $m / z 243[\mathrm{M}]^{+}$. HR-MS: $m / z$ Calcd for $\mathrm{C}_{13} \mathrm{H}_{9} \mathrm{NO}_{2} \mathrm{~S}[\mathrm{M}]^{+} ; 243.0354$, Found; 243.0330. ${ }^{1} \mathrm{H}-\mathrm{NMR}\left(\mathrm{CDCl}_{3}\right)$ $\delta: 8.15(1 \mathrm{H}, \mathrm{d}, J=7.9 \mathrm{~Hz}, \mathrm{H}-5), 8.06(1 \mathrm{H}, \mathrm{d}, J=1.8 \mathrm{~Hz}, \mathrm{H}-8), 7.75(1 \mathrm{H}, \mathrm{dd}$, $J=7.9,1.8 \mathrm{~Hz}, \mathrm{H}-6), 6.88(1 \mathrm{H}, \mathrm{q}, J=1.5 \mathrm{~Hz}, \mathrm{H}-3), 4.23\left(2 \mathrm{H}, \mathrm{s}, 7-\mathrm{CH}_{2}-\right)$, $2.22(3 \mathrm{H}, \mathrm{d}, J=1.5 \mathrm{~Hz}, \mathrm{H}-11) .{ }^{13} \mathrm{C}-\mathrm{NMR}\left(\mathrm{CDCl}_{3}\right) \delta: 184.8(\mathrm{C}-1), 184.2(\mathrm{C}-$ 4), 148.5 (C-2), 140.5 (C-7), 135.7 (C-3), 133.8 (C-6), 132.8 (C-9), 132.2 (C-10), 127.7 (C-5), 126.6 (C-8), 111.8 (7- $\left.\mathrm{CH}_{2} \mathrm{SCN}\right), 37.4\left(7-\underline{\mathrm{CH}}_{2}-\right), 16.5$ (C-11).

7-(Methyl-5,8-dioxo-5,8-dihydronaphthalen-2-yl)methyl Selenocyanate (69) The same reaction and procedure for $63(70.0 \mathrm{mg}, 0.22 \mathrm{mmol})$ as described for the preparation of $\mathbf{5 9}$ gave compound $\mathbf{6 9}(26.5 \mathrm{mg}$, $41.8 \%$ yield) as a solid (mp $147-148^{\circ} \mathrm{C}$ ). EI-MS: $m / z 290[\mathrm{M}]^{+}$. HR-MS: $m / z$ Calcd for $\mathrm{C}_{13} \mathrm{H}_{9} \mathrm{O}_{2} \mathrm{NSe}[\mathrm{M}]^{+}$; 290.9798, Found; 290.9810. ${ }^{1} \mathrm{H}-\mathrm{NMR}$ $\left(\mathrm{CDCl}_{3}\right) \delta: 8.13(1 \mathrm{H}, \mathrm{d}, J=7.9 \mathrm{~Hz}, \mathrm{H}-5), 8.05(1 \mathrm{H}, \mathrm{d}, J=1.5 \mathrm{~Hz}, \mathrm{H}-8), 7.74$ $(1 \mathrm{H}, \mathrm{dd}, J=7.9,1.5 \mathrm{~Hz}, \mathrm{H}-5), 6.83(1 \mathrm{H}, \mathrm{q}, J=1.2 \mathrm{~Hz}, \mathrm{H}-3), 4.36(2 \mathrm{H}, \mathrm{s}, 7-$ $\left.\mathrm{CH}_{2}-\right), 2.21(3 \mathrm{H}, \mathrm{d}, J=1.2 \mathrm{~Hz}, \mathrm{H}-11) .{ }^{13} \mathrm{C}-\mathrm{NMR}\left(\mathrm{CDCl}_{3}\right) \delta: 184.8(\mathrm{C}-1)$, 184.3 (C-4), 148.6 (C-2), 141.9 (C-7), 141.9 (C-3), 135.6 (C-6), 133.8 (C-9), 132.8 (C-10), 127.6 (C-5), 126.5 (C-8), 100.6 (7- $\left.\mathrm{CH}_{2} \mathrm{SeC} N\right), 31.4\left(7-\underline{\mathrm{CH}}_{2}-\right)$, 16.5 (C-11).

$S$-[(7-Methyl-5,8-dioxo-5,8-dihydromaphthalen-2-yl)methyl] Ethanetionate (70) The same reaction and procedure using $63 \quad(70.0 \mathrm{mg}$, $0.24 \mathrm{mmol}$ ) as described for the preparation of $\mathbf{5 9}$ gave compound $\mathbf{7 0}$ (32.3 mg, 51.5\% yield) as a solid (mp 122-124 $\left.{ }^{\circ} \mathrm{C}\right)$. EI-MS: $m / z 260[\mathrm{M}]^{+}$. HR-MS: $m / z$ Calcd for $\mathrm{C}_{14} \mathrm{H}_{12} \mathrm{O}_{3} \mathrm{~S}[\mathrm{M}]^{+} ; 260.0507$, Found; 260.0497 . ${ }^{1} \mathrm{H}-$ NMR $\left(\mathrm{CDCl}_{3}\right) \delta: 8.03(1 \mathrm{H}, \mathrm{d}, J=7.9 \mathrm{~Hz}, \mathrm{H}-5), 7.96(1 \mathrm{H}, \mathrm{d}, J=1.8 \mathrm{~Hz}, \mathrm{H}-8)$, $7.66(1 \mathrm{H}, \mathrm{dd}, J=7.9,1.8 \mathrm{~Hz}, \mathrm{H}-5), 6.83(1 \mathrm{H}, \mathrm{q}, J=1.5 \mathrm{~Hz}, \mathrm{H}-3), 4.20(2 \mathrm{H}, \mathrm{s}$, 7- $\left.\mathrm{CH}_{2}-\right), 2.37\left(3 \mathrm{H}, \mathrm{s}, \mathrm{SCOCH}_{3}\right), 2.19(3 \mathrm{H}, \mathrm{d}, J=1.5 \mathrm{~Hz}, \mathrm{H}-11) .{ }^{13} \mathrm{C}-\mathrm{NMR}$ $\left(\mathrm{CDCl}_{3}\right) \delta: 194.2\left(\mathrm{~S}^{2} \mathrm{CCH}_{3}\right), 185.6(\mathrm{C}-1), 184.7$ (C-4), $148.2(\mathrm{C}-2), 144.3$ (C-7), 135.6 (C-3), 133.9 (C-6), 132.4 (C-9), 131.1 (C-10), 127.1 (C-5), 126.3 (C-8), $33.0\left(7-\underline{C H}_{2}-\right), 30.3\left(\mathrm{SCO}_{-} \mathrm{H}_{3}\right), 16.5$ (C-11).

Cytotoxic Effects. Cell Lines and Culture The human colorectal carcinoma cell line (HCT 116, ATCC No. CCL-247) and human hepatoma cell line (Hep G2 No. RCB0459) were purchased from Dainippon Pharmaceutical Co., Ltd. (Osaka, Japan) and RIKEN Cell Bank (Tsukuba, Japan), respectively. Dulbecco's modified Eagle's medium (DMEM), McCoy's 5A medium, fetal bovine serum (FBS) and penicillin-streptomycin mixture (100 U/ml penicillin and $100 \mu \mathrm{g} / \mathrm{ml}$ streptomycin) were purchased from Wako Pure Chemical Industries, Ltd. (Osaka, Japan), Sigma-Aldrich (St. Louis, MO, U.S.A.), BioSource International (Camarillo, CA, U.S.A.) and Bio Whittaker (Walkersville, MD, U.S.A.), respectively. The HCT 116 cells were maintained in McCoy's 5A medium and Hep G2 cells were cultured in DMEM. Each medium was supplemented with 10\% FBS and a penicillinstreptomycin mixture. Cell cultures performed at $37^{\circ} \mathrm{C}$ in a humidified atmosphere containing $5 \% \mathrm{CO}_{2}$ in air.
Assay Procedure Aliquots $(200 \mu \mathrm{l})$ of $5 \times 10^{3}$ cells per ml of HCT 116 and Hep G2 cells were seeded in 96 well flat-bottomed plates (Microtest ${ }^{\mathrm{TM}}$ Tissue Culture Plate, 96 Well, Flat Bottom with Low Evaporation Ltd., Falcon, NJ, U.S.A.). Cell cultures were incubated in a medium containing $10 \%$ FBS and a penicillin-streptomycin mixture at $37^{\circ} \mathrm{C}$ in a humidified atmosphere of $5 \% \mathrm{CO}_{2}$ for $24 \mathrm{~h}$. The test drugs were dissolved in dimethyl sulfoxide (DMSO). The incubation medium was replaced with each test medium giving a final concentration of $0.1-500 \mu \mathrm{mol} / 1$ of test compounds and no drug in $2 \mu \mathrm{l}$ DMSO over $2 \mathrm{~d}$. The ability of the drug to inhibit cellular growth was determined by performing the MTT assay. ${ }^{18)}$ The cytotoxic effects of the test drugs were determined as previously described. ${ }^{21)}$ Each experiment was performed in duplicate wells, and all the experiments involving a control (DMSO only) and the drug treatments were performed separately three to five times. The data represent mean \pm S.D. values.

\section{References}

1) Cui X.-R., Tsukada M., Suzuki N., Shimamura T., Gao L., Koyanagi J., Komada F., Saito S., Eur. J. Med. Chem., 43, 1206-1215 (2008).

2) Shionoya M., Jimbo T., Kitagawa M., Soga T., Tohgo A., Cancer Sci., 94, 459-466 (2003).

3) Lee G., Piquette-Miller M., Can. J. Physiol. Pharmacol., 79, 876884 (2001).

4) Cui X.-R., Takahashi K., Shimamura T., Gao L., Koyanagi J., Komada F., Saito S., Chem. Pharm. Bull., 56, 497-503 (2008).

5) Tipson R. S., Clapp M. A., Cretcher L. H., J. Org. Chem., 12, 133 138 (1947).

6) Winkelstein A., J. Immunopharmacol., 1, 429-454 (1979).

7) Chen C.-C., Chen L.-T., Tsou T.-C., Pan W.-Y., Kuo C.-C., Liu J.-F., Yeh S.-C., Tsai F.-Y., Hsieh H.-P., Chang J.-Y., Br. J. Cancer, 97, 334-344 (2007).

8) Mulder J. H., Smink T., Ossewarde T., van Putten L. M., Eur. J. Cancer, 16, 699-705 (1980).

9) Kufe D. W., Major P. P., J. Biol. Chem., 256, 9802—9805 (1981).

10) Weber G., Ichikawa S., Nagai M., Natsumeda Y., Cancer Commun., 2, 129-133 (1990).

11) Bedikian A. Y., Stroehlein J., Korinek J., Karlin D., Bodey G. P., Am. J. Clin. Oncol., 6, 181-186 (1983).

12) Sadahiro S., Suzuki T., Maeda Y., Ishikawa K., Tanaka Y., Yasuda S., Kamijo A., Makuuchi H., Murayama C., Chemotherapy, 53, 442-445 (2007).

13) Hartung R. E., Paquett L. A., Heterocycles, 67, 75-78 (2006).

14) van Tuyen N., Kesteliyn B., Kimpe N., Tetrahedron, 58, 121-127 (2002).

15) Friedli F. E., Shechter H., J. Org. Chem., 50, 5710—5716 (1985).

16) Zabjek A., Petric A., Tetrahedron Lett., 40, 6077-6078 (1999).

17) Kim D. W., Choi H. Y., Lee K.-J., Chi D. Y., Org. Lett., 3, 445-448 (2001).

18) Mosmann T., J. Immunol. Methods, 139, 55-63 (1983).

19) Takara K., Sakaeda T., Tanigawara Y., Nishiguchi K., Ohmoto N., Horinouchi M., Eur. J. Pharm. Sci., 16, 159-165 (2002).

20) Saito S., Sasaki Y., Furumoto T., Sumita S., Hinomoto T., Carbohydr. Res., 258, 59-75 (1994).

21) Jin G.-Z., Quan H.-J., Koyanagi J., Takeuchi K., Miura Y., Komada F., Saito S., Cancer Lett., 218, 15-20 (2005). 